\title{
Diversity and trophic structure of the soil fauna and its influence on litter decomposition in deciduous forests with increasing tree species diversity
}

\author{
Dissertation \\ zur Erlangung des Doktorgrades \\ der Mathematisch-Naturwissenschaftlichen Fakultäten \\ der Georg-August-Universität zu Göttingen \\ vorgelegt von \\ Nadine Weland, geb. Fahrenholz \\ aus Bremen
}

Göttingen, September 2009 
Referent: Prof. Dr. Matthias Schaefer

Korreferent: Prof. Dr. Klaus Hövemeyer

Tag der mündlichen Prüfung: 30.04.2009 


\section{Table of contents}

Chapter 1

General introduction

Chapter 2

Communities of ground-living spiders in deciduous forests:

Does tree species diversity matter?

Chapter 3

Earthworm communities in relation to tree diversity

in a deciduous forest

\section{Chapter 4}

Soil macrofauna communities respond differently

to increasing tree species diversity in a temperate deciduous forest

\section{Chapter 5}

Nutrient release from decomposing leaf litter

of temperate deciduous forest trees along a gradient

of increasing tree species diversity

Chapter 6

General synthesis

Summary

Acknowledgements

Curriculum vitae 


\section{Chapter 1}

\section{General introduction}




\section{Biodiversity and ecosystem functions}

In December 1993, the Convention on Biological Diversity entered into force. A considerable number of countries have ratified it, including Germany. In the Convention, "biological diversity" is defined as "the variability among living organisms from all sources including, inter alia, terrestrial, marine and other aquatic ecosystems and the ecological complexes of which they are part; this includes diversity within species, between species and of ecosystems". Since then, biodiversity has become an important topic of ecological research. In the last years, many studies have contributed to our understanding how biodiversity influences ecosystem functioning. Besides the direct goods and services for human society, provided by biological diversity, it is generally accepted that biodiversity affects certain ecosystem processes, such as plant primary production, decomposition and nutrient cycling (e.g. Chapin et al. 2000, Loreau et al. 2001; Hooper et al. 2005). However, it has also been found that individual species can be as powerful drivers of ecosystem processes as a more diverse community (e.g. Hooper et al 2005, Cardinale et al. 2006).

\section{Biodiversity in forests}

There is a multitude of field studies concerning the effect of plant species diversity on ecosystem processes. However, most of these studies were performed in relatively shortlived test systems like grasslands or oldfields (e.g. Tilman et al. 1997, Hector et al. 1999, Loreau et al. 2001). Such simple approaches are not easily applicable to complex forest systems. Due to the longevity of the trees, research on biodiversity functions in forests is challenging. Although there is a considerable number of comparative studies concerning processes and ecosystem functions in single or two-species forest systems (e.g. Cannell et al. 1992, Aubert et al. 2003, Pretzsch 2005), differences between these systems often depended on the identity of the tree species as well as stand age and location (Kerr et al. 1992). Studies on more complex multi-species forests are still rare (Vilà et al. 2005).

During the last years a number of large-scale biodiversity experiments with trees have been initiated. In these plantations, the effects of increasing tree species richness on a number of ecosystem functions are investigated in the tropics, as well as in temperate and boreal climate zones (Scherer-Lorenzen 2005). These experimental approaches offer the advantage of manipulating tree diversity under relatively controlled conditions. However, such young even-aged stands can only imperfectly mimic natural forests and need several decades to become mature. Therefore, observational studies on mature forests should complement these manipulative diversity experiments for the understanding of ecosystem functioning in diverse forests (Underwood and Paine 2007, Leuschner et al. 2009). 


\section{Above-/belowground interactions and decomposition processes}

Studies on the influence of plant species diversity on aboveground animal diversity are numerous, but different patterns have been found depending on the level of diversity examined (functional group richness or species richness) (Siemann 1998, Symstad et al. 2000). Plant diversity has often been important but the structural complexity of vegetation that provides a diverse range of habitats is a significant factor for a species rich animal community (Schaefer 2002). Although the fundamental dependence of the soil food web on the resources provided by primary production is well studied, the knowledge of tree species diversity interactions with belowground processes and animal communities is still imperfect (Wardle, 2002, Hättenschwiler et al. 2005, Scheu 2005). Depending on scale, there is mixed evidence for correlations between above- and belowground diversity. Patterns in species richness are not necessarily correlated due to the variety of mechanisms by which aboveand belowground communities affect each other (Hooper et al. 2000).

Generally, the soil fauna is an important part of terrestrial ecosystems. In forests, the soil fauna is numerous and forms diverse communities (De Ruiter et al. 2002, Fitter et al. 2005). Trophic groups in the decomposer food webs and their interactions influence ecosystem functions and processes (Mikola et al. 2002, Wardle 2006). Plant litter decomposition is one such ecosystem process essential for organic matter turnover and nutrient cycling. The ensuing release of carbon and nutrients represents the primary source of nutrients for plants and microbes (e.g., Swift et al. 1979, Berg and McClaugherty 2008). The influence of different plant species on decomposition is well studied. Plant species composition can affect ecosystem nutrient cycling through plant-nutrient uptake and use, amount and chemical composition of the leaf litter, rhizosphere interactions and microenvironmental changes (Hättenschwiler et al. 2005, Hättenschwiler and Gasser 2005). Litter decomposition rates have repeatedly been found to be related to litter quality, most importantly to the content of nitrogen, phosphorous, lignin, polyphenols and soluble carbohydrates (e.g. Swift et al. 1979, Heal et al. 1997). Nature and abundance of decomposing organisms are also strongly influencing decomposition processes (Côuteaux et al. 1995, Jonsson and Wardle 2008). For instance, the soil fauna can increase nutrient mobilization by accelerating decomposition rates (Anderson 1973, Joergensen 1991). Generally, microorganisms are important controllers of decomposition and mineralization (Lavelle and Spain 2001), but the meso- and macrofauna affect these processes through their grazing pressure on the microflora (Schaefer 1990, Kautz and Topp, 2000, Cragg and Bargett 2001). Ecosystem engineers, e.g. earthworms, additionally influence decomposition and mineralization through structural impacts on the litter and soil matrix (Marhan and Scheu 2006, Postma-Blaauw et al. 2006). Soil animals such as litter-feeding macrofauna interact with leaf litter composition and modify effects exerted by litter species diversity (e.g. Hättenschwiler and Gasser 2005, Schädler and 
Brandl 2005). Hence, soil animal diversity and activity feed back to the aboveground food web and plant growth (Setälä 2002, Scheu 2005), because the effect of plant species on ecosystem processes is mediated by the soil organisms, which influence the processes (Wardle 2002).

\section{Study sites}

The Hainch is the largest cohesive deciduous forest in Germany. It is located in Central Germany (Thuringia) and covers a total area of 13.000 hectare (ha) on a low mountain ridge along the Thuringian basin. In 1997, 7.600 ha of forests and bordering succession areas in the southern part of the Hainich were put under protection and have been declared National Park. Here, forest cover was present at least since the middle of the $18^{\text {th }}$ century. Selective cutting or coppicing with standards were the common management systems during this time (Mund 2004). In the second half of the twentieth century, parts of the Hainich have been used as military training site and for at least 40 years only single stems were extracted (Schmidt et al. 2009).

In the north-eastern and eastern part of the Hainich National Park twelve study sites were installed in 2005. All sites were selected for comparable edaphic and climatic conditions. Their elevation is about $350 \mathrm{~m}$ a.s.l. and all sites are situated above Triassic limestone covered by loess layers of at least $60 \mathrm{~cm}$ (Guckland et al. 2009). Mean annual precipitation in this area ranges from $600 \mathrm{~mm}$ to $670 \mathrm{~mm}$ and the annual temperature average is $7.5^{\circ} \mathrm{C}$ to $8.0^{\circ} \mathrm{C}$ (Mönninghoff 1998). Nine of the study sites were fenced to prevent disturbance by animals, and in these nine sites the zoological studies were carried out. The dominant tree species is European beech (Fagus sylvatica L.) but due to the former management practices up to 14 tree species per hectare coexist in a smale-scale mosaic (Mölder et al. 2006). Three study sites each (labelled a, b and c) were assigned to a different level of tree species diversity:

- Diversity level 1 (DL 1) - low diversity, predominantly Fagus sylvatica L.,

- Diversity level 2 (DL 2) - medium diversity, with F. sylvatica, Fraxinus excelsior, Tilia cordata and T. platyphyllos and

- Diversity level 3 (DL 3) - high diversity, with: F. sylvatica, F. excelsior, T. cordata, T. platyphyllos, Carpinus betulus, Acer pseudoplatanus and A. platanoides.

The study sites belong either to the alliance of beech forests (Galio odorati-Fagion: DL 1 and DL 2a,c) or to the oak-hornbeam forests (Carpinion betuli: DL 2b and DL 3) (Mölder et al. 2006). 
In each of the study sites, the main part of zoological research was done in six smaller plots of $30 \mathrm{~m}^{2}$ (Fig 1). They were randomly selected along three transects also randomly placed into the sites. Additionally, procedures involving larger areas of litter removed (for snail handsorting) or actions which could possibly change soil chemistry (hand-sorting and mustard extraction of earthworms) were done outside in the immediate vicinity of the sites.

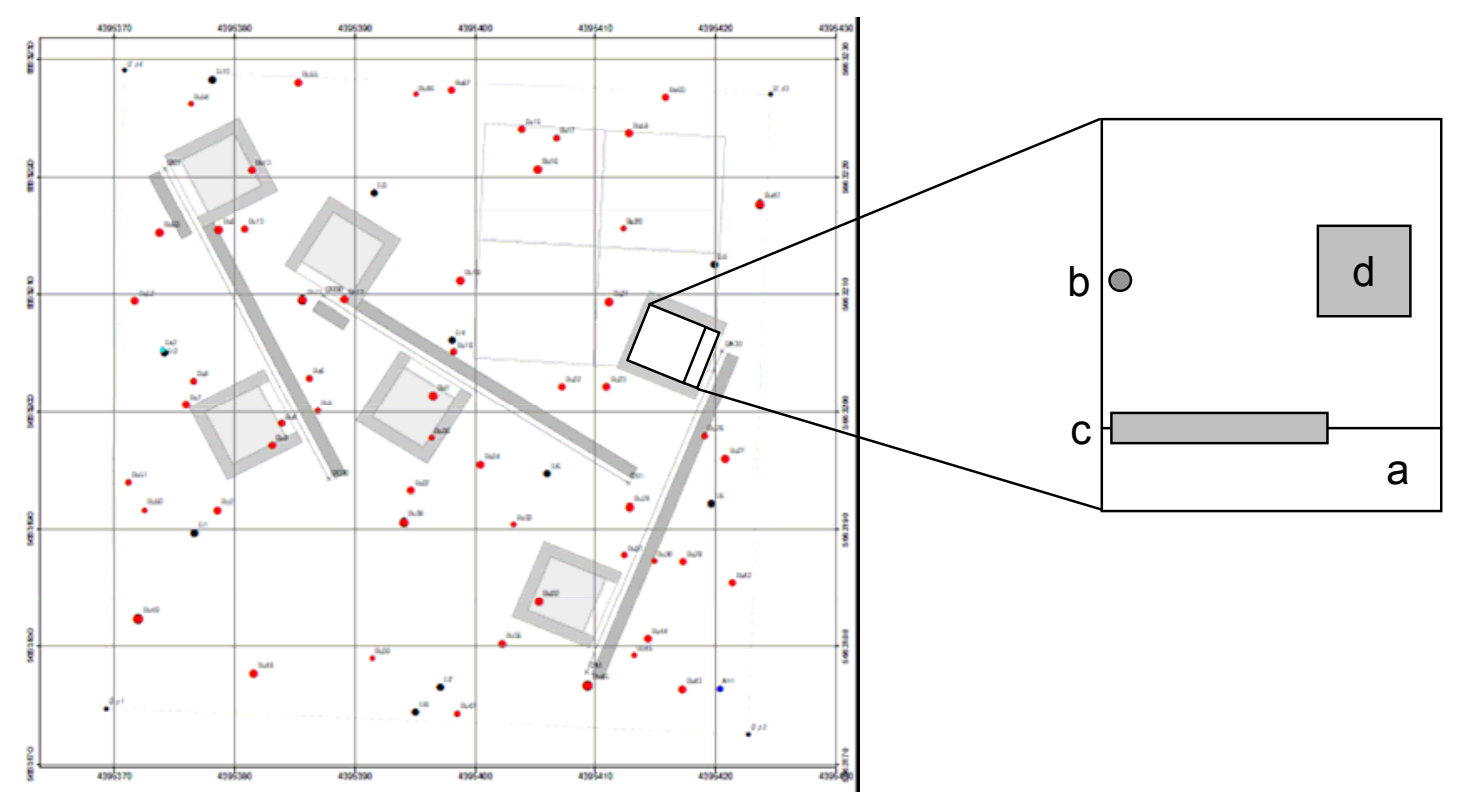

Fig 1 Overview of study site DL $1 \mathrm{~b}$ (by M. Daenner), dots = trees, transects with two study plots each, and detail of smaller plot for zoological studies, $a=5 \mathrm{~m}^{2}$ stripe for soil sampling, $b=$ pitfall trap, $c=$ litterbags, $d$ = litter exchange $\left(1 \mathrm{~m}^{2}\right)$

\section{Project - Research Training Group 1068}

The research for this thesis has been conducted as part of the Research Training Group (GK) 1086 "The role of biodiversity for biogeochemical cycles and biotic interactions in temperate deciduous forests" which is funded by German Research Foundation (DFG). The aim of the program is to assess the effect of tree species diversity on a number of ecosystem processes in a natural habitat (Leuschner et al. 2009). In this interdisciplinary program, 14 Ph.D. students from the Faculties of Biology, Acricultural and Forest Science of the GeorgAugust-University Göttingen and the Max Planck Institute for Biogeochemistry in Jena worked together in common projects.

My study focuses on the effect of tree species diversity on the soil macrofauna and its influence on decomposition processes. It attempts to relate the occurrence and abundance of soil macrofauna species to tree species diversity and environmental factors associated with different levels of tree species diversity. 
Guiding questions of my study were:

How does tree species diversity influence the soil macrofauna communities?

Do certain trophic groups react differently to increasing tree species diversity?

How does tree species diversity influence decomposition processes?

These questions will be addressed in four chapters. The first is a detailed analysis of spider communities as an important carnivorous group of the soil food web, followed by a study on the earthworm communities as an example for a major saprophagous group and for ecosystem engineers. In the next chapter, general results on the soil macrofauna diversity and abundance are summed up for snails, earthworms, isopods, ground beetles and spiders. Finally, the influence of tree species diversity and faunal activity on leaf litter decomposition will be presented.

\section{$\underline{\text { References }}$}

Anderson JM (1973) The breakdown and decomposition of sweet chestnut (Castanea sativa Mill.) and beech (Fagus sylvatica L.) leaf litter in two deciduous woodland soils. 1. Breakdown, Leaching and Decomposition. Oecologia 12: 251-274.

Aubert M, Hedde M, Decaens T, Bureau F, Margerie P, Alard D (2003) Effects of tree canopy composition on earthworms and other macro-invertebrates in beech forests of Upper Normandy (France). Pedobiologia 47: 904-912.

Berg B, McClaugherty C (2008) Plant Litter - Decomposition, Humus Formation, Carbon Sequestration. Springer, Berlin, 338 pp.

Cannell MGR, Malcolm DC, Robertson PA (Eds.) (1992) The Ecology of Mixed-Species Stands of Trees. Blackwell Scientific Publications, Oxford.

Cardinale BJ, Srivastava DS, Emmett Duffy J, Wright JP, Downing AL., Sankaran M, Jouseau C (2006) Effects of biodiversity on the functioning of trophic groups and ecosystems. Nature 443: 989-992.

Chapin FS III, Zavaleta ES, Eviner VT, Naylor RL, Vitousek PM, Reynolds HL, Hooper DU, Lavorel S, Sala OE, Hobbie SE, Mack MC, Diaz S (2000) Consequences of changing biodiversity. Nature 405: 234-242.

Côuteaux M-M, Bottner P, Berg B (1995) Litter decomposition, climate and litter quality. Tree 10: 6366.

Cragg RG, Bardgett RD (2001) How changes in soil faunal diversity and composition within a trophic group influence decomposition processes. Soil Biology \& Biochemistry 33: 2073-2081.

De Ruiter PC, Griffiths B, Moore JC (2002) Biodiversity and stability in soil ecosystems: patterns, processes and the effects of disturbance. In: Loreau M, Naeem S, Inchausti P (eds) Biodiversity and ecosystem functioning. Synthesis and perspectives. Oxford University Press, Oxford, pp 102113. 
Fitter AH, Gilligan CA, Hollingworth K, Kleczkowski A, Twyman RM, Pitchford JW, The members of the NERC Soil Biodiversity Programme (2005) Biodiversity and ecosystem function in soil. Functional Ecolology 19:369-377

Kerr G, Nixon C, Matthews RW (1992) Silviculture and yield of mixed-species stands: the UK experience. In Cannell MGR, Malcolm DC, Robertson PA, (eds) The ecology of mixed-species stands of trees. Oxford: Blackwell Scientific Publications, pp. 35-51.

Guckland A, Brauns M, Flessa H, Thomas FM, Leuschner C (2009) Acidity, nutrient stocks and organic matter content in soils of a temperate deciduous forest with different abundance of European beech (Fagus sylvatica L.). Journal of Plant Nutrition and Soil Science, in press.

Hättenschwiler S, Gasser P (2005) Soil animals alter plant litter diversity effects on decomposition. Procedings of the National Academy of Science USA 102: 1519-1524.

Hättenschwiler S, Tiunov AV, Scheu S (2005) Biodiversity and litter decomposition in terrestrial ecosystems. Annual Review of Ecology, Evololution, and Systematics 36: 191-218.

Heal OW, Anderson JM, Swift MJ (1997) Plant litter quality and decomposition: an historical overview. In: Cadisch G, Giller KE (eds) Driven by Nature. Plant Litter Quality and Decomposition. CAB International, Wallingford, UK, pp 3-30.

Hector A, Schmid B, Beierkuhnlein C, Caldeira MC, Diemer M, Dimitrakopoulos PG, Finn J, Freitas H, Giller PS, Good J, Harris R, Högberg P, Huss-Danell K, Joshi J, Jumpponen A, Körner C, Leadley PW, Loreau M, Minns A, Mulder CPH, O'Donovan G, Otway SJ, Pereira JS, Prinz A, Read DJ, Scherer-Lorenzen M, Schulze E-D, Siamantziouras A-SD, Spehn EM, Terry AC, Troumbis AY, Woodward FI, Yachi S, Lawton JH (1999) Plant diversity and productivity experiments in European grasslands. Science 286: 1123-1127.

Hooper DU, Bignell DE, Brown VK, Brussaard L, Dangerfield JM. Wall DH, Wardle DA, Coleman DC, Giller KE, Lavelle P, van der Putten WH, de Ruiter PC, Rusek J, Silver WL, Tiedje JM, Wolters V (2000) Interactions between aboveground and belowground biodiversity in terrestrial ecosystems: patterns, mechanisms, and feedbacks. BioScience 50: 1049-1061.

Hooper DU, Chapin FS, Ewel JJ, Hector A, Inchaustl P, Lavorel S, Lawton JH, Lodge DM, Loreau M, Naeem S, Schmid B, Setälä H, Symstad AJ, Vandermeer J, Wardle DA (2005) Effects of biodiversity on ecosystem functioning: a consensus of current knowledge. Ecological Monographs 75: 3-35.

Joergensen RG (1991) Organic matter and nutrient dynamics of the litter layer on a forest rendzina under beech. Biology and Fertility of Soils 11: 163-169.

Jonsson M, Wardle D, 2008. Context dependency of litter-mixing effects on decomposition and nutrient release across a long-term chronosequence. Oikos 117: 1674-1682.

Kautz G, Topp W (2000) Acquisition of microbial communities and enhanced availability of soil nutrients by the isopod Porcellio scaber (Latr.) (Isopoda: Oniscidea). Biology and Fertility of Soils 31: 102-107.

Lavelle P, Spain AV (2001) Soil Ecology. Kluwer Scientific Publications, Amsterdam.

Leuschner C, Jungkunst HF, Fleck S (2009) Functional role of forest diversity: Pros and cons of synthetic stands and across-site comparisons in established forests. Basic and Applied Ecology, 10: $1-9$. 
Loreau M, Naeem S, Inchausti P, Bengtsson J, Grime JP, Hector A, Hooper DU, Huston MA, Raffaelli D, Schmid B, Tilman D, Wardle DA (2001) Biodiversity and ecosystem functioning: current knowledge and future challenges. Science 294: 804-808.

Marhan S. Scheu S (2006) Mixing of different mineral soil layers by endogeic earthworms affects carbon and nitrogen mineralization. Biology and Fertility of Soils 42: 308-314.

Mikola J, Bardgett RD, Hedlund K (2002) Biodiversity, ecosystem functioning and soil decomposer food webs. In: Loreau M, Naeem S, Inchausti P (eds) Biodiversity and ecosystem functioning. Synthesis and perspectives. Oxford University Press, Oxford, pp 169-180.

Mönninghoff (1998) Nationalpark Hainich. VEBU, Berlin.

Mölder A, Bernhardt-Römermann M, Schmidt W (2006) Forest ecosystem research in Hainich National Park (Thuringia): first results on flora and vegetation in stands with contrasting tree species diversity. Waldökologie-Online 3: 83-99.

Mund M (2004) Carbon pools of European beech forests (Fagus sylvatica) under different silvicultural management, Göttingen, Universität Göttingen.

Postma-Blaauw MB, Bloem J, Faber JH, van Groenigen JW, de Goede RGM, Brussaard L (2006) Earthworm species composition affects the soil bacterial community and net nitrogen mineralization. Pedobiologia 50: 243-256.

Pretzsch H (2005) Diversity and productivity in forests: evidence from long-term experimental plots. In: Scherer- Lorenzen M, Körner C, Schulze E-D (eds), Forest Diversity and Function: Temperate and Boreal Systems, Ecological Studies, 176. Springer, Berlin, pp. 41-64.

Schädler M, Brandl R (2005) Do invertebrate decomposers affect the disappearance rate of litter mixtures. Soil Biology \& Biochemistry 37: 329-337.

Schaefer M (1990) The soil fauna of a beech forest on limestone: trophic structure and energy budget. Oecologia 82: 128-136.

Schaefer M (2002) The relationship between forest structure and animal species diversity. In: Spellmann H (ed.): Presentations of the 5th International Workshop of the EU-LIFE-Project: Demonstrations of Methods to Monitor Sustainable Forestry, 5.-8.5.2001. pp. 59-67.

Scherer-Lorenzen M, Potvin C, Koricheva J, Schmid B, Hector A, Bornik Z, Reynolds G, Schulze E-D (2005) The design of experimental tree plantations for functional biodiversity research. In: SchererLorenzen M, Körner C, Schulze E-D (eds), Forest Diversity and Function: Temperate and Boreal Systems, Ecological Studies, 176, Springer, Berlin, pp. 347-376.

Scheu S (2005) Linkages between tree diversity, soil fauna and ecosystem processes, in: SchererLorenzen M, Köhler C, Schulze E-D, Forest Diversity and Function: Temperate and Boreal Systems, Ecological Studies 176, Springer, Berlin, pp. 211-233.

Schmidt I, Leuschner C, Mölder A, Schmidt W (2009) Structure and composition of the seed bank in monospecific and tree species-rich temperate broad-leaved forests. Forest Ecology and Management 257: 695-702.

Setälä H (2002) Sensitivity of ecosystem functioning to changes in trophic structure, functional group composition and species diversity in belowground food webs. Ecological Research 17: 207-215.

Siemann EH (1998) Experimental tests of the effects of plant productivity and plant diversity on grassland arthropod diversity. Ecology 79: 2057-2070. 
Swift MJ, Heal OW, Anderson JM (1979) Decomposition in terrestrial ecosystems. Blackwell, Oxford, $372 \mathrm{pp}$.

Symstad AJ, Siemann E, Haarstad J (2000) An experimental test of the effect of plant functional group diversity on arthropod diversity. Oikos 89: 243-253.

Tilman D, Knops J, Wedin D, Reich P, Ritchie M, Siemann E (1997) The Influence of Functional Diversity and Composition on Ecosystem Processes. Science 277: 1300-1302.

Underwood AJ, Paine RT (2007) Two views on ecological experimentation, Bulletin of the British Ecological Society 38: 24-27.

Vilà M, Inchausti P, Vayreda J, Barrantes O, Gracia C, Ibanez JJ, Mata T (2005) Confounding factors in the observational productivity-diversity relationship in forests. In: Scherer-Lorenzen M, Körner C, Schulze E-D (eds) Forest Diversity and Function: Temperate and Boreal Systems, Springer, Berlin, pp. 65-81.

Wardle DA (2002) Communities and Ecosystems - Linking the aboveground and belowground components, Princeton University Press, Princeton.

Wardle DA (2006) The influence of biotic interactions on soil biodiversity. Ecology Letters 9: 870-886. 


\section{Chapter 2}

Communities of ground-living spiders in deciduous forests:

Does tree species diversity matter?

Andreas Schuldt, Nadine Fahrenholz, Mascha Brauns, Sonja Migge-Kleian, Christian Platner \& Matthias Schaefer

Biodiversity and Conservation 17 (5), 1267-1284, 2008 


\section{$\underline{\text { Abstract }}$}

The relationships between species diversity and ecosystem functions are in the focus of recent ecological research. However, until now the influence of species diversity on ecosystem processes such as decomposition or mineral cycling is not well understood. In deciduous forests, spiders are an integral part of the forest floor food web. In the present study, patterns of spider diversity and community structure are related to diversity of deciduous forest stands in the Hainich National Park (Thuringia). In 2005, pitfall trapping and quantitative forest floor sampling were conducted in nine plots of forest stands with one (Diversity Level 1), three (DL 2) and five (DL 3) major deciduous tree species. Species richness, measured with both methods, as well as spider abundance in forest floor samples were highest in stands with medium diversity (DL 2) and lowest in pure beech stands (DL 1). The Shannon-Wiener index and spider numbers in pitfall traps decreased from DL 1 to $D L 3$, while the Shannon-Wiener index in forest floor samples increased in the opposite direction. Spider community composition differed more strongly between single plots than between diversity levels.

Altogether, no general relationship between increasing tree species diversity and patterns of diversity and abundance in spider communities was found. It appears that there is a strong influence of single tree species dominating a forest stand and modifying structural habitat characteristics such as litter depth and herb cover which are important for ground-living spiders.

Keywords: Araneae / Community structure / Deciduous forest / Diversity / Spiders / Tree species 


\section{$\underline{\text { Introduction }}$}

Soil and litter of forests generally contain highly diverse communities with a large number of organisms (De Ruiter et al. 2002, Setälä 2005, Fitter et al. 2005). In soils, the relationship between biodiversity and soil processes is thought to be primarily controlled by the dynamics and interactions in the soil community food web including the plants. It is well established that trophic groups and their interactions in decomposer food webs significantly influence ecosystem functioning, thus warranting a food-web approach when studying the diversityfunctioning relationship in soil (Mikola et al. 2002, Wardle 2006).

Spiders as generalist predators are an integral part of the forest floor food web (Weidemann 1976, Schaefer 1991, Wise and Chen 1999). They are linked to the detritivore community by numerous direct and indirect interactions. On the one hand, they can be limited by the densities of their prey populations (Chen and Wise 1999, Wise et al. 1999). On the other hand, they are able to control the abundance of prey organisms such as microbi-detritivorous Collembola, displaying indirect stimulating or retarding top-down effects on decomposition processes and nutrient cycling (Kajak 1995, Hunter et al. 2003, Lawrence and Wise 2004, Wise 2004, Lensing et al. 2005). Species-rich spider communities have been found to regulate prey populations more effectively than less diverse communities (Riechert and Lawrence 1997). However, with increasing diversity of spider coenoses there is also a higher probability of intraguild predation (Wise and Chen 1999) modifying the effects of spiders in trophic cascades and ecosystem processes (Finke and Denno 2005).

In addition to these biotic interactions, spider communities are influenced to a large degree by abiotic environmental factors comprising structural and microclimatic features of the habitat (Hatley and MacMahon 1980, Uetz 1990, Niemelä et al. 1996, Gurdebeke et al. 2003, Oxbrough et al. 2005), which in turn might be affected by forest stand diversity (e.g. via litter diversity and differing decomposition dynamics).

Stand diversity has been found to increase structural diversity which is a key factor for spider communities (Jocque 1973). However, previous studies of the araneofauna of deciduous forests in Central Europe did not directly consider tree species diversity. They either concentrated on stands with only one major tree species (Dumpert and Platen 1985, Stippich 1986, Sührig 1997) or compared different forest stands, which in addition often varied in soil characteristics and their geographic location thus limiting comparability (Heimer and Hiebsch 1982, Hofmann 1986, Irmler and Heydemann 1988, Gurdebeke et al. 2003).

The Hainich National Park (Thuringia, Germany) offers a wide variety of mixed deciduous forest stands, where the influence of tree species diversity on animal communities can be studied under comparable geographic and pedogenetic conditions. The objective of this study was to analyze spider communities of the forest floor in a diversity gradient ranging from pure beech stands to forest stands comprising three and five major deciduous tree 
species. Since plant diversity has often been found to affect structural and biotic properties of ecosystems (e.g. Gartner and Cardon 2004, Hooper et al. 2005, Scherer-Lorenzen et al. 2005, Unsicker et al. 2006), it might also positively or negatively influence spider communities either directly or indirectly by modifying important habitat features for forest floor species (e.g. spatial and temporal changes in litter structure and microclimate).

Guiding questions were: (i) Are there distinct spatial or temporal patterns of spider species richness or abundance related to different levels of forest stand diversity? (ii) Are there differences in community structure and species composition? (iii) Which factors correlate with observed differences? Can they be attributed to the influence of different stand diversities or do spiders respond to factors independent of tree species diversity?

\section{Materials and methods}

\section{Study sites}

The Hainich National Park is located at the southern end of the Hainich, a low mountain range in Thuringia, Central Germany, between the cities of Mühlhausen and Eisenach. Mean annual temperature averages from 7.5 to $8.0^{\circ} \mathrm{C}$ and mean annual precipitation is $600 \mathrm{~mm}$, indicating a subatlantic climate with a slight subcontinental impact in the eastern part (Mönninghoff 1998).

Five study sites were established in the north-eastern part of the national park at about 300$370 \mathrm{~m}$ a.s.l. (approx. 51_10 N, 10_50 E), 0.5-4 km apart from each other (Fig. 1). Due to former forest management, the national park consists of a wide variety of very different deciduous forest stands on a small scale (Ahrns and Hofmann 1998). A total of nine plots was selected within five study sites (Fig. 1) belonging to three different stand types of increasing diversity levels (DL): one-species stands (DL 1) with beech (Fagus sylvatica L.), three-species stands (DL 2) with beech, ash (Fraxinus excelsior L.) and lime (Tilia cordata Mill. and/or Tilia platyphyllos Scop.) and five-species stands (DL 3) with beech, ash, lime, hornbeam (Carpinus betulus L.) and maple (Acer pseudoplatanus L. and/or Acer platanoides L.) as major tree species (i.e., dominating species as compared to species with just very few trees growing in or at the edge of the stands). Thus, the diversity levels represent a gradient from pure beech stands to complex mixed stands.

Each diversity level was replicated three times (plots a, b and c). Phytosociologically, the plots belong to the alliance of beech forests (Galio odorati-Fagion: all DL 1 and DL 2a,c) and oak-hornbeam forests (Carpinion betuli: DL 2b and all DL 3; Mölder et al. 2006). The parent rock is limestone which in most parts is covered by a loess layer of up to $120 \mathrm{~cm}$ forming cambisols and partially planosols (Seidel 1995, A. Guckland et al. unpublished data). To control for confounding factors as best as possible in an observational study, plots were 
chosen to be as similar as possible concerning pedological and biochemical properties of the stands, stand structure and stand age (approx. 80-120 years).

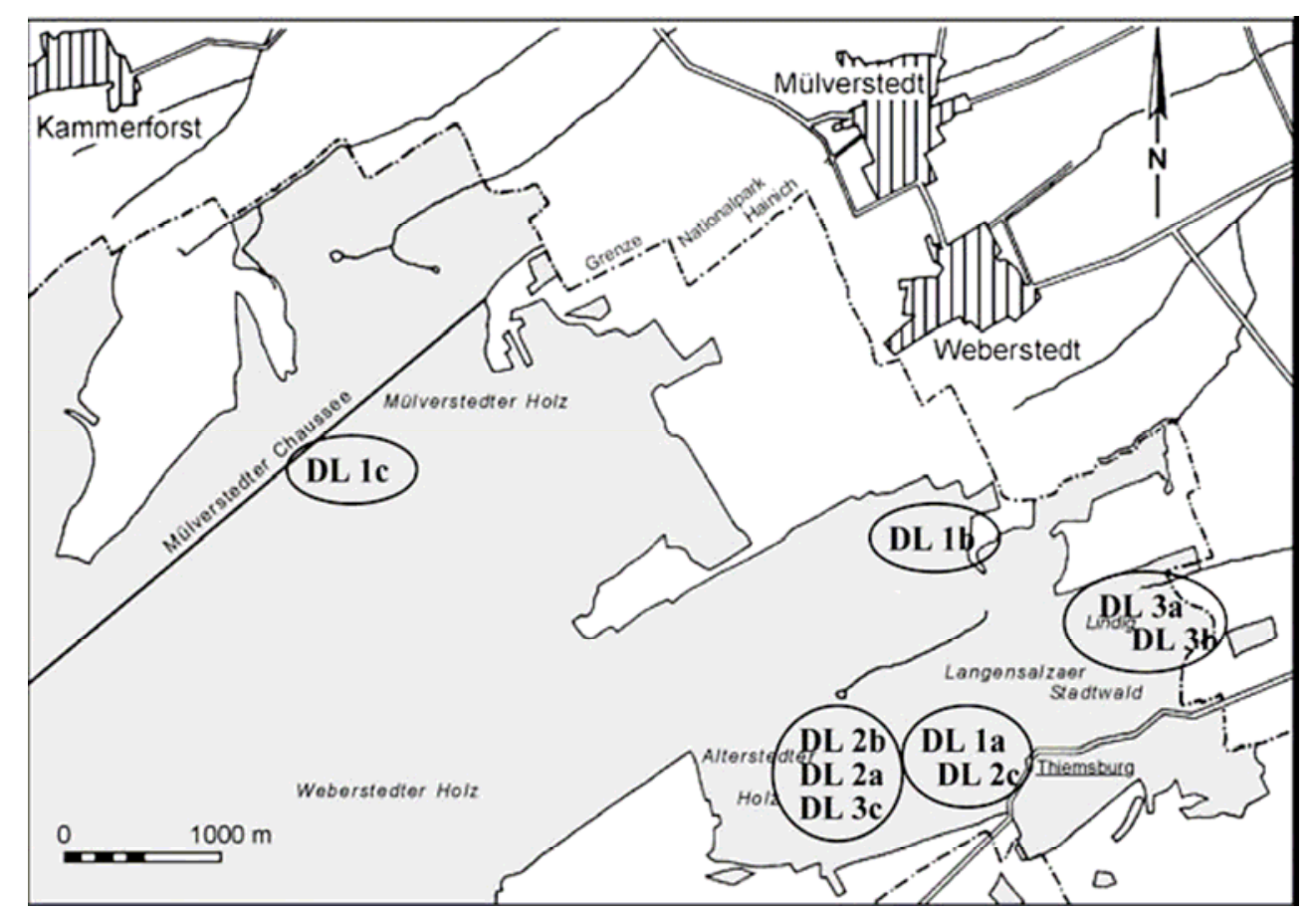

Fig. 1 Study area in the Hainich National Park with the location of the nine plots at the five study sites (circled). Tree species diversity levels: DL 1 (pure beech stands), DL 2 (mixed stands with three major tree species), DL 3 (mixed stands with five major tree species). Replicates are indicated by letters a, b and c.

\section{Sampling design}

The plots had a size of $50 \times 50 \mathrm{~m}$ and were fenced to keep out wild game. Six pitfall traps were installed randomly in each of the plots, measuring spider activity. Trapping was done continuously from 27 April to 26 October, 2005, (182 days) and traps were emptied every two weeks. The traps consisted of $0.4 \mathrm{I}$ jars (diameter of the opening $5.5 \mathrm{~cm}$ ) filled up to one third with a $50 \%$ ethylene glycol solution in water, with a few drops of an odourless detergent. $A$ mesh wire cage (mesh size $1.5 \mathrm{~cm}$ ) with a plastic roof was placed above each trap to keep out small vertebrates and to prevent dilution of the ethylene glycol solution by precipitation.

For measuring spider abundance, samples of the litter layer and the upper $5 \mathrm{~cm}$ of the soil layer $(\varnothing 21 \mathrm{~cm}=1 / 28 \mathrm{~m} 2)$ were taken on 11 May, 3 August and 23 November, 2005, about three meters away from the pitfall traps (six samples per plot) and animals were extracted by heat using the modified high-gradient canister method (Kempson et al. 1963; Schauermann 1982). These samples, comprising the litter layer and the upper soil layer, are termed "forest floor" samples. 


\section{Environmental variables}

Temperature and relative humidity were recorded continuously during the trapping period by one "HOBO pro H8-32" datalogger attached under the roof of the centermost trap on each plot. The percentage of herb cover was estimated monthly on a $595 \mathrm{~m}$ area surrounding each pitfall trap. The species composition of litter was recorded with litter collectors (buckets with a diameter of $0.6 \mathrm{~m}$ ) placed close to the traps, collecting falling leaves from August to December, 2005. Litter depth, litter pH, soil moisture and densities of springtails (Collembola) were determined from small forest floor samples (diameter of $5 \mathrm{~cm}$ ), taken together with the larger samples for spider extraction. Collembolans were extracted by heat (Macfadyen 1961).

\section{Data analyses}

To detect differences in spider species richness, spider numbers and activity of selected spider species, analysis of variance (ANOVA) and Tukey's post hoc test were used in a design with the factor "plot" nested within the factor "diversity level". Thus, by splitting total variance, plot effects within the diversity levels could be separated from actual effects of the three diversity levels. A second ANOVA comparing the nine plots was used to assess the significance of observed plot effects. They were considered to be relevant only if one of the three plots within a diversity level differed significantly from the other two plots.

Before testing, data were checked for normality of distribution (Shapiro-Wilk) and homogeneity of variance (Bartlett's test) and if necessary log-transformed. Multiple comparisons were secured by MANOVA ("protected ANOVA", Scheiner and Gurevitch 1993), which in all cases yielded a statistically significant model $(P<0.001)$. Analyses were performed using SAS for Windows 8.2 (SAS Institute, Cary, NC, USA). As a measure for species diversity the Shannon-Wiener index was calculated (Magurran 2004).

Data were pooled for pitfall traps because of continuous trapping, whereas forest floor sample data were analyzed separately for each of the three sampling dates. Principal components analysis (PCA) was used for multivariate analysis of community structure using Canoco for Windows 4.5 (Ter Braak and Šmilauer 2002). Data were logtransformed thus downweighting highly abundant, ubiquitous species. Additionally, species with less than four individuals in the pitfall trap dataset were excluded to reduce the influence of accidental occurrences. Integration of environmental factors was done by redundancy analysis (RDA). Relevance of the selected variables was confirmed by comparing PCA and RDA eigenvalues and by Monte Carlo permutation procedure (Ter Braak and Šmilauer 2002). Spearman's rank correlation was performed to test relationships between environmental variables and species richness as well as spider numbers, using SAS for Windows 8.2. 


\section{$\underline{\text { Results }}$}

\section{Environmental variables}

Diversity level characteristics are summarized in Table 1, with herb cover increasing $\left(F_{2,45}=\right.$ 58.0; $P<0.001)$ and litter depth decreasing $\left(F_{2,45}=34.48 ; P<0.001\right)$ significantly with increasing tree diversity. Collembolan densities were higher in DL 1 than in DL 2 and DL 3 $\left(F_{2,45}=24.02 ; P<0.001\right)$. For herb cover there was also a significant plot effect $\left(F_{6,45}=9.18\right.$; $P<0.001)$ in DL 2 because of reduced herb cover on plot DL 2c. Temperature and relative humidity were not markedly different between diversity levels, but data could not be analysed statistically due to missing values on some plots after datalogger malfunctions. Soil moisture was not continuously high or low on any diversity level, while litter $\mathrm{pH}$ was lowest on the DL 1 plots throughout the year.

Table 1 Habitat characteristics for the stands of the three tree species diversity levels (DL 1, DL 2 and DL 3, see Figure 1) recorded during the sampling period (April to November 2005).

\begin{tabular}{|c|c|c|c|}
\hline & DL 1 & DL 2 & $\mathrm{DL} 3$ \\
\hline Temperature $\left({ }^{\circ} \mathrm{C}\right)^{*}$ & $13.8 \pm 0.1$ & $13.5 \pm 0.1$ & $13.6 \pm 0.1$ \\
\hline Relative humidity $(\%)^{*}$ & $89.9 \pm 0.7$ & $91.4 \pm 0.0$ & $92.2 \pm 0.6$ \\
\hline Herb cover $(\%)^{*}$ & $23.4 \pm 2.5^{\mathrm{c}}$ & $48.3 \pm 5.5^{\mathrm{b}}$ & $67.8 \pm 3.7^{\mathrm{a}}$ \\
\hline Litter diversity (Shannon-index) ${ }^{\star *}$ & $0.01-0.31$ & $0.8-1.27$ & $1.36-1.53$ \\
\hline Litter depth $(\mathrm{cm})^{*}$ & $2.9 \pm 0.1^{a}$ & $2.5 \pm 0.1^{\mathrm{b}}$ & $1.9 \pm 0.1^{c}$ \\
\hline Litter $\mathrm{pH}^{\star *}$ & $4.2-5.4$ & $5.3-6.7$ & $5.5-7.0$ \\
\hline Soil moisture $(\%)^{* *}$ & $23.1-36.4$ & $20.5-30.8$ & $22.9-33.0$ \\
\hline Prey abundance (Collembola) $)^{*}$ & $184.2 \pm 20.5^{\mathrm{a}}$ & $87.7 \pm 8.7^{b}$ & $64.1 \pm 5.3^{b}$ \\
\hline
\end{tabular}

Mean values with different letters show significant differences between diversity levels at $P=0.05$ using ANOVA and Tukey's post hoc test.

${ }^{*}$ Mean \pm 1 SE

${ }^{* *}$ Range

Litter composition in the near vicinity of pitfall traps was rather homogeneous (Fig. 2) within DL 1 and DL 2, whereas litter composition between plots of DL 3 differed to a larger degree. Two plots had high proportions of lime (DL 3a and DL 3b) and only a low proportion of beech. DL 3c as the third DL 3 plot, however, was characterized by comparably larger amounts of beech as well as ash and only about $15 \%$ lime. 


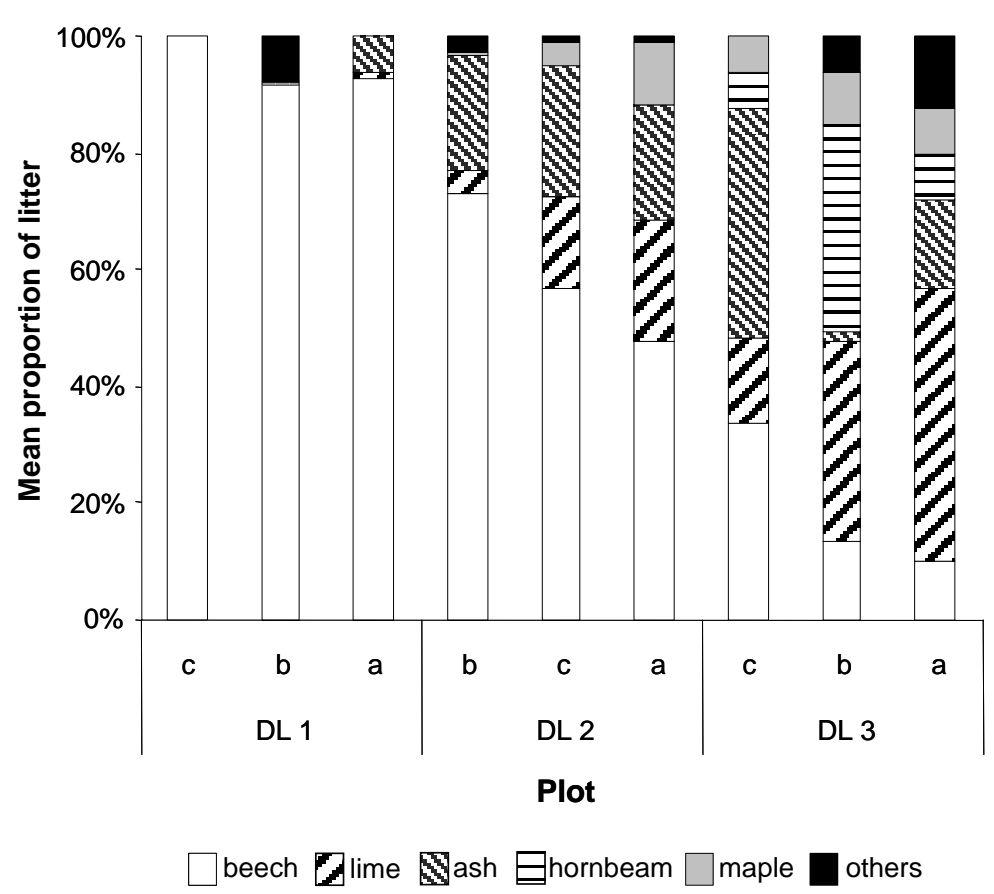

Fig. 2 Mean proportion (\%) of litter of the major tree species at the nine studied plots in the vicinity of pitfall traps and of forest floor samples. DL 1, DL 2 and DL 3: tree species diversity levels (see Fig. 1)

\section{Spider diversity and numbers}

In total 6,877 individuals were collected with pitfall traps; 4,463 spiders (65\%) were adults belonging to 64 species. Forest floor samples yielded 1,730 individuals with 390 adults (23\%) belonging to 32 species with only four of these not caught in pitfall traps. Spider numbers in pitfall traps were dominated by Linyphiidae and Amaurobiidae with Coelotes terrestris (Wider 1834) being the dominant species, whereas forest floor samples comprised mostly Hahniidae and Linyphiidae with Hahnia pusilla C.L. Koch 1841 being most abundant. Most species and individuals were web builders. Hunting spiders were collected rarely, even in pitfall traps (7\% of all individuals).

Mean species richness of spiders in pitfall trap catches was highest in DL 2 and significantly lower in DL $1\left(F_{2,45}=2.83 ; \mathrm{P}=0.012\right.$; Fig. 3a). The plot effect within the levels $\left(F_{6,45}=2.39\right.$; $P=0.043$ ) was not relevant and did not affect the results for the diversity levels. The mean number of all-adult and juvenile-spiders $\left(F_{2,45}=15.54 ; \mathrm{P}<0.001\right)$ and of adult spiders $\left(F_{2}\right.$, ${ }_{45}=13.31 ; \mathrm{P}<0.001$ ) was significantly higher in $\mathrm{DL} 1$ than in $\mathrm{DL} 3$, with activity of all spiders decreasing steadily with increasing stand diversity (Fig. $3 b$ and $c)$. Plot effects $\left(F_{6,45}=3.10\right.$; $P=0.013$ for all spiders and $F_{6,45}=3.95 ; P=0.003$ for adults) were weak and did not influence mean spider numbers. 

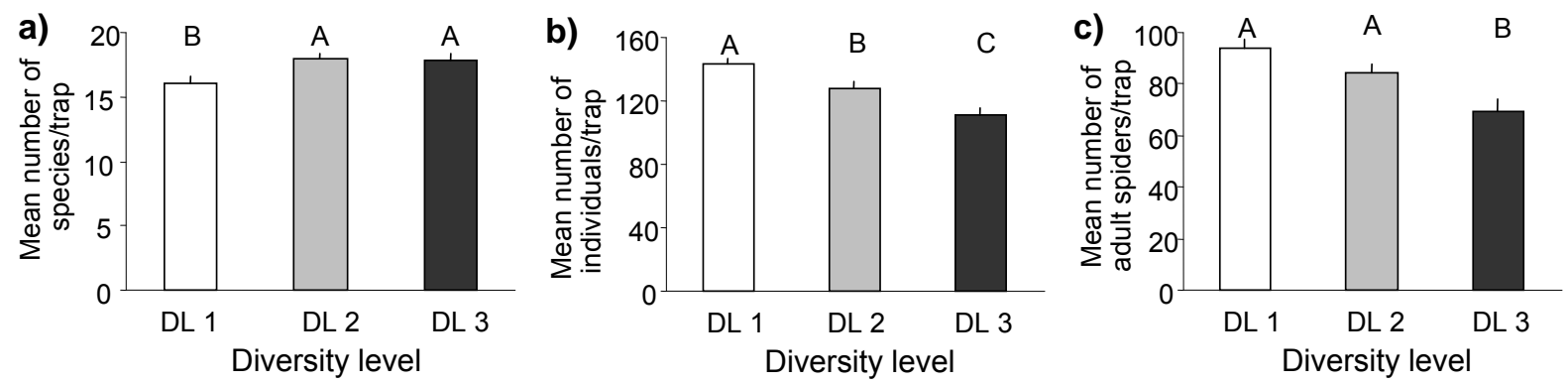

Fig. 3 Mean values ( \pm 1 SE) of spider species richness (a), number of all spiders $(b)$ and number of adult spiders (c) per pitfall trap for the three tree species diversity levels (DL 1, DL 2 and DL 3, see Fig. 1) for the whole sampling period. Bars with different letters show significant differences between diversity levels at $P=0.05$ using ANOVA and Tukey's post hoc test

Temporal changes in numbers of adult spiders caught in pitfall traps were similar for DL 1 and 2, with two distinct peaks of activity in June/July and in September, whereas in DL 3 the first peak was more or less missing (Fig. 4).

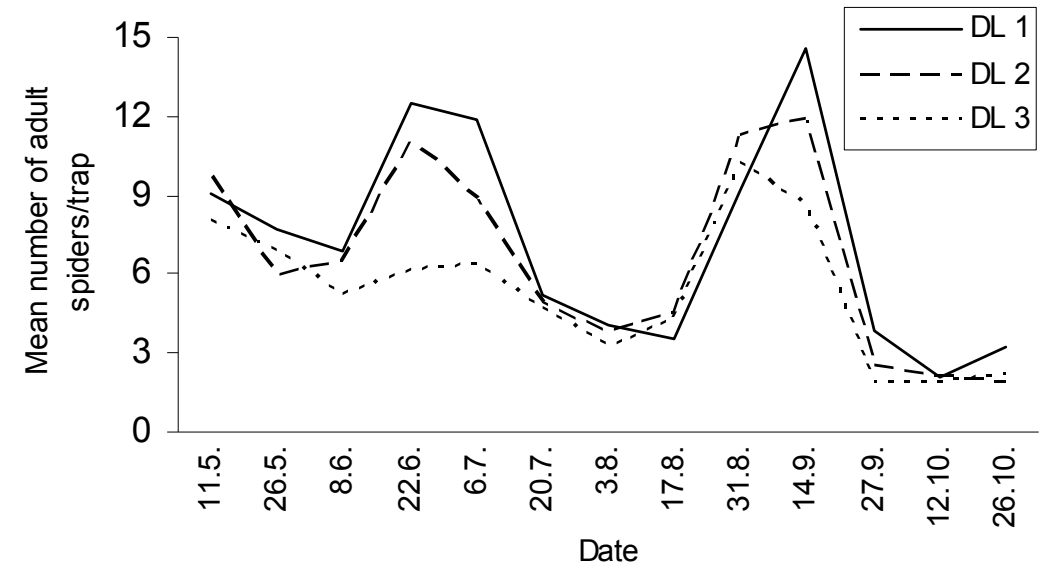

Fig. 4 Temporal changes in the number of adult spiders (mean values) caught per pitfall trap for the three tree species diversity levels (DL 1, DL 2 and DL 3, see Figure 1) during the trapping period

Species richness in forest floor samples differed significantly on two (May and August) of the three sampling dates, being highest in $\mathrm{DL} 2$ and lowest in $\mathrm{DL} 1\left(\mathrm{~F}_{2,45}=7.53 ; \mathrm{P}=0.002\right.$ and $F_{2,45}=5.84 ; P=0.006$; Fig. $\left.5 a-c\right)$. Differences in total abundance for all spiders were only significant in May $\left(F_{2,45}=4.61 ; P=0.015\right.$; Fig. $\left.5 d-f\right)$, whereas numbers of adults were markedly higher in DL 2 than in DL 1 on all sampling dates (May: $F_{2,45}=10.24 ; P<0.001$, August: $F_{2,45}=8.86 ; P<0.001$ and November: $\left.F_{2,45}=4.95 ; P=0.011\right)$. DL 3 was intermediate, with abundance being high in May and November and low in August (Fig. $5 \mathrm{~g}-$ i). Weak and negligible plot effects appeared in May for species richness $\left(F_{6,45}=4.0\right.$; $P=$ $0.003)$ and for abundance of all individuals $\left(F_{6,45}=2.53 ; P=0.034\right)$. 

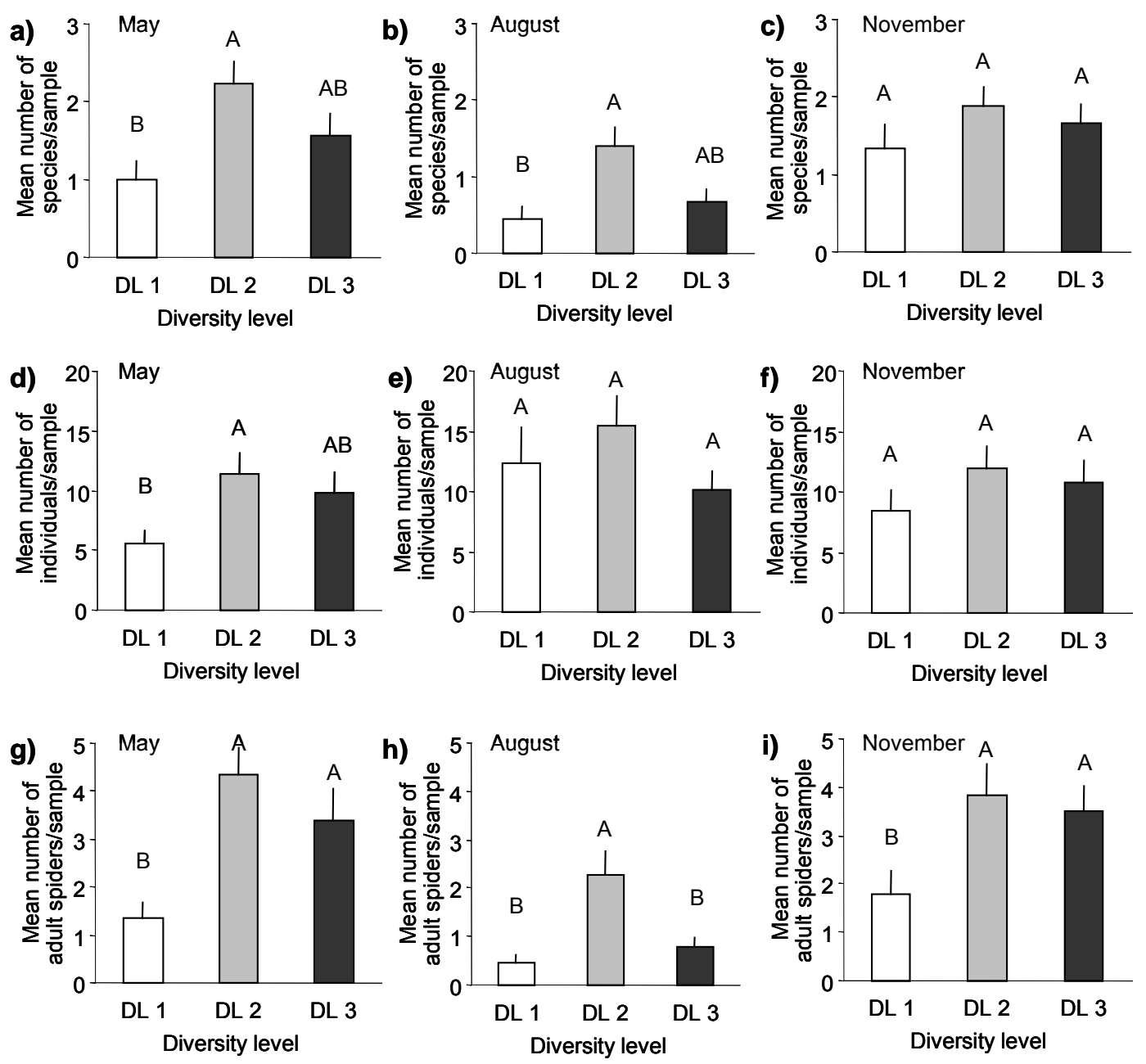

Fig. 5 Mean values $( \pm 1 \mathrm{SE}$ ) of spider species richness $(\mathrm{a}-\mathrm{C})$, abundance of all spiders $(\mathrm{d}-\mathrm{f})$ and abundance of adult spiders ( $\mathrm{g}-\mathrm{i}$ ) per forest floor sample for the three tree species diversity levels (DL 1, DL 2 and DL 3, see Fig. 1) on three sampling dates (May, August and November). Bars with different letters show significant differences between diversity levels at $P=0.05$ using ANOVA and Tukey's post hoc test. ANOVAs performed with logtransformed values, but means of untransformed values are shown

The Shannon-Wiener index for pitfall trap catches increased with stand diversity from DL 1 to DL 3 due to increasing evenness (Table 2). Forest floor sample data rendered opposite results with decreasing diversity from $D L 1$ to $D L 3$ on all three sampling dates due to decreasing evenness (Table 2).

Table 2 Shannon-Wiener index (HS), evenness (E) and total number of species for stands of the three tree species diversity levels (DL 1, DL 2 and DL 3, see Fig. 1) for pitfall trapping (whole trapping period) and forest floor sampling (May, August and November)

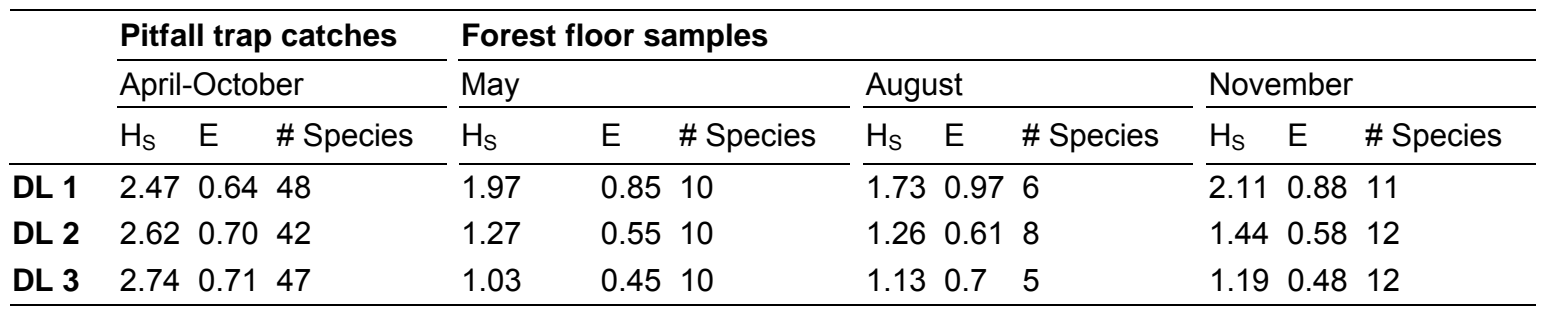




\section{Community structure}

The ordination of the pitfall trap dataset revealed differences in community structure between plots rather than between diversity levels (Fig. 6). Differentiation was significant mainly along the first axis, the eigenvalue of the second axis being very low. The two plots DL $3 a$ and DL $3 \mathrm{~b}$, located at the same study site (cf. Fig. 1), were distinct from the other seven plots, which formed a rather homogeneous group without clear separation of the plots. While many spider species were common on most plots, there was a group of spiders accounting for the differences in spider community structure. The species Diplocephalus picinus (Blackwall 1841) and Hahnia pusilla were important for DL 1, the former being abundant especially on plot $\mathrm{DL} 1 \mathrm{c}$, the latter being almost totally absent from all DL 1 plots. Species such as Diplostyla concolor (Wider 1834), Tenuiphantes cristatus (Menge 1866) and Tenuiphantes tenebricola (Wider 1834) were highly associated with plots DL $3 a$ and DL 3b, whereas other species, especially Harpactea lepida (C.L. Koch 1838), Histopona torpida (C.L. Koch 1834), Saloca diceros (O.P.-Cambridge 1871) and Walckenaeria corniculans (O.P.-Cambridge 1851) were less frequent or missing on these plots. These differences were highly significant, as shown by ANOVA comparing the nine plots (Table 3 ). Comparison between diversity levels yielded considerable plot effects within DL 3 for these species. Thus, the statistical analysis of the nine plots was preferred to a comparison of the three diversity levels, the latter obscuring significant differences within these levels.

Table 3 Mean number ( $\pm 1 \mathrm{SE}$ ) of adults of selected spider species per pitfall trap (whole trapping period) on the nine plots of the three tree species diversity levels (DL 1, DL 2, DL 3, see Fig. 1) and ANOVA F- and P-values.

\begin{tabular}{|c|c|c|c|c|c|c|c|c|c|c|c|}
\hline & \multicolumn{3}{|l|}{ DL 1} & \multicolumn{3}{|l|}{ DL 2} & \multicolumn{3}{|l|}{ DL 3} & \multirow{2}{*}{\multicolumn{2}{|c|}{$F_{8,45} p$}} \\
\hline & c & $b$ & a & $\mathrm{C}$ & $\mathrm{b}$ & a & $\mathrm{C}$ & $\mathrm{b}$ & $a$ & & \\
\hline D. picinus & $10,7^{a}$ & $1,8^{\mathrm{cd}}$ & $5,7^{\mathrm{abc}}$ & $7,5^{\mathrm{ab}}$ & $1,8^{\mathrm{bcd}}$ & $1,7^{\text {cd }}$ & $1,0^{d}$ & $1,2^{\text {cd }}$ & $1,3^{\text {cd }}$ & 7.86 & $<0.001$ \\
\hline H. torpida & $16,8^{\mathrm{ab}}$ & $27,2^{a}$ & $11,7^{\mathrm{ab}}$ & $10,7^{\mathrm{bc}}$ & $13,2^{\mathrm{ab}}$ & $8,7^{b c}$ & $11,5^{\mathrm{bc}}$ & $4,5^{d}$ & $7,0^{\mathrm{cd}}$ & 7.85 & $<0.001$ \\
\hline S. diceros & $6,3^{a}$ & $2,8^{a b}$ & $5,5^{\mathrm{a}}$ & $4,5^{a}$ & $5,5^{a}$ & $6,8^{a}$ & $6,7^{\mathrm{a}}$ & $0,2^{b}$ & $0^{\mathrm{b}}$ & 9.65 & $<0.001$ \\
\hline H. lepida & $8,0^{a}$ & $4,8^{a}$ & $5,3^{a}$ & $8,2^{a}$ & $4,0^{a}$ & $4,2^{a}$ & $3,5^{a b}$ & $0,5^{\mathrm{b}}$ & $0,7^{b}$ & 9.18 & $<0.001$ \\
\hline W. corniculans & $7,0^{a}$ & $13,3^{a}$ & $7,5^{a}$ & $6,7^{a}$ & $7,2^{a}$ & $8,5^{a}$ & $7,7^{\mathrm{a}}$ & $0^{\mathrm{b}}$ & $1,8^{b}$ & 18.43 & $<0.001$ \\
\hline H. pusilla & $0^{d}$ & $0^{d}$ & $0,3^{d}$ & $3,0^{b c}$ & $2,5^{\mathrm{C}}$ & $6,3^{a b}$ & $7,3^{a}$ & $2,2^{C}$ & $2,3^{C}$ & 24.40 & $<0.001$ \\
\hline T. tenebricola & $0^{c}$ & $0^{c}$ & $0,8^{c}$ & $1,2^{\mathrm{C}}$ & $0,8^{c}$ & $1,7^{b c}$ & $1,2^{\mathrm{C}}$ & $6,5^{a}$ & $4,5^{a b}$ & 11.33 & $<0.001$ \\
\hline D. concolor & $0,2^{c}$ & $0,2^{c}$ & $0^{\mathrm{C}}$ & $0,5^{\mathrm{abc}}$ & $2,8^{a b c}$ & $1,5^{a b c}$ & $0,3^{b c}$ & $3,2^{a}$ & $3,3^{a b}$ & 4.71 & $<0.001$ \\
\hline
\end{tabular}

Mean values with different letters show significant differences between plots at $P=0.05$ using ANOVA and Tukey's post hoc test. High numbers of individuals of each species are typed in bold. ANOVAs performed with log-transformed values, but untransformed values are shown 


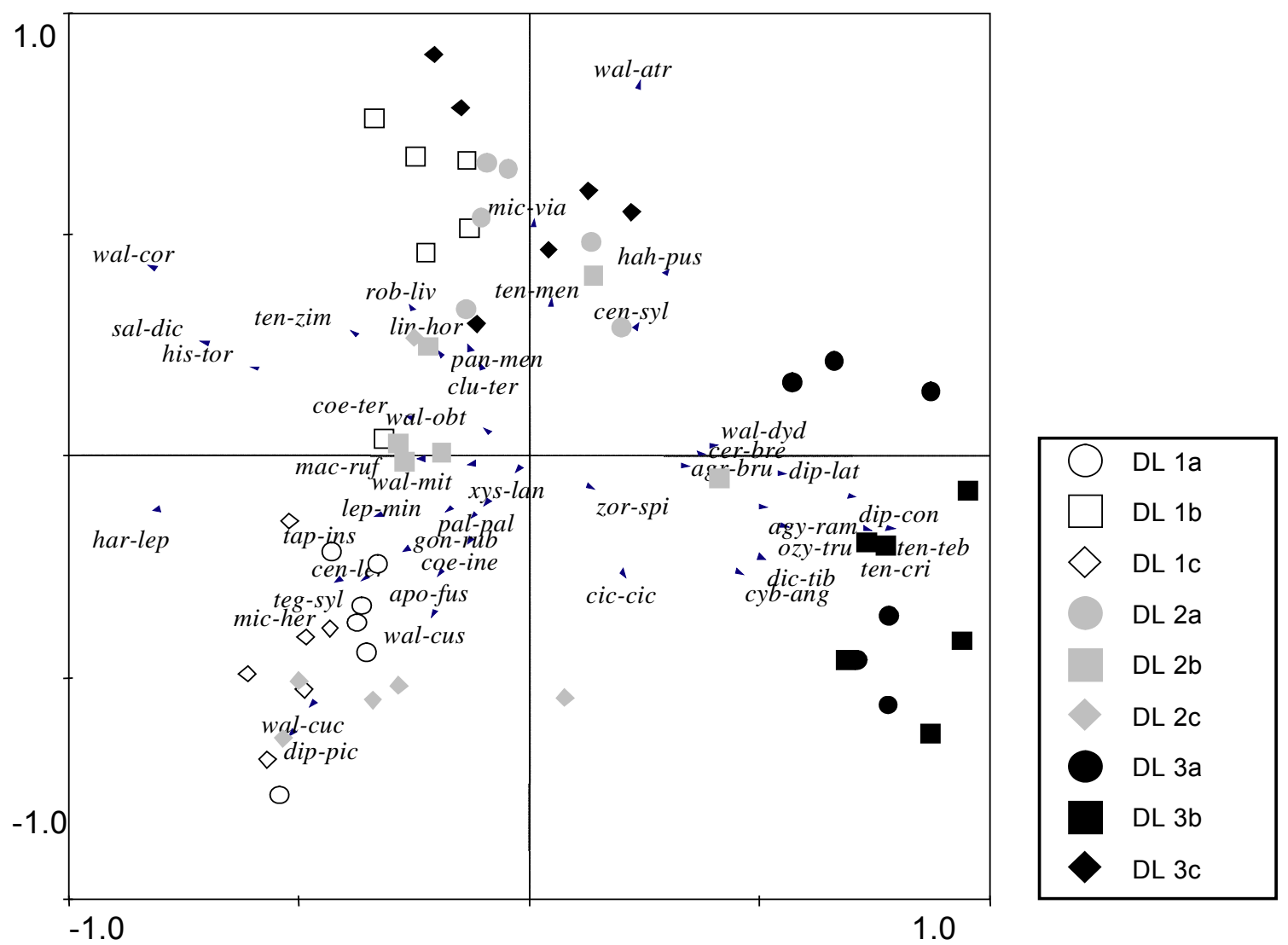

Fig. 6 PCA ordination plot for spider data (whole trapping period) from pitfall traps of the nine studied plots (DL 1a-DL 3c, see Fig. 1). Data were log-transformed. Eigenvalues: first axis (horizontal) $=0.277$, second axis (vertical $)=0.148$. Cumulative percentage variance of species data for both axes: $42.5 \%$. Only species with [3 individuals were included into the analysis. Circles and squares each represent a trap. Triangles represent species. Abbreviations are names of species: Agroeca brunnea (Blackwall 1833), Agyneta ramosa Jackson 1912, Apostenus fuscus Westring 1851, Centromerus leruthi Fage 1833, Centromerus sylvaticus (Blackw. 1841), Ceratinella brevis (Wider 1834), Cicurina cicur (Fabricius 1793), Clubiona terrestris Westr. 1851, Coelotes inermis (L. Koch 1855), Coelotes terrestris (Wider 1834), Cybaeus angustiarum L. Koch 1868, Dicymbium tibiale (Blackw. 1836), Diplocephalus latifrons (O.P.- Cambr. 1863), Diplocephalus picinus (Blackw. 1841), Diplostyla concolor (Wider 1834), Gonatium rubellum (Blackw. 1851), Hahnia pusilla C.L. Koch 1841, Harpactea lepida (C.L. Koch 1838), Histopona torpida (C.L. Koch 1834), Lepthyphantes minutus (Blackw. 1833), Linyphia hortensis Sundevall 1830, Macrargus rufus (Wider 1834), Micrargus herbigradus (Blackw. 1854), Microneta viaria (Blackw. 1841), Ozyptila trux (Blackw. 1847), Palliduphantes pallidus (O.P.-Cambr. 1871), Panamomops mengei Simon 1926, Robertus lividus (Blackw. 1836), Saloca diceros (O.P.-Cambr. 1871), Tapinocyba insecta (L. Koch 1869), Tegenaria silvestris L. Koch 1872, Tenuiphantes cristatus (Menge 1866), Tenuiphantes mengei Kulczynski 1887, Tenuiphantes tenebricola (Wider 1834), Tenuiphantes zimmermanni Bertkau 1890, Walckenaeria atrotibialis O.P.-Cambr. 1878, Walckenaeria corniculans (O.P.-Cambr. 1851), Walckenaeria cucullata (C.L. Koch 1837), Walckenaeria cuspidata (Blackw. 1833), Walckenaeria dysderoides (Wider 1834), Walckenaeria mitrata (Menge 1868), Walckenaeria obtusa Blackw. 1836, Xysticus lanio C.L. Koch 1824, Zora spinimana (Sundev. 1833) 
Spider communities in the forest floor were even more homogeneous across the diversity gradient than spider assemblages in pitfall traps. Thus, only the ordination of November data is shown, where eigenvalues were largest (Fig. 7). Community structure of forest floor samples was strongly affected by the distribution of the dominant species Hahnia pusilla and Saloca diceros. The almost entire absence of $H$. pusilla in the DL 1 plots caused a separation of these plots from most of the DL 2 and DL 3 samples, but high variation of samples within all plots obscured this differentiation to a certain extent. However, mean densities of the highly abundant $H$. pusilla were significantly lower in DL 1 compared to DL 2 and DL 3 on all sampling dates without any plot effects (May: $F_{2,45}=28.21$; $P<0.001$, August: $F_{2,45}=14.76$; $P<0.001$ and November: $\left.F_{2,45}=24.31 ; P<0.001\right)$. Comparable to pitfall trap data, the second most abundant species, S. diceros, was missing in plots DL $3 a$ and DL $3 b$, while being highly abundant on the other plots. However, these differences were not statistically significant because of the high variation within plots (Table 4).

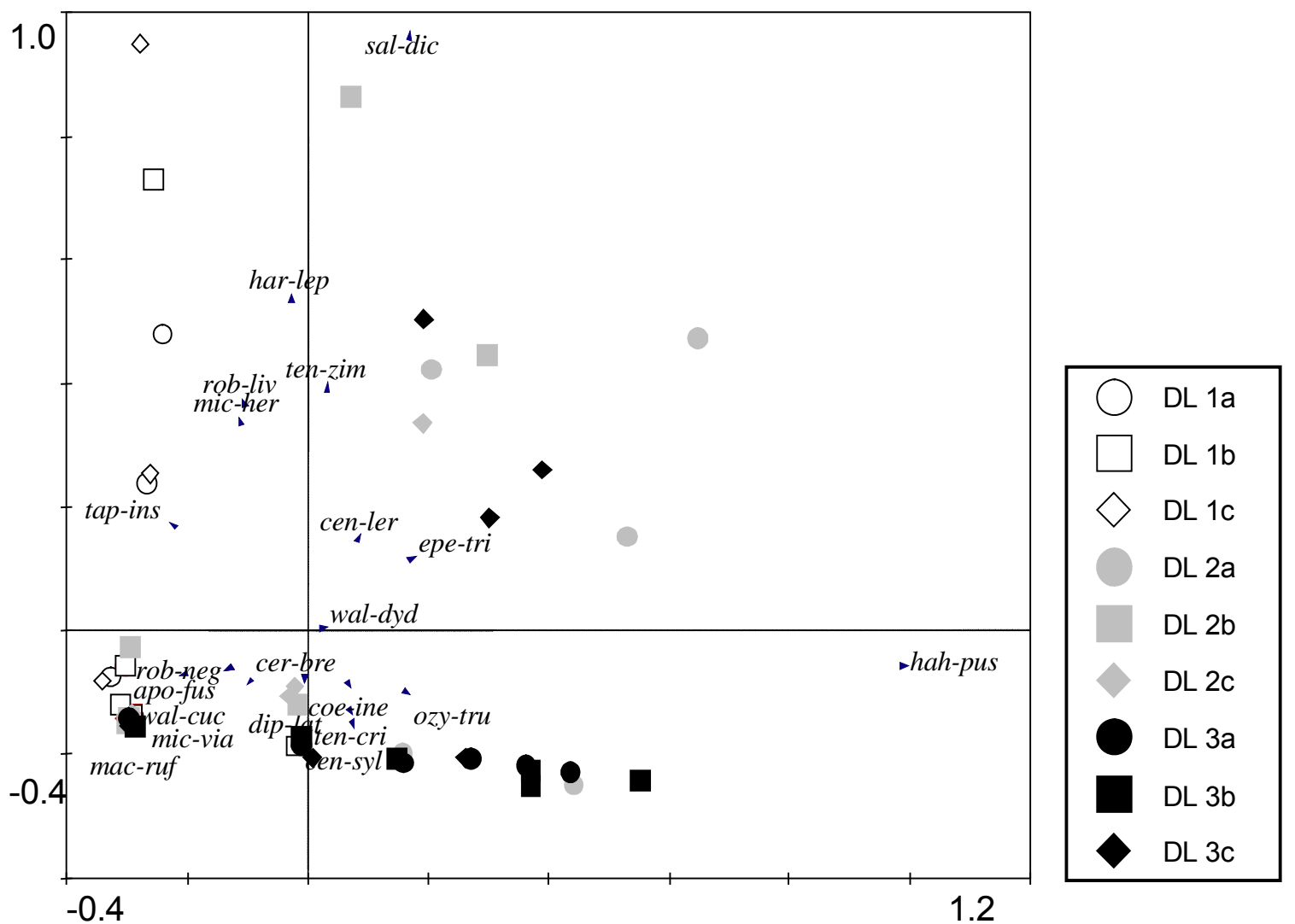

Fig. 7 PCA ordination plot for spider data (November samples) from forest floor sampling of the nine studied plots (DL 1a-DL 3c, see Fig. 1). Data were log-transformed. Eigenvalues: first axis (horizontal) $=0.446$, second axis (vertical) $=0.205$. Cumulative percentage variance of species data for both axes: $65 \%$. Circles and squares each represent a trap. Triangles represent species. Additional abbreviations to those listed in Fig. 6: Eperigone trilobata (Emerson 1882) and Robertus neglectus (O.P.-Cambr. 1871) 
Table 4 Mean abundance ( $\pm 1 \mathrm{SE}$ ) of adults of Hahnia pusilla and Saloca diceros per forest floor sample on the nine plots of the three tree species diversity levels (DL 1, DL 2, DL 3, see Fig. 1) in May, August and November, and ANOVA F- and P-values.

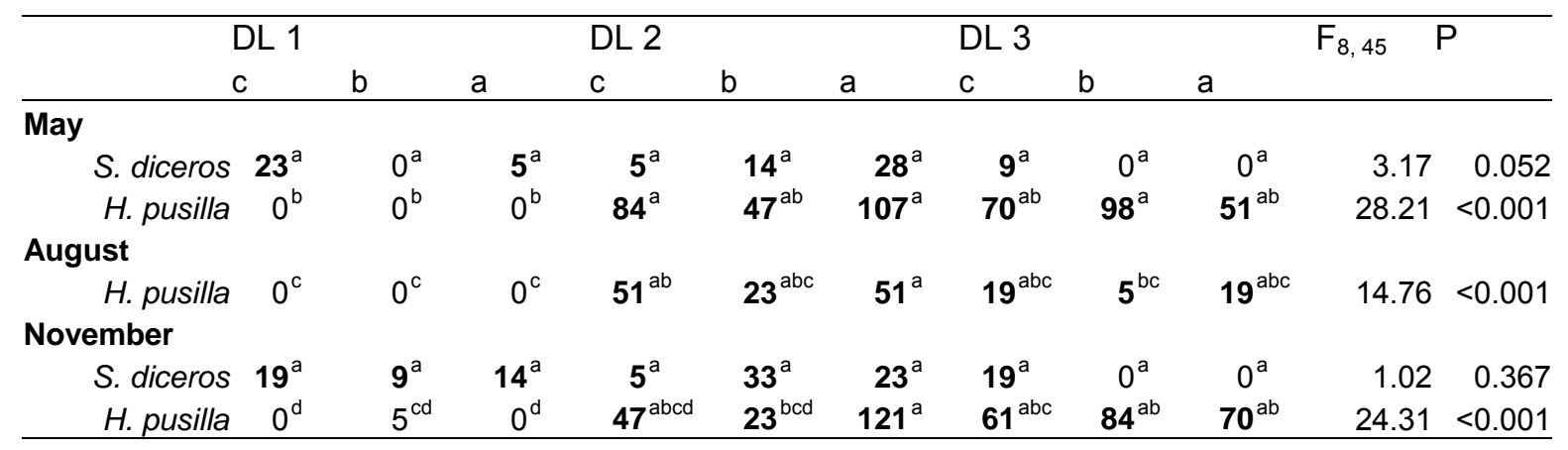

Mean values with different letters show significant differences between plots at $P=0.05$ using ANOVA and Tukey's post hoc test. High abundance of individuals is typed in bold. ANOVA performed with logtransformed values, but untransformed values are shown

\section{Influence of environmental parameters}

For forest floor samples, eigenvalues of PCA (cf. Fig. 7) and RDA (first axis 0.230, second axis 0.032) as well as the distribution of plots within the ordinations differed considerably, even though Monte Carlo testing of axes was significant $(P=0.004)$. Thus, the correlations between ordination of spider communities and environmental variables in the RDA do not adequately explain community patterns and the RDA graph is not presented here.

RDA for pitfall trap data showed highly negative correlations between community structure of DL $3 a$ and DL $3 b$ and litter depth, amount of beech litter, and Collembolan densities, as well as positive correlations with the amount of lime litter and percentage of herb cover (Fig. 8). In this case eigenvalues of RDA and PCA differed only marginally confirming the significance of the Monte Carlo permutation test, thus indicating good correlations between environmental variables and community patterns.

Since species richness and total spider numbers of the plots could not be included into RDA, separate correlations were performed for the 54 pitfall traps/forest floor samples. There was a highly significant positive correlation between species numbers and litter diversity (Shannon-Wiener index; $\rho=0.47, \mathrm{P}<0.001$ ) for pitfall trap data. Total number of individuals was correlated negatively with litter diversity $(\rho=-0.46 ; P<0.001)$ and herb cover $(\rho=-0.54$; $P<0.001)$ and positively with litter depth $(\rho=0.58 ; P<0.001)$ and Collembolan densities ( $q$ $=0.53 ; \mathrm{P}<0.001)$. There was no significant correlation for species richness of forest floor samples with any of the above environmental variables. Only total spider abundance correlated with the amount of lime litter in May $(\rho=0.42 ; P=0.001)$, but this effect disappeared completely in August and November. 


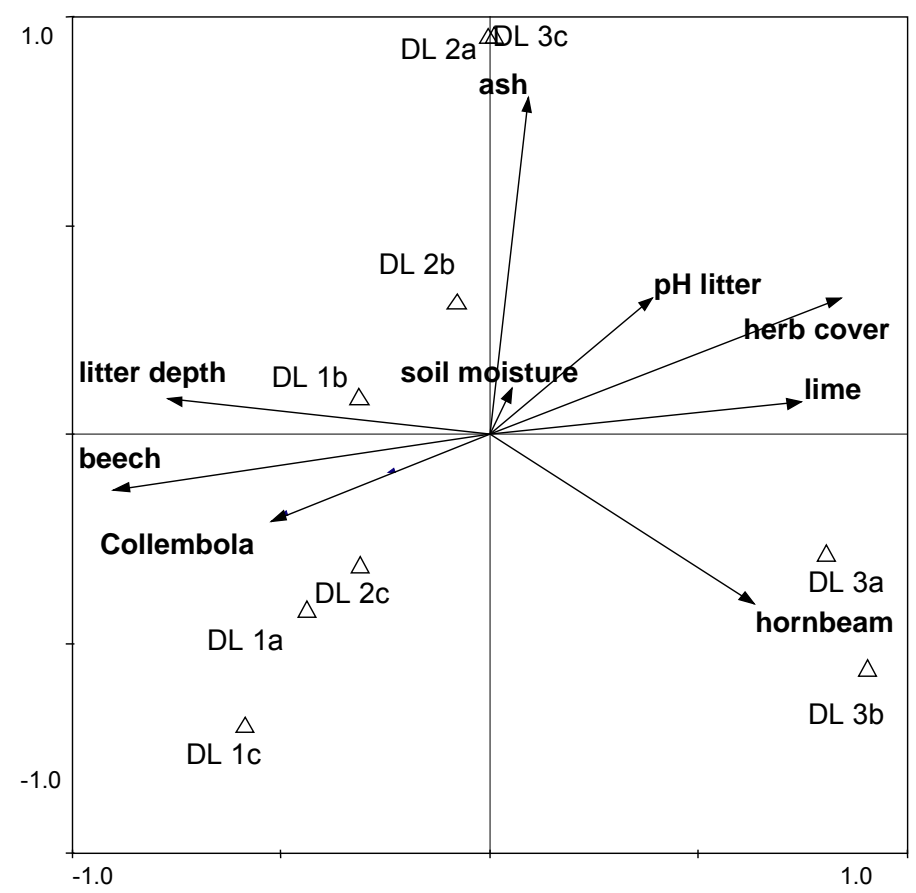

Fig. 8 RDA ordination plot for spider communities (pitfall trap catches) of the nine studied plots (DL 1a- DL 3c, shown as centroids = weighted means of spider data) and correlated environmental variables (arrows). Data logtransformed. Eigenvalues: first axis (horizontal) $=0.239$, second axis (vertical) $=0.059$. Cumulative percentage variance of species data for both axes: $29.8 \%$. Only species with $>3$ individuals were included into the analysis (Species are not shown in ordination plot). Monte Carlo permutation test: first axis $F=13.8$ and $P=0.002$; all axes $\mathrm{F}=3.1$ and $\mathrm{P}=0.002$

\section{Discussion}

\section{Spider diversity and numbers}

With both methods, pitfall trapping [methodological constraints having been extensively discussed by Adis (1979), Churchill and Arthur (1999), Wagner et al. (2003) and many others] and quantitative forest floor sampling, mean species richness was highest in medium diverse (DL 2) and lowest in least diverse forest stands (DL 1). Mean abundance of spiders in forest floor samples exhibited the same pattern, being more pronounced for adults than for total numbers including juveniles, while activity in pitfall traps decreased from DL 1 to DL 3 . Thus, except for the latter trend, there was no clear gradient attributable to increasing stand diversity. Rather, the results indicate a strong influence of factors that appear to be modified by the relative dominance of beech or lime rather than by tree species diversity itself, as will be discussed below. There are no studies directly comparable to this analysis, considering tree species diversity in deciduous forests. However, there is a plentitude of descriptive and experimental studies in single forest stands dealing with influencing variables on spider diversity and abundance, which can be used to derive general patterns determining the composition of the spider fauna in forests. 
In the present study, the spider fauna presumably was affected to a large extent by litter depth and herb cover, although no definite conclusions can be drawn since no manipulative experiments were done. Litter depth is dependent on the dominant tree species, with beech being decomposed much more slowly than ash or lime, resulting in a constantly deep litter layer (Swift et al. 1979, Dunger 1983).

High species numbers in DL 2 may be ascribed to the beneficial combination of litter depth and herb cover. Both factors are known to promote spider species richness in deciduous forests (Uetz 1976 and 1990, Stevenson and Dindal 1982, Docherty and Leather 1997, Bird et al. 2000, Willett 2001). In DL 1 the herb layer was only poorly developed and in DL 3 the litter layer was sparsely developed due to high earthworm activity (Cesarz et al. 2007), while in DL 2 both herb and litter layer were well developed, enabling the occurrence of both litterand ground-vegetation inhabiting species. Whereas Uetz (1979 and 1990) found litter depth to be the all-important factor influencing wandering spiders, in the present study herb cover appears to have a major influence as well, since mostly webbuilding spiders were recorded. These can use the lower parts of plants for web construction (Standen 2000, Oxbrough et al. 2005).

Mean spider activity strongly correlated with litter depth, decreasing from DL 1 to $\mathrm{DL} 3$. As with species richness, this factor is known to affect spider activity (pitfall traps) as well as spider abundance (forest floor samples) by increasing interstitial space and thus available habitat within the litter (Bultman and Uetz 1982, Stippich 1989, Uetz 1990, Irmler 2005). Spider numbers also correlated with prey densities (Collembola), another influencing factor which can be separated from litter depth only experimentally (Chen and Wise 1999). There is no direct explanation for the deviating pattern in spider abundance of forest floor samples. High values in DL 2 and low values in DL 1 were rather unexpected. Possibly, this pattern is caused by the absence of the otherwise highly abundant species Hahnia pusilla from DL 1 . According to Hänggi et al. (1995), this species is rare in pure beech forests and more numerous in mixed deciduous forests. This is supported by studies from beech forests on acidic soil with a deep litter layer, where this species was very rare (Albert 1976, Dumpert and Platen 1985, Roß-Nickoll 2000). Still, the underlying factors causing low spider abundance in DL 1, despite high availability of habitat and prey, require closer experimental investigation.

Soil moisture and humidity, often cited as important environmental factors for spider diversity and abundance (Abraham 1983, De Bakker et al 2001), were not crucial in this study as they were not distinctly different between diversity levels or between plots.

Diversity indices are often considered to be a more indicative diversity measure than mere species richness (Magurran 2004). The results for Shannon-Wiener indices differed from those for species richness. However, they also differed between the two sampling methods, 
with the Shannon-Wiener index increasing with stand diversity for pitfall trap catches and decreasing for forest floor samples. Apart from the low number of adults in the forest floor samples, this is probably a result of sampling different components of the soil, litter and epigeic fauna by using these two methods (see Hutha 1971). Thus, for diversity and equitability of assemblages of epigeic spiders in pitfall traps, herb cover might have been an important factor, as was also found by Docherty and Leather (1997), Bird et al. (2000) and Willett (2001). Spiders from forest floor samples might be more affected by the litter layer. Uetz (1975) assumes that evenness of spiders on the forest floor is enhanced by reduction of inter- and intraspecific predation in deep litter resulting in higher diversity.

\section{Community structure}

Pitfall trap spider assemblages did not distinctly differ between diversity levels. Only few species were especially associated with plots of DL 1 (Diplocephalus picinus and Histopona torpida) or were missing there (Hahnia pusilla). Altogether, communities of the three diversity levels were characterized by high similarity of species composition and dominance structure (see also Luczak 1963, Hutha 1965, Whitehouse et al. 2002). However, differences of community composition were present at the study site or plot level. Thus, variation of environmental factors between plots was more important than variation caused by actual tree species diversity, as was already discussed for species richness. This is seen clearly by the different community structures of plots $\mathrm{DL} 3 \mathrm{a}$ and $\mathrm{DL} 3 \mathrm{~b}$, which is probably due to the high dominance of lime or rather lower proportion of beech compared to the other plots. This results in specific modifications of environmental factors such as strong reduction of litter during the summer months, which is caused by the high palatability of lime litter for saprophagous invertebrates such as earthworms, diplopods and isopods. All these animal taxa were highly abundant in DL $3 a$ and DL $3 b$ (Cesarz et al. 2007, N. Fahrenholz, unpublished data). Tenuiphantes tenebricola, one of the differentiating spider species, was found to prefer a sparse litter layer and an ample herb layer (A. Sührig, unpublished data), typical for these two plots. Despite a lack of detailed information on habitat preferences of Diplostyla concolor, Tenuiphantes cristatus and Diplocephalus latifrons (O.P.-Cambridge 1863), there is evidence that they are influenced by factors similar to those important for $\mathrm{T}$. tenebricola (Beyer 1972, Heimer and Hiebsch 1982, Bauchhenss et al. 1987, Höfer 1989, Hänggi et al. 1995). Those species being rare or absent from these two plots (Histopona torpida, Harpactea lepida, Saloca diceros and Walckenaeria corniculans) are known to prefer forest sites with a deep and continuous litter layer (Stippich 1986, A. Sührig, unpublished data). Avoidance of $D L 3 a$ and $D L 3 b$ by these mostly spring to summer active species and low numbers on DL $3 c$ also explain the generally low spider activity in DL 3 in June/July. 
Apart from differences in dominating tree species, there was also a clear effect of the vicinity of plots on spider community composition due to clustering within study sites. Centroids (weighted means) of neighbouring plots were also situated close to each other in multivariate ordination (see map, Fig. 1 and RDA, Fig. 8). Increased and wide-ranging activity of species caught in pitfall traps during maturity, radiating into adjacent plots, probably attenuated the impact of differences in environmental characteristics between diversity levels. Proximity of plots resulting in higher similarity of plots despite rather different habitat features was also observed by Luczak (1963), Heublein (1983), Hofmann (1986), Irmler and Heydemann (1988), Platen (1989) and Platen and Rademacher (2002).

As noted above, forest floor samples were characterized by low numbers of adult specimens leading to a high variation of samples within plots. Consequently, distinct patterns, as revealed with pitfall traps, were less obvious. Still, there were similar trends with the most abundant species Hahnia pusilla and Saloca diceros. Extreme dominance of the former species caused a more defined separation of mixed stands (DL 2 and DL 3) from pure beech stands (DL 1) than found for pitfall trap assemblages, which were dominated by a higher number of species common in both pure and mixed stands. Once again, this demonstrates the differences in the sampling procedures of the two methods.

RDA of forest floor samples was even more strongly affected by the above-mentioned high variation of samples and indistinct separation of plots. Though the correlations between environmental factors and spiders did not adequately explain differentiation of plots, it can be assumed that the determining factors influencing pitfall trap spider assemblages are important for forest floor sample spiders, too, as was found by Hutha (1971), Stippich (1989) and Irmler (2005).

\section{Conclusions}

No consistent general relationship between increasing tree species diversity and patterns of diversity and abundance of spider communities emerged. The diversity indices for the spider fauna based on data obtained by the two sampling methods correlated differently with the diversity of the forest stands, thus hampering a coherent interpretation. Diversification of forest stands can affect patterns of species richness and spider numbers as compared to pure beech stands. However, underlying structuring factors are not necessarily dependent on stand diversity. Rather, results indicate a strong influence of the dominating tree species (beech or lime) and its specific modifications of habitat characteristics. Similar trends were also found for higher strata (A. Schuldt, unpublished data). Still, the impact of actual tree species diversity on the multi-factorial complex determining species richness and abundance of the spider fauna cannot ultimately be separated from effects of the dominance of certain 
tree species. Both variables are directly linked to each other in the present study, impeding evaluation of their relative importance and demanding further experimental studies.

\section{Acknowledgements}

The study was part of a larger project of the Research Training Group "The role of biodiversity for biochemical cycles and biotic interactions in temperate deciduous forests", funded by the German Research Foundation (DFG). We thank the colleagues from the DFG Research Training Group 1086 supporting our studies with data, especially Karl-Maximilian Daenner, Anja Guckland and Andreas Mölder, and the administration of the Hainich National Park for their assistance.

\section{$\underline{\text { References }}$}

Abraham BJ (1983) Spatial and temporal patterns in a sagebrush steppe spider community (Arachnida, Araneae). Journal of Arachnology11:31-50.

Adis J (1979) Problems of interpreting arthropod sampling with pitfall traps. Zoologischer Anzeiger 202:177-184.

Ahrns C, Hofmann G (1998) Vegetationsdynamik und Florenwandel im ehemaligen mitteldeutschen Waldschutzgebiet ,Hainich” im Intervall 1963-1995. Hercynia 31:33-64.

Albert R (1976) Struktur und Dynamik der Spinnenpopulationen in Buchenwäldern des Solling. Verhandlungen der Gesellschaft für Ökologie 1976:83-91.

Bauchhenss E, Dehler W, Scholl G (1987) Bodenspinnen aus dem Raum Veldensteiner Forst (Naturpark „Fränkische Schweiz/Veldensteiner Forst”). Berichte der Naturwissenschaftlichen Gesellschaft Bayreuth 19:7-44.

Beyer R (1972) Zur Fauna der Laubstreu einiger Waldstandorte im Naturschutzgebiet „Prinzenschneise” bei Weimar. Archiv für Naturschutz und Landschaftsforschung 12:203-229.

Bird S, Coulson RN, Crossley DA (2000) Impacts of silvicultural practices on soil and litter arthropod diversity in a Texas pine plantation. Forest Ecology and Management 131:65-80.

Bultman TL, Uetz GW (1982) Abundance and community structure of forest floor spiders following litter manipulation. Oecologia 55:34-41.

Cesarz S, Fahrenholz N, Migge-Kleian S, Platner C, Schaefer M (2007) Earthworm communities in relation to tree diversity in a deciduous forest. European Journal of Soil Biology 43: S61-S67.

Chen B, Wise DH (1999) Bottom-up limitation of predaceous arthropods in a detritus-based terrestrial food web. Ecology 80:761-772.

Churchill TB, Arthur JM (1999) Measuring spider richness: effects of different sampling methods and spatial and temporal scales. Journal of Insect Conservation 3:287-295.

De Bakker D, Maelfait JP, Baert L, Hendrickx F (2001) Spider diversity and community structure in the forest of Ename (Eastern Flanders, Belgium). Bulletin del l'Institut Royal des Science Naturelles de Belgique, Entomologie 71:45-54. 
De Ruiter PC, Griffiths B, Moore JC (2002) Biodiversity and stability in soil ecosystems: patterns, processes and the effects of disturbance. In: Loreau M, Naeem S, Inchausti P (eds.) Biodiversity and ecosystem functioning. Synthesis and perspectives. Oxford University Press, Oxford, pp 102113.

Docherty M, Leather SR (1997) Structure and abundance of arachnid communities in Scots and lodgepole pine plantations. Forest Ecology and Management 95:197-207.

Dumpert K, Platen R (1985) Zur Biologie eines Buchenwaldbodens, 4. Die Spinnenfauna. Carolinea 42:75- 106.

Dunger W (1983) Tiere im Boden, 3rd edn. A. Ziemsen, Wittenberg.

Finke DL, Denno RF (2005) Predator diversity and the functioning of ecosystems: the role of intraguild predation in dampening trophic cascades. Ecology Letters 8:1299-1306.

Fitter AH, Gilligan CA, Hollingworth K, Kleczkowski A, Twyman RM, Pitchford JW, The members of the NERC Soil Biodiversity Programme (2005) Biodiversity and ecosystem function in soil. Functional Ecology 19:369-377.

Gartner TB, Cardon ZG (2004) Decomposition dynamics in mixed-species leaf litter. Oikos 104:230246.

Gurdebeke S, De Bakker D, Vanlanduyt N, Maelfait JP (2003) Plans for a large regional forest in eastern Flanders (Belgium): assessment of spider diversity and community structure in the current forest remnants. Biodiversity and Conservation 12:1883-1900.

Hänggi A, Stöckli E, Nentwig W (1995) Habitats of Central European spiders. Miscellanae Faunistica Helvetica 4:1-459.

Hatley CL, MacMahon JA (1980) Spider community organization: seasonal variation in the role of vegetation architecture. Environmental Entomology 9:632-639.

Heimer S, Hiebsch H (1982) Beitrag zur Spinnenfauna der Naturschutzgebiete Großer und Kleiner Hakel unter Einbeziehung angrenzender Waldgebiete. Hercynia 19:74-84.

Heublein D (1983) Räumliche Verteilung, Biotoppräferenzen und kleinräumige Wanderungen der epigäischen Spinnenfauna eines Wald-Wiesen-Ökotons; ein Beitrag zum Thema „Randeffekt”. Zoologische Jahrbücher, Abteilung für Systematik 110:473-519.

Höfer H (1989) Beiträge zur Wirbellosenfauna der Ulmer Region: 1. Spinnen (Arachnida: Araneae). Mitteilung des Vereines für Naturwissenschaft und Mathematik UIm (Donau) 35:157-176.

Hofmann I (1986) Die Webspinnenfauna (Araneae) unterschiedlicher Waldstandorte im Nordhessischen Bergland. Berliner Geographische Abhandlungen 41:183-200.

Hooper DU, Chapin FS, Ewel JJ, Hector A, Inchaustl P, Lavorel S, Lawton JH, Lodge DM, Loreau M, Naeem S, Schmid B, Setälä H, Symstad AJ, Vandermeer J, Wardle DA (2005) Effects of biodiversity on ecosystem functioning: a consensus of current knowledge. Ecological Monographs 75:3-35.

Hunter MD, Adl S, Pringle CM, Coleman DC (2003) Relative effects of macroinvertebrates and habitat on the chemistry of litter during decomposition. Pedobiologia 47:101-115.

Hutha V (1965) Ecology of spiders in the soil and litter of Finnish forests. Annales Zoologici Fennici 2:260-308. 
Hutha V (1971) Succession in the spider communities of the forest floor after clear-cutting and prescribed burning. Annales Zoologici Fennici 8:483-542.

Irmler $U$ (2005) Long-term fluctuations on the spider populations (Araneida) in a northern German woodland. Faunistisch-ökologische Mitteilungen 8:337-352.

Irmler U, Heydemann B (1988) Die Spinnenfauna des Bodens schleswig-holsteinischer Waldökosysteme. Faunistisch-ökologische Mitteilungen 6:61-85.

Jocque R (1973) The spider fauna of adjacent woodland areas with different humus types. Biologisch Jaarboek Dodonaea 41:153-178.

Kajak A (1995) The role of soil predators in decomposition processes. European Journal of Entomology 92:573-580.

Kempson D, Lloyd M, Ghelardi R (1963) A new extractor for woodland litter. Pedobiologia 3:1-21.

Lawrence KL, Wise DH (2004) Unexpected indirect effect of spiders on the rate of litter disappearance in a deciduous forest. Pedobiologia 48:149-157.

Lensing JR, Todd S, Wise DH (2005) The impact of altered precipitation on spatial stratification and activity-densities of springtails (Collembola) and spiders (Araneae). Ecological Entomology 30:194200.

Luczak J (1963) Differences in the structure of communities of web spiders in one type of environment (young pine forest). Ekologia Polska 6:159-219.

Macfadyen A (1961) Improved funnel-type extractors for soil arthropods. Journal of Animal Ecology 30:171-184.

Magurran AE (2004) Measuring biological diversity. Blackwell Science, Malden, MA.

Mikola J, Bardgett RD, Hedlund K (2002) Biodiversity, ecosystem functioning and soil decomposer food webs. In: Loreau M, Naeem S, Inchausti P (eds.) Biodiversity and ecosystem functioning. Synthesis and perspectives. Oxford University Press, Oxford, pp 169-180.

Mölder A, Bernhardt-Römermann M, Schmidt W (2006) Forest ecosystem research in Hainich National Park (Thuringia): First results on flora and vegetation in stands with contrasting tree species diversity. Waldoekologie online 3:83-99.

Mönninghoff W (1998) Nationalpark Hainich. VEBU, Berlin.

Niemelä J, Haila Y, Punttila P (1996) The importance of small-scale heterogeneity in boreal forests: variation in diversity in the forest-floor invertebrates across the succession gradient. Ecography 19:352-368.

Oxbrough AG, Gittings T, O'Halloran J, Giller PS, Smith GF (2005) Structural indicators of spider communities across the forest plantation cycle. Forest Ecology \& Management 212:171-183.

Platen R (1989) Struktur der Spinnen- und Laufkäferfauna (Arach.: Araneida, Col.: Carabidae) anthropogen beeinflusster Moorstandorte in Berlin (West). Taxonomische, räumliche und zeitliche Aspekte. Dissertation, Technical University of Berlin.

Platen R, Rademacher J (2002) Charakterisierung von Kiefernwäldern und - forsten durch Spinnen in den Bundesländern Berlin und Brandenburg. Naturschutz und Landschaftspflege in Bradenburg 11:243-251. 
Riechert SE, Lawrence K (1997) Test for predation effects of single versus multiple species of generalist predators: spiders and their insect prey. Entomologia Experimentalis et Applicata 84:147-155.

Roß-Nickoll M (2000) Biozönologische Gradientenanalyse von Wald-, Hecken- und Parkstandorten der Stadt Aachen. Verteilungsmuster von Phyto-, Carabido- und Araneozönosen. Publikationsreihe des interdisziplinären Umwelt-Forums der RWTH Aachen 11:1-148.

Schaefer M (1991) The animal community: diversity and resources. In: Röhrig E, Ulrich W (eds.) Ecosystems of the world 7. Temperate deciduous forests. Elsevier, Amsterdam, pp 51-120.

Schauermann J (1982) Verbesserte Extraktion der terrestrischen Bodenfauna im Vielfachgerät modifiziert nach Kempson und Macfadyen. Mitteilungen des SFB 135:47-50.

Scheiner SM, Gurevitch J (eds.) (1993) Design and analysis of ecological experiments. Chapman \& Hall, New York.

Scherer-Lorenzen M, Körner Ch, Schulze E-D (2005) Forest diversity and function. Temperate and boreal systems. Ecological Studies 176. Springer, Berlin.

Seidel G (ed.) (1995) Geologie von Thüringen. Schweizerbart, Stuttgart.

Setälä H (2005) Does biological complexity relate to functional attributes of soil food webs? In: De Ruiter P, Wolters V, Moore JC (eds.) Dynamic food webs: multispecies assemblages, ecosystem development, and environmental change. Elsevier, Amsterdam, pp 308-320.

Standen V (2000) The adequacy of collecting techniques for estimating species richness of grassland invertebrates. Journal of Applied Ecology 37:884-893.

Stevenson BG, Dindal DL (1982) Effect of leaf shape on forest litter spiders: community organization and microhabitat selection of immature Enoplognatha ovata (Clerck)(Theridiidae). Journal of Arachology 10:165-178.

Stippich G (1986) Die Spinnenfauna (Arachnida: Araneida) eines Kalkbuchenwaldes: Bedeutung von Habitatstruktur und Nahrung. Dissertation, University of Göttingen.

Stippich G (1989) Die Bedeutung von natürlichen und künstlichen Strukturelementen für die Besiedlung des Waldbodens durch Spinnen (Zur Funktion der Fauna in einem Mullbuchenwald 14). Verhandlungen der Gesellschaft für Ökologie 17:293-298.

Sührig A (1997) Die Spinnenfauna des Göttinger Waldes (Arachnida: Araneida). Göttinger Naturkundliche Schriften 4:117-135.

Swift MJ, Heal OW, Anderson JM (1979) Decomposition in terrestrial ecosystems. Blackwell, Oxford. Ter Braak CJF, Šmilauer P (2002) CANOCO Reference Manual and CanoDraw for Windows User's Guide: software for canonical community ordination (version 4.5). Microcomputer Power, Ithaca.

Uetz GW (1975) Temporal and spatial variation in species diversity of wandering spiders (Araneae) in deciduous forest litter. Environmental Entomology 4:719-724.

Uetz GW (1976) Gradient analysis of spider communities in a streamside forest. Oecologia 22:373385.

Uetz GW (1979) The influence of variation in litter habitats on spider communities. Oecologia 40:2942. 
Uetz GW (1990) Habitat structure and spider foraging. In: Bell SS, McCoy ED, Mushinsky HR (eds.) Habitat structure. The physical arrangement of objects in space. Chapman \& Hall, London, pp 325348.

Unsicker SB, Baer N, Kahmen A, Wagner M, Buchmann N, Weisser WW (2006) Invertebrate herbivory along a gradient of plant species diversity in extensively managed grasslands. Oecologia 150:233-246.

Wagner JD, Toft S, Wise DH (2003) Spatial stratification in litter depth by forest-floor spiders. Journal of Arachnology 31:28-39.

Wardle DA (2006) The influence of biotic interactions on soil biodiversity. Ecology Letters 9:870-886.

Weidemann G (1976) Struktur der Zoozönose im Buchenwald-Ökosystem des Solling. Verhandlungen der Gesellschaft für Ökolologie 1976:59-74.

Whitehouse MEA, Shochat E, Shachak M, Lubin Y (2002) The influence of scale and patchiness on spider diversity in a semi-arid environment. Ecography 25:395-404.

Willett TR (2001) Spiders and other arthropods as indicators in old-growth versus logged redwood stands. Restoration Ecology 9:410-420.

Wise DH (2004) Wandering spiders limit densities of a major microbi-detritivore in the forest-floor food web. Pedobiologia 48:181-188.

Wise DH, Chen B (1999) Impact of intraguild predators on survival of a forest-floor wolf spider. Oecologia 121:129-137.

Wise DH, Snyder WE, Tuntibunpakul P, Halaj J (1999) Spiders in decomposition food webs of agroecosystems: theory and evidence. Journal of Arachnology 27:363-370. 


\section{Chapter 3}

Earthworm communities in relation to tree diversity in a deciduous forest

Simone Cesarz, Nadine Fahrenholz,

Sonja Migge-Kleian, Christan Platner \&

Matthias Schaefer

European Journal of Soil Biology 43, S61-S67, 2007 


\section{$\underline{\text { Abstract }}$}

The understanding of belowground biodiversity is still rather incomplete and interactions between above- and belowground systems have rarely been looked at when explaining belowground biodiversity patterns. The present study presents results of the influence of tree species diversity on the earthworm community in a central European deciduous mixed forest. Within the Hainich National Park three replicate sites were chosen within three levels of tree diversity ranging from one species (beech, DL1) to three species (beech, lime, ash, DL2) to five species stands (beech, lime, ash, hornbeam, maple, DL3). Earthworms were extracted by heat from soil and litter samples at four sampling dates at each site. In addition, in spring four samples per site were sorted by hand and identified to species level. Generally, earthworm densities were positively correlated with tree diversity in May and November but negatively in February. Sites with low tree species diversity had earthworm populations which were more stable due to a more permanent and deeper litter layer. Increasing proportions of high quality litter in DL2 und DL3 were correlated with higher densities of both epigeic and endogeic earthworm species, while litter in DL1 sites was mainly inhabited by epigeic species. Generally, there was a positive correlation between earthworm and tree species diversity indicating the importance of diverse food qualities for the decomposer fauna at the local scale especially in springtime.

Keywords: Lumbricidae / Earthworm diversity / Tree diversity / Mixed forest / Beech / Lime / Ash 


\section{$\underline{\text { Introduction }}$}

Central European forestry management is changing and more and more monospecific stands are transformed into mixed stands. This influences stand microclimate, soil characteristics and soil biota (Chapman et al. 1988, Hättenschwiler et al. 2005, SchererLorenzen et al. 2005, Scheu et al. 2003). However, little is known about the influence of different levels of tree diversity on belowground processes and soil animal communities (Hättenschwiler 2005, Scheu 2005). Earthworms and trees are both considered ecosystem engineers (Jones et al. 1994) modifying the habitat they live in. While different ecological groups of earthworms (epigeic, endogeic, anecic) play different but equally important roles in forest nutrient cycling (Postma-Blaauw et al. 2006), tree litter quality influences earthworm food choice (e.g. Zicsi and Pobozsny 1977, Hendricksen 1990), reproduction (Huerta et al. 2005) and biomass (e.g. Satchell 1967, Phillipson et al. 1978). Thus, the effect of plant species on ecosystems processes results from 'their effect on those soil organisms that drive the processes' (Wardle 2002). However, the reverse also has been shown that soil organisms such as litter feeding macrofauna can alter effects induced by litter species diversity (Hättenschwiler and Gasser 2005). The understanding of belowground biodiversity is rather incomplete and interactions between above- and belowground systems need to be looked at when explaining belowground biodiversity patterns (Wardle 2002, Scheu and Setälä 2002).

The Hainich National Park in Central Germany is a mosaic of beech-dominated deciduous forests where diversity hotspots with up to 10 tree species per $250 \mathrm{~m}^{2}$ can be found next to near monospecific stands. This paper presents results on the earthworm community at three levels of tree diversity (low, medium, high) in this forest. The main questions of this paper are if earthworm density and diversity are correlated with tree diversity and which factors (among them litter depths and diversity, $\mathrm{pH}$, moisture, and diversity of the herb layer) influence the earthworm community in mixed forests of the same soil types and similar humus forms.

\section{Materials and methods}

\section{Site description}

The study sites are located in the Hainich National Park in central Germany (province of Thuringia). With a size of 7600 ha the Hainich is the greatest cohesive deciduous forest area in Germany. It is a limestone mountain range covered by a homogeneous loess layer (Mölder et al. 2006) reaching in parts a maximum elevation of $494 \mathrm{~m}$ a.s.l. (annual temperature of $7.5^{\circ} \mathrm{C}$, annual rainfall of $700 \mathrm{~mm}$ ). The soil type is a luvisol with $\mathrm{pH}$ ranging from 3.8 to 6.1 in soil (Table 1). Humus forms range from L-mull to F-mull (Scheffer and 
Schachtschabel 2002). The forest is dominated by beech (Fagus sylvatica) but locally a mosaic of up to 10 tree species occurs with varying composition within $500 \mathrm{~m}$ ranges. According to the dominant tree species, three replicate study sites of $50 \times 50 \mathrm{~m}^{2}$ were chosen for each of three levels of tree diversity. Diversity level (DL) 1 was dominated by beech, DL2 by beech, lime (Tilia cordata) and ash (Fraxinus excelsior) and DL3 by beech, lime, ash, hornbeam (Carpinus betulus) and maple (Acer spp. ${ }^{1}$ ). Clusters of sites are indicated in Table 1 while a detailed map is given in ref. (Mölder et al. 2006). Actual tree diversity within diversity levels differed slightly, thus in the graphics displayed here, sites are arranged according to the Shannon-Wiener diversity index of tree species crown area.

Table 1 Site characteristics

\begin{tabular}{|c|c|c|c|c|c|c|c|c|c|}
\hline & \multicolumn{9}{|c|}{ Levels of tree diversity } \\
\hline & \multicolumn{3}{|l|}{ DL1 } & \multicolumn{3}{|l|}{ DL2 } & \multicolumn{3}{|l|}{ DL3 } \\
\hline & $1 \mathrm{c}$ & $1 a$ & $1 b$ & $2 c$ & $2 b$ & $2 a$ & $3 c$ & $3 b$ & $3 a$ \\
\hline Clusters of sites & 1 & 2 & 3 & 2 & 4 & 4 & 4 & 5 & 5 \\
\hline $\begin{array}{l}\text { Tree diversity } \\
\text { (Shannon-Wiener-Index) }\end{array}$ & 0.00 & 0.12 & 0.17 & 0.40 & 0.41 & 0.51 & 0.58 & 0.64 & 0.66 \\
\hline $\mathrm{pH}\left(\right.$ soil $\left._{0-3 \mathrm{~cm}}\right)$ & 3.82 & 4.05 & 4.09 & 5.03 & 4.97 & 5.37 & 6.10 & 5.71 & 5.93 \\
\hline $\begin{array}{l}\text { Water content (litter/soil, } \\
\% \text { fresh weight) }\end{array}$ & $71 / 43$ & $75 / 46$ & $66 / 35$ & $76 / 44$ & $79 / 44$ & $82 / 46$ & $82 / 45$ & $76 / 42$ & $77 / 42$ \\
\hline Litter depth (cm) & 2.92 & 2.42 & 2.33 & 2.50 & 2.17 & 1.42 & 1.75 & 1.58 & 1.92 \\
\hline
\end{tabular}

Data of soil pH and litter moisture and depth from February 2006. Sites are sorted according to tree diversity (Shannon-index, diversity level DL 1, 2 and 3).

\section{Sampling}

In May, August, November (all 2005) and February 2006 soil cores $\left(0.035 \mathrm{~m}^{2}\right.$, organic layer and $5 \mathrm{~cm}$ of upper mineral soil) were taken from six plots $(6 \times 5 \mathrm{~m})$ of each site. Litter depth was measured and earthworms were extracted by heat and counted. In addition, soil and litter samples were taken from each plot to measure gravimetric soil moisture content and $\mathrm{pH}_{\mathrm{KCl}}$. Diversity of herb cover and tree crown area was measured within each site and expressed as Shannon-diversity index per site (Mölder et al. 2006, M. Brauns unpublished). In spring (April 2006) when all earthworm species are active and representation of community structure is best, four samples $\left(0.11 \mathrm{~m}^{2}, 20 \mathrm{~cm}\right.$ depth) were taken along the sides of each site (min. $20 \mathrm{~m}$ apart), hand-sorted, anecic earthworms were extracted from the hole using a $0.33 \%$ mustard solution (Gunn 1992), and specimens were identified to species level.

\footnotetext{
${ }^{1}$ several maple species of were present: A. pseudoplatanus, A. platanoides, rarely A. campestre.
} 


\section{Statistical analysis}

Raw density data from heat extraction (individuals per sample, four sampling dates) were analysed for diversity level effects for each date (one-way analysis of variance, ANOVA, with the factor 'diversity level $D L$ ') and for diversity level changes throughout the year (repeated ANOVA with MANOVA statistic using Roy's greatest root [RGR] for the factors DL and time, SAS 8.2, SAS Institute; Scheiner and Gurevitch 2001). Each date was analysed separately first to test for site (=within-DL) effects (site used as error term in a nested ANOVA). A significant site effect requires per site averaging of samples before analysing for diversity level effects. There was no significant site effect for heat extraction data, but for hand-sorting data mean values per site had to be used for the ANOVA of diversity level effects. Tukey's test was performed to test for differences between means. Data were log-transformed to achieve homogeneity of variances and normality.

Redundancy analysis was performed using raw mean lumbricid species density per site, soil/litter $\mathrm{pH}$ and litter moisture, herb diversity (Shannon index) and litter depth as environmental data and dominance of beech, lime and ash as supplementary (passive) variables. Shannon-Wiener diversity index was calculated for lumbricid species per plot and mean diversity was correlated with tree diversity using Spearman's Rho correlation coefficient.

\section{$\underline{\text { Results }}$}

Highest densities of lumbricids occurred in May 2005 in plots with highest tree diversity (DL3; overall tree diversity effect $F=5, P=0.011$ ). The same pattern could be observed in November, although differences were not significant (Fig. 1, Table 2).

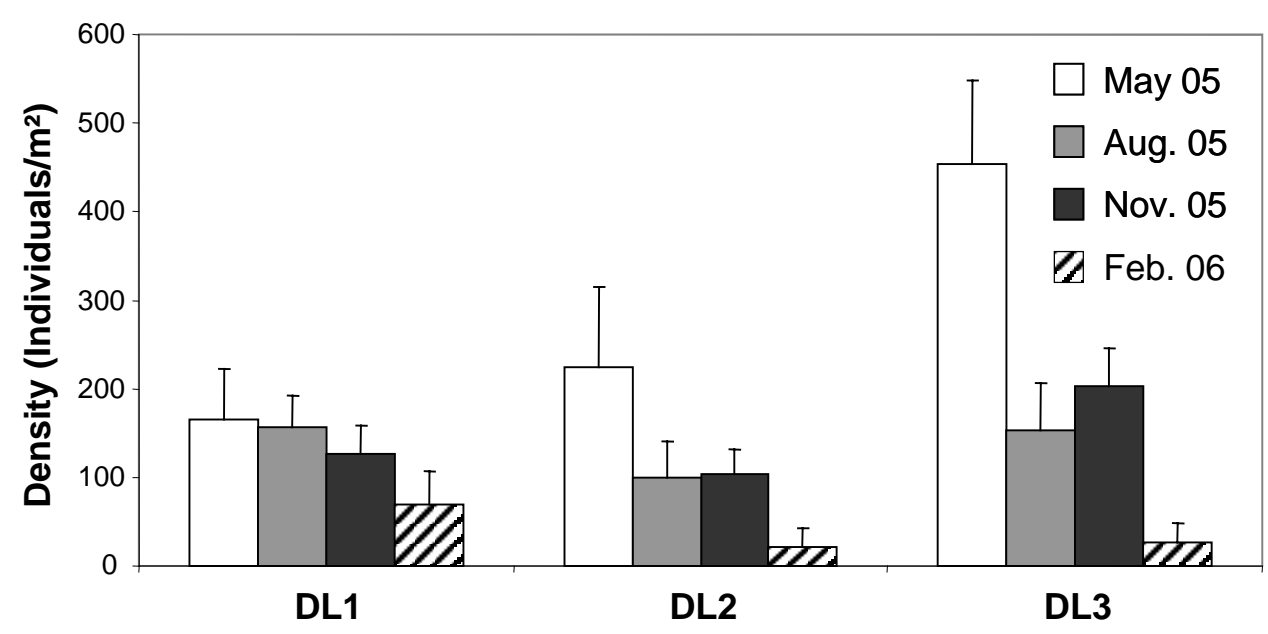

Fig. 1 Mean earthworm densities (+SD) at three sites of low (DL1), medium (DL3) and high (DL3) tree species diversity during the course of a year. All samples per DL were pooled since there was no site effect (May: $F=$ 1.76, $\mathrm{P}=0.13$; August: $\mathrm{F}=1.02, \mathrm{P}=0.42$; November: $\mathrm{F}=0.95, \mathrm{P}=0.47$; February: $\mathrm{F}=1.57 \mathrm{P}=0.18$ ) in nested ANOVA for neither date. 
In February 2006 densities were lowest in sites with higher tree species diversity (DL2 and $D L 3$ ) resulting in a reverse effect of tree diversity (RGR for time $x$ tree diversity: $F=10.2, P<$ $0.001)$. Overall lumbricid densities declined strongly during the course of the year in all sites (RGR for time $\mathrm{F}=54.5, \mathrm{P}<0.001$ ), but populations were most stable in sites with low tree species diversity (Fig. 1). Earthworms collected by hand in April 2006 again tended to have higher densities in sites with higher tree species diversity (DL2: 208 ind. $\mathrm{m}^{-2}$, DL3: 234 ind. $\mathrm{m}^{2}$ ) compared to DL1 sites (DL1: 76 ind. $\mathrm{m}^{-2} ; \mathrm{F}=5.12, \mathrm{P}=0.050$ ). However, there were strong differences between sites of DL1 (Fig. 2).

Table 2 Mean lumbricid density and F-statistics of single ANOVA for the influence of tree diversity (DL1: low, DL2: medium, DL3: high tree diversity) at four sampling dates.

\begin{tabular}{|c|c|c|c|c|c|c|c|c|}
\hline & \multicolumn{5}{|c|}{$\begin{array}{l}\text { ANOVA per date } \\
\text { Mean lumbricid density (ind. } \mathrm{m}^{-2} \text { ) }\end{array}$} & \multicolumn{2}{|c|}{$\begin{array}{l}\text { Repeated ANOVA } \\
\text { Significance between dates of }\end{array}$} & \multirow{2}{*}{$\begin{array}{l}\text { Overall } \\
\text { means } \\
\text { (ind. } \mathrm{m}^{-2}\end{array}$} \\
\hline & DL1 & DL2 & DL3 & F-values & $P$-values & Effect change & Means & \\
\hline May & $147^{\mathrm{B}}$ & $201^{\mathrm{b}}$ & $420^{a}$ & 13.9 & $<0.001$ & & & 231 \\
\hline Aug. & $161^{a}$ & $112^{\mathrm{a}}$ & $148^{a}$ & 2.1 & 0.129 & & & 139 \\
\hline Nov. & $122^{\mathrm{a}}$ & $119^{a}$ & $193^{a}$ & 3.1 & 0.052 & & 10. & 141 \\
\hline Feb. & $72^{\mathrm{a}}$ & $40^{\mathrm{b}}$ & $44^{\mathrm{ab}}$ & 4.0 & 0.025 & & & 51 \\
\hline
\end{tabular}

Means with the same letter are not significantly different within a sampling date. Contrast significance from repeated ANOVA is given for differences between consecutive dates (overall mean density per date) and for changes of tree diversity effects between dates. Means were back-transformed from log-means. ${ }^{* *}$ : $P<0.001 ;{ }^{* *}$ : $\mathrm{P}<0.01$; n.s.: not significant.

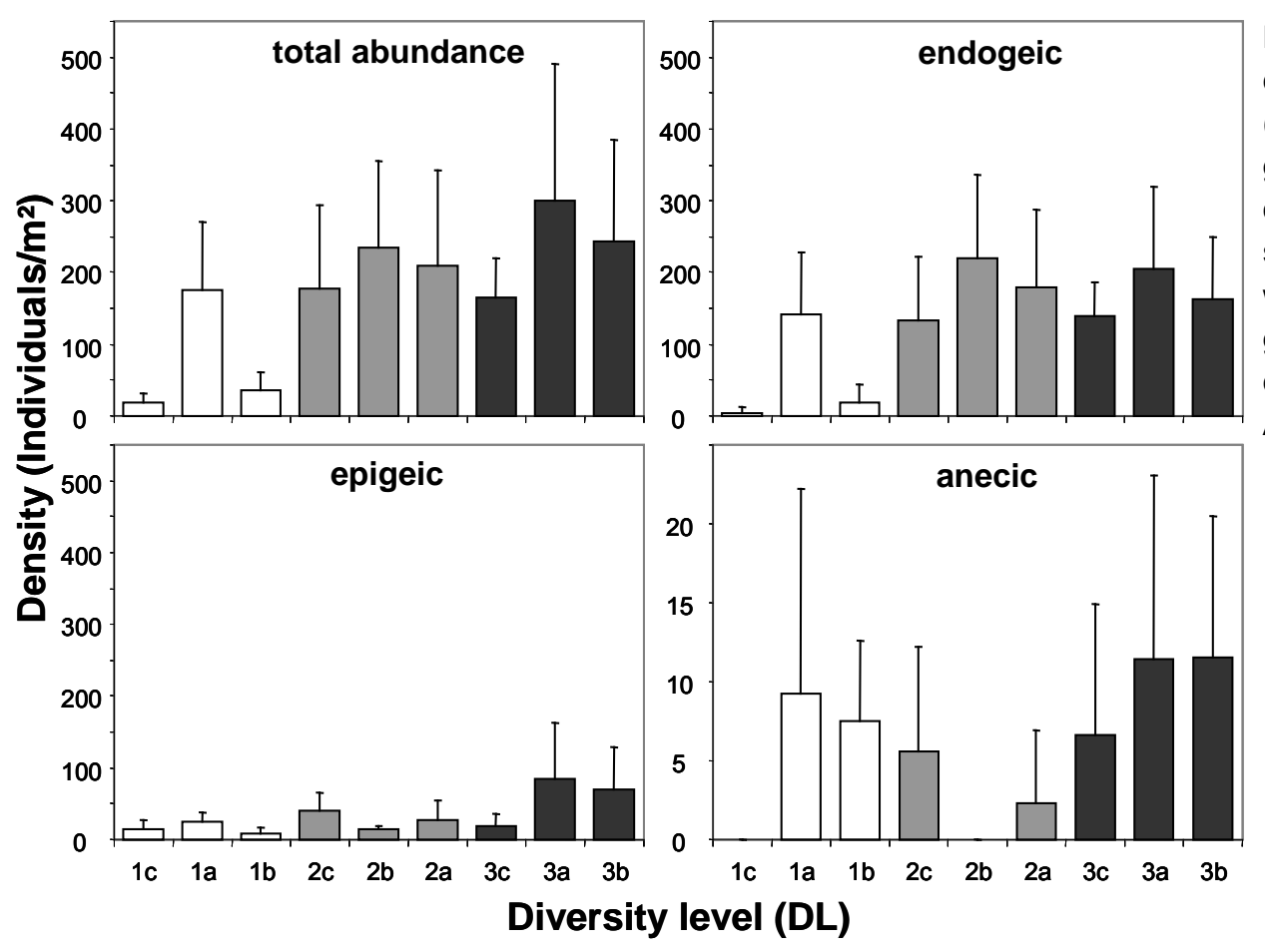

Fig. 2 Mean $(+S D)$ density of earthworms (total) and ecological groups after hand-sorting of litter and soil from sites with low (DL1, white), medium (DL2, grey) and high tree diversity (DL3, black) in April 2006. 
The dominant earthworm species in nearly all plots was Aporrectodea caliginosa which together with two other endogeic species (Octolasion tyrtaeum and $A$. rosea) made up 53 to $95 \%$ of all species except in one site with low tree species diversity (DL1c). In this site epigeic species dominated but in much lower densities than in the other sites (Fig. 2).

Thus, the earthworm community of low tree species diversity sites (DL1) differed strongly from sites with higher tree species diversity (DL2 and DL3, Fig. 3). Only DL2c was similar to DL1 sites (effect of site cluster, Tab.1). Characteristic species for DL1 sites were Dendrobaena octaedra and Dendrodrilus rubidus whose densities were positively correlated with increasing litter depth. Higher $\mathrm{pH}$ and litter moisture as well as high diversity of the herb layer were associated with higher tree diversity (DL2 and 3, Fig. 3) while soil moisture did not differ between sites or diversity levels (Tab.1). Lumbricid communities in DL2 and DL3 sites were characterised by higher densities of epigeic $L$. castaneus and endogeic species, while Lumbricus terrestris occurred in nearly all sites (Fig. 3).

In total 7 earthworm species were collected from litter and soil in April 2006. Total species numbers were similar in all sites (minimum 3, maximum 6). However, densities and species number differed between samples resulting in a positive correlation between Shannon diversity of earthworm and tree species at the local scale (Spearman's Rho for single samples: $0.45, P=0.007$, for means: 0.62, $P=0.077$, Fig. 4).

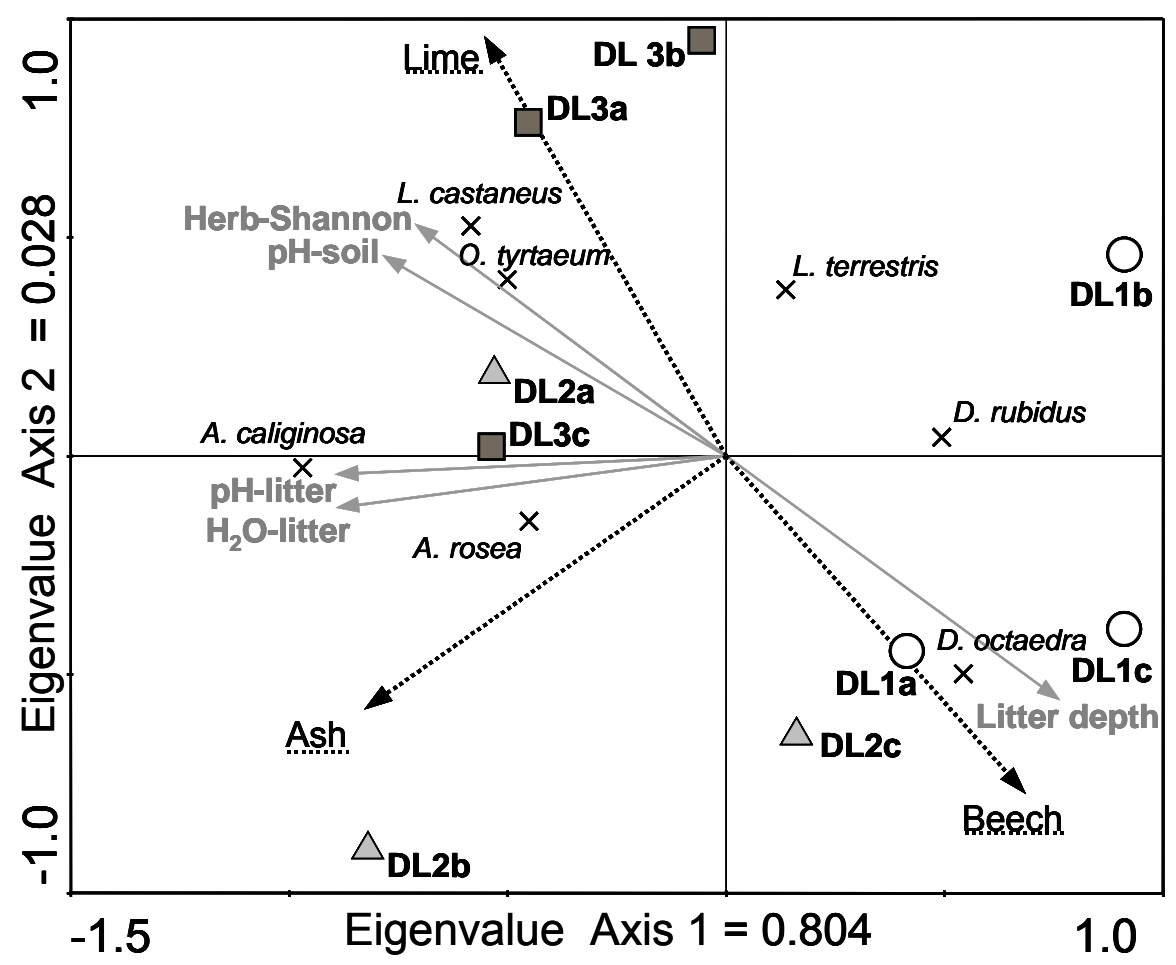

Fig. 3 Redundancy analysis of hand-sorted earthworm data (species scores in italics, April 2006) and environmental variables (arrows, bold) in sites of different tree species diversity [sample scores for low (DL1), medium (DL2) and high (DL3) tree diversity sites]. Dominance of major tree species are included as passive variables (underline). 


\section{$\underline{\text { Discussion }}$}

In general, lumbricid species number found in Hainich litter and soil in spring 2006 seems to be rather low considering there are 38 species known from Germany (Schaefer 2006). However, this number of local species richness is average compared to other base-rich and beech dominated forests in this area supporting 6 to 11 species (Nordström and Rundgren 1973, Phillipson et al. 1976, Schaefer and Schauermann 1990). It is also within the range of local diversity estimates reported globally (Lavelle and Spain 2001). This altogether rather limited species pool (Schaefer 1991) poses difficulties when comparing diversities of earthworms with that of other organisms, such as trees. Thus, we included abundance data and calculated the Shannon index for lumbricid and tree species diversity. There was a positive correlation between diversity of the two groups but only at the local scale (single sample data), indicating that tree diversity can increase lumbricid diversity by the mechanism of creating small scale microhabitat diversity.

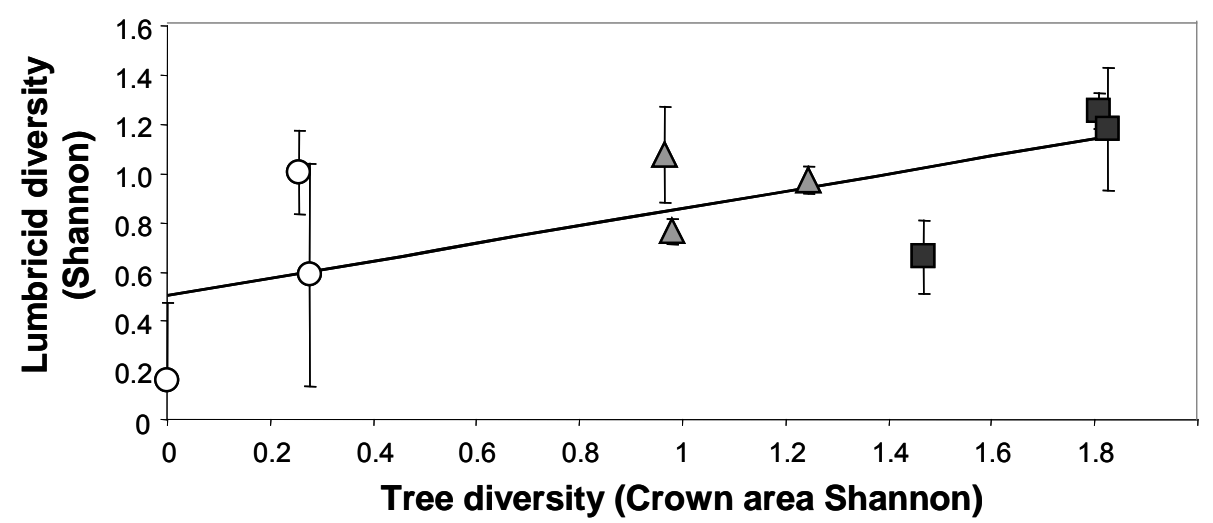

Fig. 4 Correlation between earthworm and tree species diversity (both Shannon-Wiener index). Hand sorting data, April 2006. Mean diversity indices per site $(n=4)$ are given for DL1 (circles), DL2 (triangles) and DL3 (squares).

Besides major differences in feeding habits (deep soil vs. humus rich soil vs. litter) earthworms are also known to selectively feed on litter types which differ in nitrogen content (Tian et al. 1993) and polyphenolic contents (Satchell 1967) resulting also from different decomposition stages (Zicsi and Pobozsny 1977), and are even known to distinguish between different litter-colonizing fungi (Bonkowski et al. 2000). While, for example, beech and hornbeam litter lose their tannins after half a year, ash has originally no high phenol content (Brown et al. 1963, Zicsi and Pobozsny 1977) and is fed on shortly after litter fall. Thus litter species diversity can create microhabitats exploited by different decomposer species (Hättenschwiler and Gasser 2005) increasing their diversity.

Further investigation will show if this positive correlation of tree and earthworm diversity is a high density spring effect or if it is sustainable during the year. While in spring lumbricid densities were significantly higher in sites with higher tree diversity (DL2 and DL3) compared 
to DL1 sites there was a strong decline in high diversity sites during the course of the year. Low densities in winter were partly due to shallow sampling since many endogeic species move down in the soil profile for hibernation (Edwards and Bohlen 1996) and thus only active specimens could be sampled. In DL 1 sites on the other hand, populations were more constant indicating that pure beech stands form a more stable habitat also allowing higher winter activity. This can be explained by the more pronounced litter layer in these sites which was decomposed more steadily compared to the rapid decomposition of ash, lime and maple litter in the DL2 and DL3 sites (N. Fahrenholz unpubl.). Also, litter dwellers were dominating the earthworm community in most DL1 plots.

Generally, high earthworm density in spring occurs due to the hatching of juveniles from cocoons with most species hatching in (March-)April to May(-June) even if cocoon production takes place during the whole year (Satchell 1967). High densities in spring and rather low densities in winter are common for earthworm populations in base-rich Central European forests (Satchell 1967, Phillipson et al. 1978, Rozen 1988, Scheu 1992). The strong decline seems to be correlated with the abundance of easily degradable leaf litter which was shown in a 50-yr-old fallow dominated by ash (Scheu 1992). Came summer the litter had completely decomposed leaving no habitat for litter-dwelling earthworms or humus for endogeics and causing the strong decline already after one season instead of three. Earthworms have been known to depend on nitrogen supply by the litter input (Curry 2004) but recent studies indicate that actually carbon is the limiting factor in base-rich soils (Scheu and Schaefer 1998, Tiunov and Scheu 2004). Our paper suggests that not only the amount of carbon is important for sustaining an earthworm population but also the seasonal availability of the carbon. All study sites receive approximately similar amounts of carbon through leaf litter fall (M. Brauns, unpublished) but in high diversity plots this carbon pool seems to be depleted more quickly than in DL1 sites due to the high litter quality and the associated speedy decomposition in these sites (N. Fahrenholz, unpublished). Litter quality, i.e. the amount of soluble carbohydrates and nitrogen increase earthworm biomass leading to increased cocoon production in sites with high tree diversity (Satchell 1967,17). In addition to this 'resource pulse' in fall (Wardle 2002) the more diverse herb layer in DL2 and DL3 compared to DL1 plots also delivers a second carbon/nitrogen pulse in late spring (Wolters 1999) allowing hatchlings to grow. However, also this carbon pool seems to be depleted quickly leading to high levels of competition for food, high mortality rates and lower numbers in August and November. Summing up, it appears that there is a chain of causal effects: higher litter species diversity containing high quality litter leads to higher earthworm abundance and feeding activity in spring, which in turn is followed by a decrease of the amount of litter in summer and autumn accompanied by a decrease of earthworm abundance (and diversity) lasting until spring next year. 
Another important factor influencing earthworm activity and abundance is litter and soil moisture (Edwards and Bohlen 1996). While in winter and spring litter moisture correlated with higher tree diversity, it decreased with decreasing litter depth during the summer months (S. Cesarz unpubl.). However, soil moisture did not vary between sites (spring, winter) or variation was not correlated to tree species diversity (summer, fall; S. Cesarz unpubl.) indicating that differences in litter quality and quantity play a stronger role than small differences in soil moisture contents.

\section{$\underline{\text { Acknowledgement }}$}

We thank Mascha Brauns and Andreas Mölder for supplying the vegetation diversity data, Klaus Richter for help with earthworm sampling, Hermann Jungkunst for discussions and two anonymous reviewers for helpful comments on the manuscript. The study is funded by the German Research Council (DFG) within the Research Training Group 1086.

\section{$\underline{\text { References }}$}

Bonkowski M, Griffiths BS, Ritz K (2000) Food preferences of earthworms for soil fungi. Pedobiologia 44: 666-676.

Brown BR, Love CW, Handley WRC (1963) Protein-fixing constituents of plants: Part III Rep. Forest. Res. Lond. 1961/1962, pp. 90-93.

Chapman K, Whittaker JB, Heal OW (1988) Metabolic and faunal activity in litters of tree mixtures compared with pure stands. Agriculture Ecosystems \& Environment 24: 33-40.

Curry JP (2004) Factors affecting earthworm abundance in soils, in: Edwards CA, Earthworm ecology, CRC Press LLC, Boca Raton, pp. 91-113.

Edwards CA, Bohlen PJ (1996) Biology and ecology of earthworms, 3rd edition, Chapman and Hall, London.

Gunn A (1992) The use of mustard to estimate earthworm populations. Pedobiologia 36: 65-67.

Hättenschwiler S (2005) Effects of tree species diversity on litter quality and decomposition, in: Scherer-Lorenzen M, Köhler C, Schulze E-D (eds.) Forest diversity and function: temperate and boreal systems. Ecological Studies Vol. 176, Springer, Heidelberg, pp. 149-164.

Hättenschwiler S, Gasser P (2005) Soil animals alter plant litter diversity effects on decomposition. Proceedings of the National Acadademy of Sciences USA 102: 1519-1524.

Hättenschwiler S, Tiunov AV, Scheu S (2005) Biodiversity and litter decomposition in terrestrial ecosystems. Annual Review of Ecology Evolution and Systematics 36: 191-218.

Hendricksen NB (1990) Leaf litter selection by detritivore and geophagous earthworms. Biology and Fertility of Soils 10: 17-21.

Huerta E, Fragoso C, Barois I, Lavelle P (2005) Enhancement of growth and reproduction of the tropical earthworm Polypheretima elongata (Megascolecidae) by addition of Zea mays and Mucuna pruriens var. utilis litter to the soil. European Journal of Soil Biology 41: 45-53. 
Jones CG, Lawton JH, Shachak M (1994) Organisms as ecosystem engineers. Oikos 69: 373-386.

Lavelle P, Spain AV (2001) Soil Ecology, Kluwer Academic Publishers, Dordrecht.

Mölder A, Bernhardt-Römermann M, Schmidt W (2006) Forest ecosystem research in Hainich National Park (Thuringia): first results on flora and vegetation in stands with contrasting tree species diversity. Waldökologie online 3: 83-99.

Nordström S, Rundgren S (1973) Associations of lumbricids in southern Sweden. Pedobiologia 13: 301-326.

Phillipson J, Abel R, Steel J, Woodell SRJ (1976) Earthworms and the factors governing their distribution in an English beechwood. Pedobiologia 16: 258-285.

Phillipson J, Abel R, Steel J, Woodell SRJ (1978) Earthworm numbers, biomass and respiratory metabolism in a beech woodland - Wytham Woods, Oxford. Oecologia 33: 291-309.

Postma-Blaauw MB, Bloem J, Faber JH, van Groenigen JW, de Goede RGM, Brussaard L (2006) Earthworm species composition affects the soil bacterial community and net nitrogen mineralization. Pedobiologia 50: 243-256.

Rozen A (1988) The annual cycle in populations of earthworms (Lumbricidae Oligochaeta) in three types of oak-hornbeam of the Niepolomicka Forest. II. Dynamics of population numbers, biomass and age structure. Pedobiologia 31: 169-178.

Satchell JE (1967) Lumbricidae, in: Burges A, Raw F (eds.) Soil Biology, Academic Press, London, pp. 259-322.

Schaefer M (1991) The animal community: diversity and resources, in: Röhrig E, Ulrich B, (eds.) Temperate deciduous forests. Ecosystems of the world 7, Elsevier, Amsterdam, pp. 51-120.

Schaefer M (2006) Brohmer - Fauna von Deutschland, Quelle and Meyer, Wiebelsheim.

Schaefer M, Schauermann J (1990) The soil fauna of beech forests: comparison between a mull and a moder soil. Pedobiologia 34: 299-314.

Scheffer F, Schachtschabel P (2002) Lehrbuch der Bodenkunde, 15th ed. Spektrum Akademischer Verlag, Berlin.

Scheiner SM, Gurevitch J (2001) Design and analysis of ecological experiments, 2nd ed., Oxford University Press, Oxford.

Scherer-Lorenzen M, Köhler C, Schulze E-D (2005) Forest diversity and function: temperate and boreal systems. Ecological Studies Vol. 176, Springer, Heidelberg.

Scheu $S$ (1992) Changes in the lumbricid coenosis during secondary succession from a wheat field to a beechwood on limestone. Soil Biololgy \& Biochemistry 24: 1641-1646.

Scheu S (2005) Linkages between tree diversity, soil fauna and ecosystem processes, in: SchererLorenzen M, Köhler C, Schulze E-D (eds.) Forest diversity and function: temperate and boreal systems. Ecological Studies Vol. 176, Springer, Heidelberg, pp. 211-233.

Scheu S, Schaefer M (1998) Bottom-up control of the soil macrofauna community in a beechwood on limestone: manipulation of food resources. Ecology 79: 1573-1585.

Scheu S, Setälä H (2002) Multitrophic interactions in decomposer food-webs, in: Tscharntke T, Hawkins BA (eds.) Multitrophic level-Interactions. Cambridge University Press, Cambridge. 
Scheu S, Albers D, Alphei J, Buryn R, Klages U, Migge S, Platner C, Salamon J-A (2003) The soil fauna community in pure and mixed stands of beech and spruce of different age: trophic structure and structuring forces. Oikos 101: 125-238.

Tian G, Kang BT, Brussaard L (1993) Biological effects of plant residues with contrasting chemical compositions under humid tropical conditions: decomposition and nutrient release. Soil Biology \& Biochemistry 24: 1051-1061.

Tiunov AV, Scheu S (2004) Carbon availability controls the growth of detritivores (Lumbricidae) and their effect on nitrogen mineralization. Oecologia 138: 83-90.

Wardle DA (2002) Communities and Ecosystems - Linking the aboveground and belowground components. Princeton University Press, Princeton.

Wolters $\vee$ (1999) Allium ursinum litter triggering decomposition on a beech forest floor - the effect of earthworms. Pedobiologia 43: 528-536.

Zicsi A, Pobozsny M (1977) Einfluss des Zersetzungsverlaufes der Laubstreu auf die Konsumintensität einiger Lumbriciden-Arten, in: Lohm U, Persson T (eds.) Soil organisms as components of ecosystems. Ecological Bulletins (Stockholm) 25: 229-239. 


\section{Chapter 4}

Soil macrofauna communities respond differently to increasing tree species diversity in a temperate deciduous forest

Nadine Fahrenholz, Simone Cesarz, Insa Mende, Andreas Schuldt, Nina Spottek, Sonja Migge-Kleian, Christian Platner \& Matthias Schaefer 


\section{$\underline{\text { Abstract }}$}

Plant diversity has often been found to affect structural and biotic properties of ecosystems, but there are only few studies about the interaction of above- and belowground systems when explaining belowground diversity patterns. This is especially true for forests with mixtures of more than two tree species. The effect of mixtures of different deciduous tree species on the composition of the soil macrofauna communities was studied for three levels of tree diversity. Nine research plots were established in the Hainich National Park (Thuringia, Germany) in a diversity gradient ranging from pure beech stands to stands comprising three and five dominant deciduous tree species (Diversity Levels 1, 2 and 3).

Canopy litter diversity had a significant effect on the composition of the soil macrofauna communities. However, there was no general (linear) relationship between increasing tree species diversity and diversity or abundance of the animal taxa studied (gastropods, lumbricids, isopods, carabids and araneids). Trophic groups responded differently to tree species diversity: the abundance of key groups of primary decomposers such as isopods and earthworms was increased by a high diversity of litter resources, whereas sapro- and phytophagous snails were most diverse and abundant in the medium-diversity forest sites. The numbers of predators in the litter layer such as spiders and carabid beetles decreased in the highly diverse sites due to the fast decomposition of the litter resulting in a reduction of the litter habitat. On the other hand predator diversity was positively correlated with the more diverse herb and litter layer in mixed sites. Beech as the dominant tree species strongly influences ground-dwelling invertebrates by modifying microhabitat characteristics such as soil $\mathrm{pH}$, litter depth and herb layer. It is evident that the ecosystem engineers Fagus sylvatica and Lumbricus terrestris have a key role with their direct and indirect effects on the whole forest ecosystem. Overall, tree species diversity is an important driving force for soil macrofauna, but it is complemented by structuring forces exerted by single keystone species.

Keywords: Araneae / Carabidae / Decomposer fauna / Isopoda / Lumbricidae / Gastropoda 


\section{$\underline{\text { Introduction }}$}

There is an ongoing debate about the influence of plant species diversity on ecosystem structure and function in managed and near-natural habitats (e.g. Hooper et al. 2005, Cardinale et al. 2006, Hector et al. 2007). Plant diversity has often been found to affect structural and biotic properties of ecosystems (e.g. Gartner and Cardon 2004, SchererLorenzen et al. 2005), but the majority of research concerning the relationship between plant diversity and ecosystem properties was done in grassland or old fields focusing on plant productivity (e.g. Tilman 1996, Hector et al. 1999). The knowledge of the effects of tree species diversity in forest ecosystems is mainly based on comparative studies between single and two species systems (e.g. Chapman et al. 1988, Aubert et al. 2003, Scheu et al. 2003). Differences between these systems often depended on the identity of the tree species as well as on age and location of the stands (Kerr et al. 1992).

Different patterns for the relationship between aboveground animal species diversity and plant species diversity have been found (Siemann 1998, Symstad et al. 2000, Wardle 2002), but vegetation structure is also important as structural complexity providing a variety of habitats for a high diversity of species (Schaefer 2002). However, the influence of tree species diversity on belowground animal communities and processes and their interrelationship is still not well known (Wardle 2002, Hättenschwiler et al. 2005, Scheu 2005). Trends are often indistinct because above- and belowground diversity are not necessarily correlated (Hooper et al. 2000).

The soil fauna plays an important role in terrestrial ecosystems. Especially forest soil and litter are known to house many organisms in diverse communities (De Ruiter et al. 2002, Fitter et al. 2005). The decomposer food web is fundamentally dependent on the resources provided by primary producers (Scheu et al. 2003, Scheu 2005), but on the other hand trophic groups in decomposer food webs and their interactions influence ecosystem functioning (Mikola et al. 2002, Wardle 2006). For instance, the soil fauna can reduce nutrient immobilization by accelerating decomposition rates (Anderson 1973, Joergensen 1991). Although microorganisms are crucial for processes such as decomposition and mineralization (Lavelle and Spain 2001), the meso- and macrofauna influence these processes through their grazing pressure on the microflora and, especially in the case of ecosystem engineers like earthworms, through their impact on the structure of the litter and soil matrix (Schaefer 1990, Kautz and Topp 2000, Postma-Blaauw et al. 2006). It has also been shown that soil organisms such as litter-feeding macrofauna can modify effects exerted by litter species diversity (Chapman et al. 1988, Hättenschwiler and Gasser 2005). Thus, the effect of plant species on ecosystem processes is mediated by the soil organisms, which influence the processes (Wardle 2002), and soil animal diversity and activity feed back to the aboveground food web and plant growth (Setälä 2002, Scheu 2005) 
Although detailed studies answering questions of functioning and interactions in forest ecosystems with several tree species are lacking or still in progress (Scherer-Lorenzen et al. 2005), modern management of Central European deciduous forests often means the conversion of pure beech (Fagus sylvatica) stands to mixed stands with broadleaved tree species (Spiecker 2006). Accordingly, we studied the influence of tree species diversity on soil animal communities under comparable pedogenetic and geographic conditions in the Hainich National Park, Germany (Leuschner et al. 2009), a large area of deciduous forests dominated by European beech (Fagus sylvatica L.).

This study aims at answering the questions (i) if abundance and diversity of the soil macrofauna are related to tree species diversity, (ii) how trophic groups of the macrofauna differ in their response to increasing tree species diversity, and (iii) which factors related to tree species diversity influence the composition of soil macrofauna communities.

\section{Materials and Methods}

\section{Study sites}

The research area is situated in the north-eastern and eastern part of the Hainich National Park. This national park covers a surface of 7,600 hectares in Central Germany (Thuringia) and consists almost totally of species-rich deciduous woodlands and succession plains. Nine research sites were established in a diversity gradient ranging from pure beech (Fagus sylvatica L.) stands (Diversity Level [DL] 1) to stands comprised of beech, lime and ash (Fagus, Tilia cordata Mill./T. platyphyllos Scop. and Fraxinus excelsior L.; DL 2) and stands mainly consisting of beech, lime, ash, hornbeam (Carpinus betulus L.) and maple (Acer pseudoplatanus L. and A. platanoides L.; DL 3; Leuschner et al. 2009; Mölder et al. 2006). The sites belong either to the beech forest alliance (Galio odorati-Fagion) or the oakhornbeam forest alliance (Carpinion betuli; Mölder et al. 2006). The soil type of the research sites is a Luvisol with stagnic properties, developed from loess and underlain with Triassic limestone (FAO 2006). The soil is further characterized by a high silt content $(\sim 75 \%)$ and loess layers with a thickness of at least $60 \mathrm{~cm}$ (Guckland et al. 2009). Elevation is about 350 $\mathrm{m}$ a.s.I., and the mean annual precipitation reaches values between 600 and $670 \mathrm{~mm}$. The mean annual temperature averages from 7.5 to $8.0^{\circ} \mathrm{C}$ (Mönninghoff 1998).

\section{Sampling}

The soil fauna was studied in six randomly located plots $(5 \times 6 \mathrm{~m})$ per site. A strip of $1 \times 5 \mathrm{~m}$ each was available for invasive soil sampling. In the remaining $5 \times 5 \mathrm{~m}$ square floristic analyses were conducted and a pitfall trap was installed. Soil cores (six per site) of the size of $1 / 28 \mathrm{~m}^{2}$ (organic layer and mineral soil of $5 \mathrm{~cm}$ depth) were taken in May, August and 
November 2005 and in February 2006. Soil animals were extracted by heat using a modified canister method and counted. Earthworms, woodlice and spiders were identified to species level. In April 2005, pitfall traps were installed for 6 months to measure the activity of spiders, carabids and woodlice (for details see Schuldt et al. 2008). Snails were collected in July 2005 by hand-sorting the litter of four $1-\mathrm{m}^{2}$-plots located directly near the study sites. In April and October 2006 earthworms were hand-sorted from litter and soil of four 1/9-m ${ }^{2}$-plots (organic layer and mineral soil of $20 \mathrm{~cm}$ depth), also located directly near the study sites. Anecic earthworms were extracted from the sample sites with a $0.33 \%$ mustard solution (Cesarz et al. 2007).

\section{Environmental variables}

Tree diversity was measured and the Shannon-Wiener Index was calculated for tree crown area (Jacob et al. 2009). Herb diversity was measured in spring and summer 2005 (Mölder et al. 2006) and herb cover was estimated on a $5 \times 5 \mathrm{~m}$ area surrounding each pitfall trap. Litter input was recorded in autumn 2005 with litter collectors $\left(0.3 \mathrm{~m}^{2}\right)$ placed directly adjacent to the sampling plots and the Shannon-Wiener Index of leaf litter was calculated (Schuldt et al. 2008). Small litter and soil samples (5 cm depth) were used to measure litter depth, moisture content, $\mathrm{pH}_{\mathrm{CaCl}}$ and microbial biomass (substrate induced respiration measuring oxygen consumption; Anderson and Domsch 1978, Scheu 1992, Jacob et al. 2009; Table 1).

Table 1 Stand characteristics of the three diversity levels (DL 1: low, DL 2: medium, DL 3: high tree diversity). Given are means from 3 sites. Different letters indicate significant differences between the three diversity levels; $P<0.05$ (Tukey post-hoc).

\begin{tabular}{llll}
\hline & DL 1 & DL 2 & DL 3 \\
\hline Tree diversity (Shannon-Index) & $0.18^{\mathrm{c}}$ & $1.06^{\mathrm{b}}$ & $1.70^{\mathrm{a}}$ \\
Herb diversity (Shannon-Index) & $0.42^{\mathrm{c}}$ & $0.78^{\mathrm{b}}$ & $1.40^{\mathrm{a}}$ \\
Herb cover (\%) & $23.4^{\mathrm{c}}$ & $48.3^{\mathrm{b}}$ & $67.8^{\mathrm{a}}$ \\
Litter diversity (Shannon-Index) & $0.21^{\mathrm{c}}$ & $1.06^{\mathrm{b}}$ & $1.46^{\mathrm{a}}$ \\
Litter depth (cm) & $2.84^{\mathrm{a}}$ & $2.41^{\mathrm{b}}$ & $1.89^{\mathrm{c}}$ \\
Water content (litter/soil) (\%DM) & $161^{\mathrm{b}} / 48^{\mathrm{a}}$ & $195^{\mathrm{a}} / 49^{\mathrm{a}}$ & $198^{\mathrm{a}} / 52^{\mathrm{a}}$ \\
$\mathrm{pH}$ (litter/soil) & $4.92^{\mathrm{b}} / 3.95^{\mathrm{c}}$ & $6.05^{\mathrm{a}} / 4.95^{\mathrm{b}}$ & $6.14^{\mathrm{a}} / 5.69^{\mathrm{a}}$ \\
Microbial biomass (litter/soil) & $10.0^{\mathrm{a}} / 0.60^{\mathrm{b}}$ & $10.6^{\mathrm{a}} / 0.89^{\mathrm{a}}$ & $9.9^{\mathrm{a}} / 1.07^{\mathrm{a}}$ \\
(mgCmic/gDM) & & & \\
\hline
\end{tabular}

\section{Statistical analysis}

Pitfall trap data of each plot were added up for the whole sampling period. From soil sample data the annual mean was calculated. Total species richness was assessed as total species number per DL from pooled pitfall trap and soil sample data. Mean species richness was calculated from the species numbers per plot. Species density of lumbricids was calculated 
per site, to allow for the combination of different sampling methods. If necessary, data were transformed (log or square root) to achieve homogeneity of variance and normality. Animal data (abundance and species density, i.e. the mean number of species per sample or plot) were analysed for diversity level (DL) effects and for between-site effects (two-factorial analysis of variance, ANOVA, with "site" hierarchically nested in "DL"). Species densities of lumbricids were analysed by one-factorial ANOVA. Tukey's post hoc test was performed to test for differences between means. Analyses were performed using SAS for Windows 9.1 (SAS Institute, Cary, NC, USA).

Saprophagous and zoophagous communities of the animal taxa were analysed by principal component analysis (PCA) and redundancy analysis (RDA) with the program CANOCO for Windows 4.5 (Ter Braak and Šmilauer 2002). Rare species (less than four individuals) were excluded and data were log-transformed. The data for the analysis of saprophages (lumbricids and isopods) were obtained from soil samples, for zoophages (carabids and spiders) from pitfall traps. Plant diversity, proportion of beech, lime and ash litter, microbial biomass, and soil and litter parameters were used as explanatory (environmental) variables in the RDA. The factor "site" (including DL) was included in the analyses as passive variable, i.e. without affecting the ordination.

Due to high multicollinearity among many of the recorded environmental variables, those with best explanatory value for each animal group were selected. The Monte Carlo permutation procedure (Ter Braak and Šmilauer 2002) was performed to test the relevance of the selected factors. Additionally, the eigenvalues of PCA and RDA were compared.

\section{$\underline{\text { Results }}$}

\section{Gastropods}

In the leaf litter 2,745 snails were found belonging to 25 species. Discus rotundatus was most numerous with 490 individuals $(17.9 \%)$ and was abundant on all sites. Further dominant species were Punctum pygmaeum, Aegopinella pura and juvenile Aegopinella spp.; together with $D$. rotundatus they made up more than half of the total number of snails. Total species number of the snails was lowest in the beech dominated sites (DL 1), as compared to DL 2 and DL 3 . Mean species density significantly differed between the diversity levels, with the maximum in the medium-diversity sites (Fig. 1a, Table 2). Characteristic species of the DL 1 sites were Nesovitrea hammonis and Euconulus fulvus. Acanthinula aculeata was only abundant in DL 2 and DL 3. The medium-diversity sites (DL 2) harboured most individuals (Fig. 1b), but because of a high between-site variation (Table 2) mean abundance in DL 1 was not significantly different. The significantly lowest abundance was observed for the highly diverse DL 3 sites. 


\section{Lumbricids}

In total, 2,401 earthworms were found, soil cores and hand-sorting combined, belonging to 10 species, of which Aporrectodea caliginosa was most abundant in almost all sites. Juvenile Lumbricus spp. individuals were also commonly found, but could not be further assigned to the co-occurring species $L$. castaneus, $L$. rubellus or $L$. terrestris. Total species number and mean species number were almost identical for all three DL sites (Fig. 1c, Table 2). Most individuals were found in the highly diverse sites irrespective of the sampling method. In the soil cores earthworms were significantly less abundant in the DL 1 and DL 2 sites than in the highly diverse sites (Fig. 1d, Table 2), whereas hand-sorting yielded higher abundance of lumbricids in the DL 2 and DL 3 sites (Fig. 1e, Table 2). Adult Lumbricus terrestris individuals were only found with hand-sorting and mustard extraction. They occurred in almost all sites but DL 3 harboured most individuals which is also represented by a significantly higher number of middens in the $D L 3$ sites $(F=8.21, P=0.0013)$. Strong seasonal differences in total earthworm abundance also occurred in these sites while differences were less pronounced in less diverse sites (for more details see Cesarz et al. 2007).

\section{Isopods}

With pitfall trapping 906 individuals were collected belonging to 7 species. Trachelipus ratzeburgii was the most common species in the pitfall traps with 524 individuals (58\%). Trichoniscus pusillus was the dominant species in the forest floor samples, with 1807 (89\%) out of 2,039 individuals. The only species not caught with pitfall traps was Haplophthalmus mengii. Total species number was highest in the medium-diversity sites while mean species density was significantly lower in DL 1 than in DL 2 and 3 (Fig. 1f, Table 2). Isopod abundance differed between the diversity levels depending on the sampling method. Soil samples yielded significantly fewer individuals in the pure beech stand DL 1 compared to the mixed tree species sites DL 2 and 3 (Fig. 1g, Table 2). Isopod activity, however, was highest in the medium-diversity sites $\mathrm{DL} 2$ but not significantly different from that in the other diversity levels (Fig. 1h).

\section{Carabids}

Altogether, 4,622 carabid beetles were caught belonging to 32 species. With 1,995 individuals $(43 \%)$ Pterostichus burmeisteri was most abundant followed by Abax parallelepipedus with $17 \%$ and Pterostichus oblongopunctatus with $12 \%$ of the total number of individual. Most species occurred in DL 3, followed by DL 2 and DL 1. Mean species density exhibited the same pattern and was significantly higher in DL 3 than DL 2 and 1 (Fig. 1i). In contrast, mean carabid activity was significantly higher in DL 1 than in DL 2 and 3 (Fig. 
1j). The between-site variation was high for species density as well as for activity of carabid beetles (Table 2).

\section{Species richness}

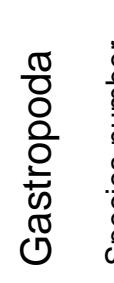

a.

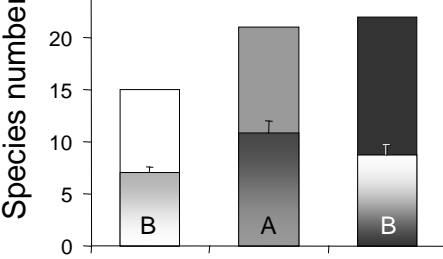

C.

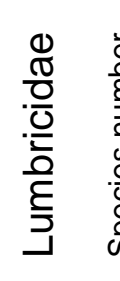

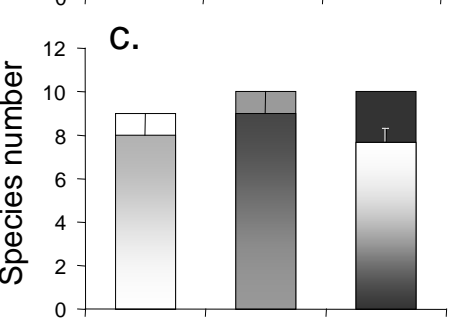

f.
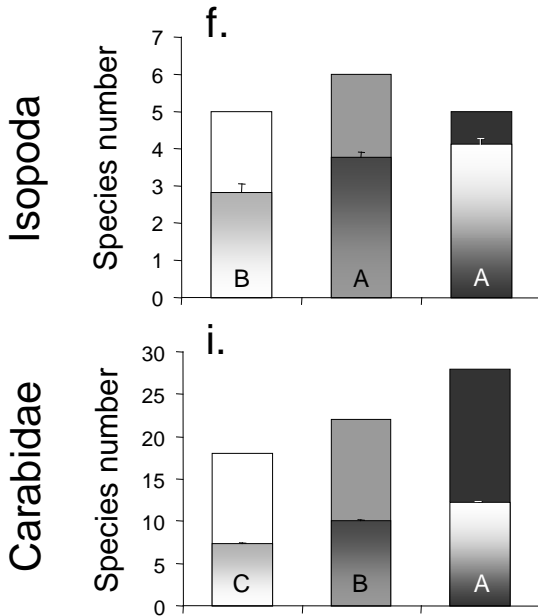

$\mathrm{k}$.

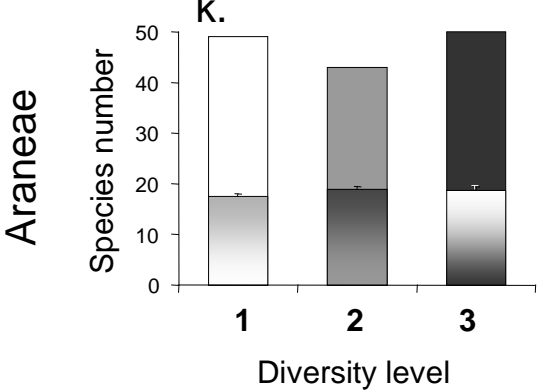

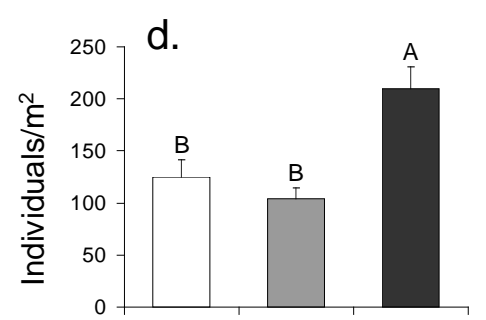

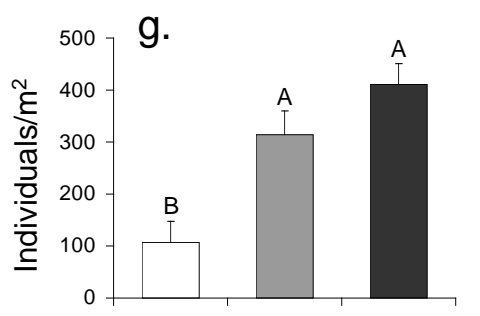

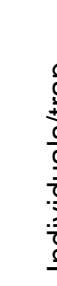

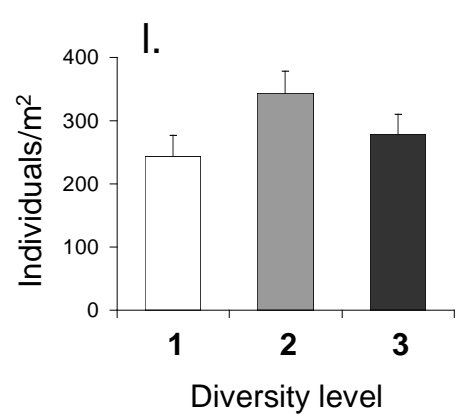

\section{Abundance}

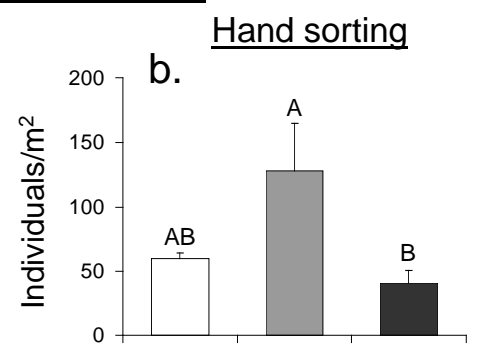

e.

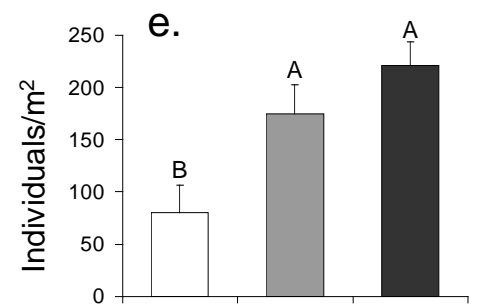

h. Pitfall traps
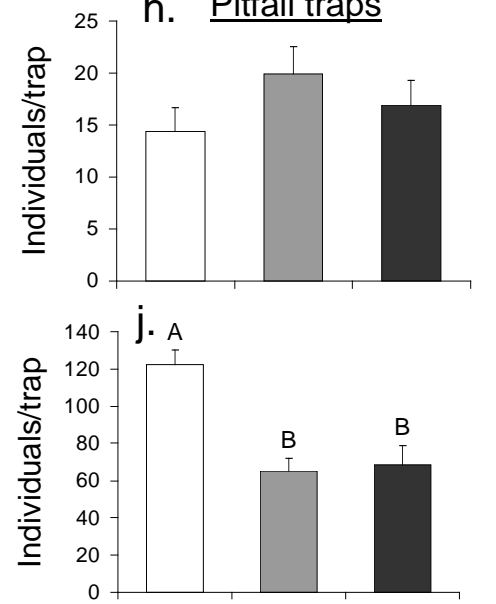

$\mathrm{m}$.

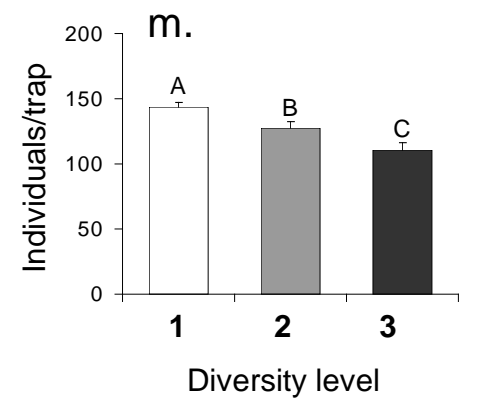

Fig. 1 Species richness (solid columns: total species number per DL; columns with colour gradient: mean species number per sample, for lumbricids species per site) and abundance of Gastropoda (a.-b.), Lumbricidae (c.-e.), Isopoda (f.-h.), Carabidae (i.-j.) and Araneae (k.-m.) in forest sites with low, medium and high tree species diversity (diversity level 1,2 and 3, respectively). Note the different sampling methods. Given are means of 18 samples $\pm \mathrm{SE}$, for lumbricid and gastropod hand-sorting means of 12 samples $\pm \mathrm{SE}$. Different letters indicate significant differences between the DLs $(p<0.05)$. 


\section{Spiders}

With pitfall trapping 6,877 individuals (65\% adults) were sampled belonging to 64 species. Coelotes terrestris was the most common species in the pitfall traps. Thirty-six species were found in the soil samples with a total number of 2,221 individuals ( $24 \%$ adults). Five of the species were not caught in pitfall traps. Hahnia pusilla was the most abundant species in the soil samples. The total number of species was lower in the medium-diversity level as compared to DL 1 and DL 3. However, mean species density per site did not differ significantly between the diversity levels (Fig. 1k). Differences in spider abundance between diversity levels depended on the sampling method. Whereas most individuals were found in the soil samples of the DL 2 sites (Fig. 1I), spiders had their significantly highest activity in the DL 1 sites, followed by DL 2 and DL 3 (Fig. 1m, Table 2). For a more detailed overview of the spider community pattern see Schuldt et al. (2008).

Table $2 \mathrm{~F}$ statistics of two-factorial ANOVA for the influence of tree diversity on soil macrofauna taxa. Lumbricidae species richness was analysed by one-way ANOVA. Significant differences are displayed in bold.

\begin{tabular}{lllrlllr} 
& & & $\mathrm{DL}$ & \multicolumn{3}{c}{ Site } \\
\cline { 3 - 8 } Taxon & & Method & $\mathrm{F}$ & $\mathrm{P}$ & $\mathrm{F}$ & $\mathrm{P}$ \\
\hline Gastropoda & species richness & hs & 12.74 & $\mathbf{0 . 0 0 0 1}$ & 10.67 & $<.0001$ \\
Lumbricidae & species richness & hs+sc & 0.59 & 0.5831 & & \\
Isopoda & species richness & pf+sc & 20.73 & $<.0001$ & 4.47 & $\mathbf{0 . 0 0 1 3}$ \\
Araneida & species richness & pf+sc & 1.79 & 0.1787 & 2.29 & 0.0514 \\
Carabidae & species richness & pf & 36.24 & $<.0001$ & 3.40 & $\mathbf{0 . 0 0 7 5}$ \\
\hline Gastropoda & abundance & hs & 17.30 & $<.0001$ & 17.59 & $<.0001$ \\
Lumbricidae & abundance & hs & 9.13 & $\mathbf{0 . 0 0 0 9}$ & 1.86 & 0.124 \\
Lumbricidae & abundance & sc & 10.95 & $\mathbf{0 . 0 0 0 1}$ & 1.36 & 0.2507 \\
Isopoda & activity & pf & 1.20 & 0.3111 & 0.58 & 0.7480 \\
Isopoda & abundance & sc & 20.02 & $<.0001$ & 1.25 & 0.3010 \\
Carabidae & activity & pf & 18.83 & $<.0001$ & 4.30 & $\mathbf{0 . 0 0 1 7}$ \\
Araneae & activity & pf & 15.54 & $<.0001$ & 3.10 & $\mathbf{0 . 0 1 2 5}$ \\
Araneae & abundance & sc & 2.76 & 0.0742 & 2.70 & $\mathbf{0 . 0 2 5 1}$ \\
\hline
\end{tabular}

$\mathrm{DL}=$ Diversity level effect, Site = Between-site effect. $\mathrm{pf}=$ pitfall traps, $\mathrm{sc}=$ soil cores, hs = hand-sorting

\section{Community structure and the influence of environmental factors}

\section{Saprophages}

The relationship between the saprophagous macrofauna and the characteristics of the forest stands with different diversity levels were studied using multivariate ordination methods (PCA and RDA). The PCA of lumbricids and isopods clearly separated the diversity levels. The first axis correlated with the diversity gradient representing $38.7 \%$ of the variation in abundance data from the soil samples (PCA eigenvalue first axis $=0.387$, second axis $=0.120$, 
ordination not shown). The direct gradient analysis (RDA) included plant diversity, proportion of beech, lime and ash litter and soil and litter parameters as predictor variables for the decomposer community. Only a slight decline of variance was observed represented by the first and second axis (33.9 and 7.1\%, respectively, Fig. 2) as compared to the PCA.

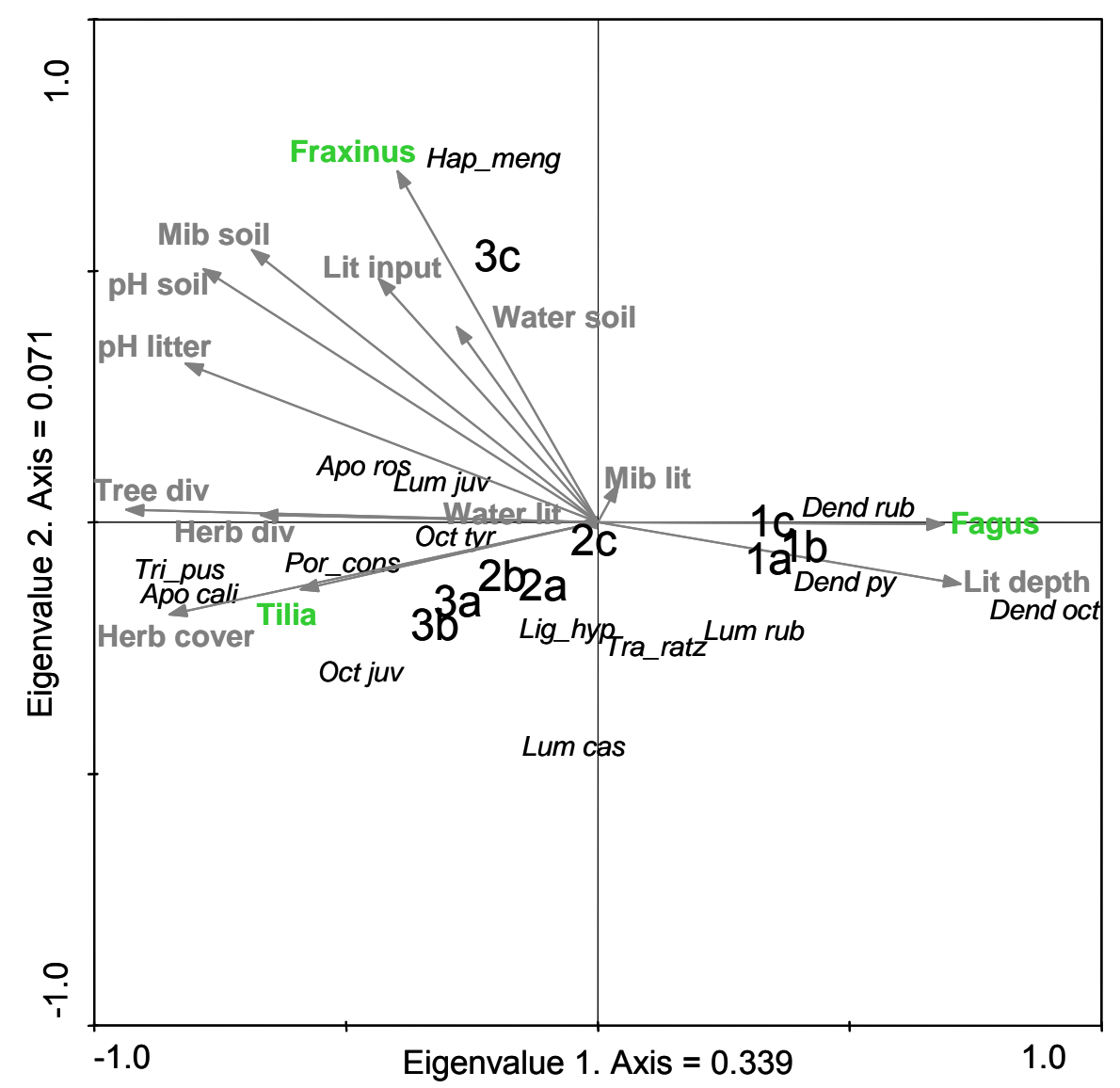

Fig. 2 RDA ordination plot for lumbricid and isopod communities (soil samples) of the nine studied plots (DL 1aDL 3c, shown as weighted means of data) and correlated environmental variables (arrows). Data log-transformed. Only species with $>3$ individuals were included into the analysis. Monte Carlo permutation test: first axis $F=20.0$ and $P=0.001$; all axes $F=3.5$ and $P=0.001$. Genus and species names are abbreviated with the first three letters respectively. Isopod genus and species separated with "_," lumbricids without. Mib = Microbial biomass, lit $=$ litter, div = diversity. For complete species list see appendix.

The decomposer community of low tree species diversity sites (DL 1) differed strongly from that of the sites with higher tree species diversity (DL 2 and DL 3). The DL 1 sites were characterised by high densities of Dendrobaena octaedra, D. pygmea and Dendrodrilus rubidus which were positively correlated with increasing proportion of beech litter and litter depth. Lumbricid communities in DL 2 and DL 3 sites were characterised by higher densities of the epigeic species Lumbricus castaneus and of endogeic taxa like Aporrectodea spp. and Octolasion spp. They were positively correlated with increasing tree species diversity, as well as herb diversity and density, increasing $\mathrm{pH}$ and microbial biomass in the soil. 
The dominant isopod Trichoniscus pusillus was also positively correlated with these environmental factors and occurred in high densities in the DL 3 sites, together with Porcellium conspersum. Haplophthalmus mengii was only found in site DL $3 \mathrm{c}$, for which high ash litter input and high soil water content were typical. DL 2 sites were characterised by a high abundance of Ligidium hypnorum and Trachelipus ratzeburgii. No isopod species had high densities in the low-diversity DL 1 sites (Fig. 2).

\section{Zoophages}

The PCA of the pitfall trap data reflected well the differences between the diversity levels (PCA eigenvalue first axis $=0.287$, second axis $=0.107$, ordination not shown). When the environmental data as explanatory variables were included, variance declined only slightly represented by marginally smaller eigenvalues for the first and second ordination axis (RDA eigenvalues first axis $=0.259$, second axis $=0.078$, Fig. 3 ). Study sites with low tree diversity all had a very similar species composition differing from communities in medium- and highdiversity sites. Similarly, two of the three high-diversity sites (DL $3 a$ and b) also had a distinct community of spiders and carabid beetles, while the species composition of the third site (DL 3c) was typical for sites with medium tree species diversity. Among spiders characteristic for DL 1 were Diplocephalus picinus, Histopona torpida, Harpactea lepida, Walckenaeria corniculans, Walckenaeria cucullata and Saloca diceros, the activities of which were correlated with a high proportion of beech litter and a thick litter layer. Hahnia pusilla was almost completely absent from the DL 1 sites. Together with species such as Diplostyla concolor, Tenuiphantes cristatus and Tenuiphantes tenebricola its activity maxima were correlated with high tree species diversity, high herb cover and high $\mathrm{pH}$ typical for the sites DL $3 a$ and 3b.

Carabid beetles typical for the low diversity sites were Pterostichus oblongopunctatus, Molops piceus and Abax parallelepipedus. In contrast, Carabus coriaceus, Pterostichus aethiops, P. madidus and Cychrus caraboides were associated with the diverse sites DL $3 a$ and 3b. Molops elatus and Trechus obtusus were abundant on the medium-diversity sites characterised by a high proportion of ash litter (Fig. 3). 


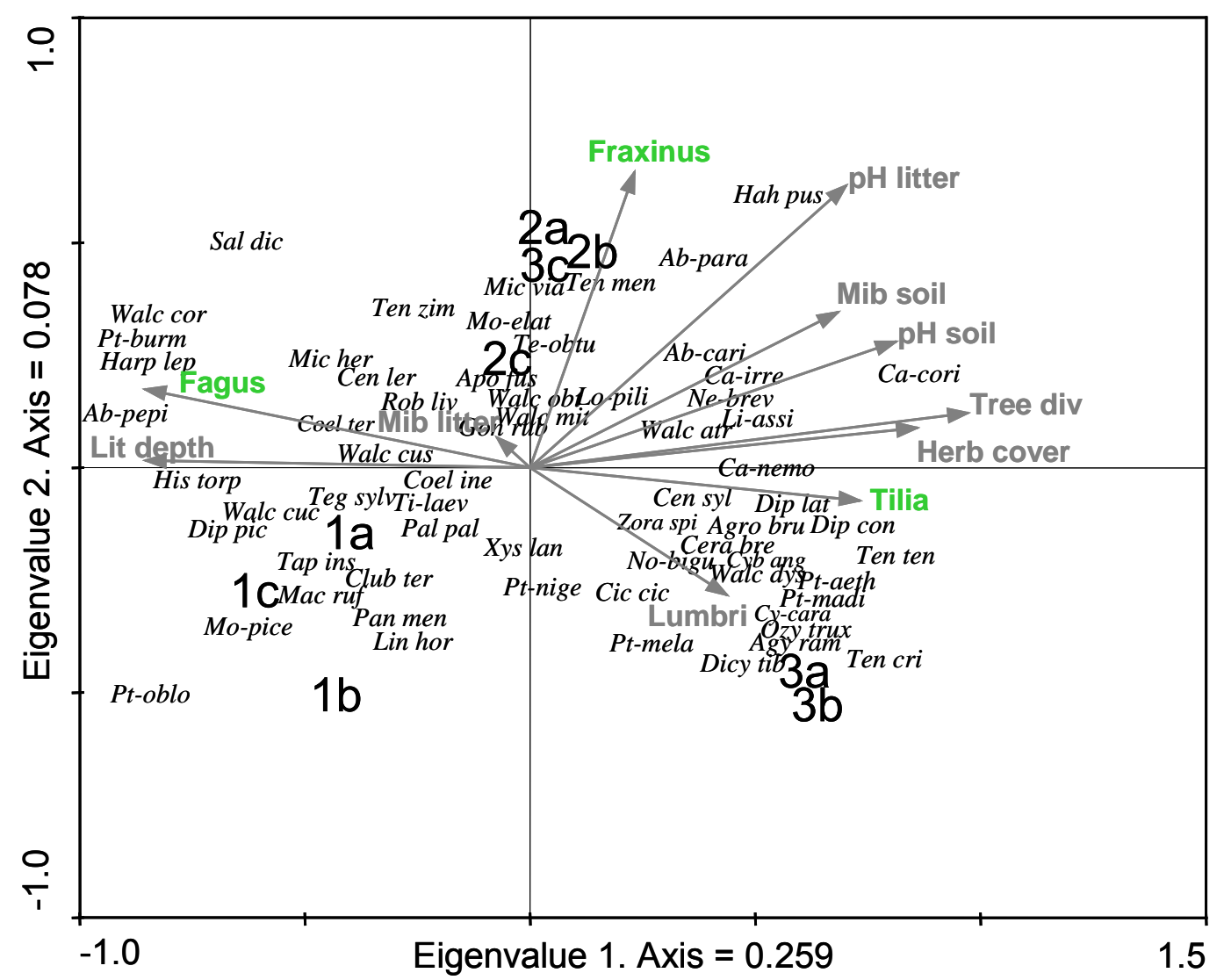

Fig. 3 RDA ordination plot for spider and carabid communities (pitfall trap catches) of the nine studied plots (DL 1a- DL 3c, shown as weighted means of data) and correlated environmental variables (arrows). Data logtransformed. Only species with $>3$ individuals were included into the analysis. Monte Carlo permutation test: first axis $F=14.7$ and $P=0.001$; all axes $F=3.7$ and $P=0.001$. Carabid genus and species separated with "-", spiders without. Mib = Microbial biomass, lit = litter, div = diversity, lumbri = lumbricid abundance. For complete species list see appendix.

\section{Discussion}

We studied the response of the soil fauna community to differences in canopy tree species mixture. Tree species diversity influences a number of factors - among them $\mathrm{pH}$, herb cover and diversity, litter depth and litter diversity. Litter depth is controlled by beech, the dominant tree species, as beech leaves decompose slowly, resulting in thick litter layers (Sydes and Grime 1981a, Sydes and Grime 1981b). In contrast to beech, litter of other broad-leaved tree species, such as ash, hornbeam and lime, rapidly decompose after litter fall (Jacob et al. 2009). Litter of these tree species leads to higher $\mathrm{pH}$ and base saturation of the soil (Augusto et al. 2002, Aubert et al. 2004). Thus, in the present study the slightly higher overall litter input in mixed compared to pure beech sites (Guckland et al. 2009) was not accompanied by a higher standing crop of organic matter in the more diverse sites. The effect of a decrease of organic matter in the litter layer parallel to increasing tree species diversity is twofold: (1) The all-season availability of food resources and the volume of habitable space are reduced. However, the transformation of pure beech stands to more diverse tree mixtures positively affects the amount of microbial biomass in the soil (Table 1; Jacob et al. 2009). (2) The 
development of a diverse herb layer is favoured which increases the structural complexity of the ground zone. These contrasting effects of tree species diversity offer the opportunity to study the relative importance of these diversity-related variables as driving factors for the composition of the decomposer and predator community.

\section{Gastropods}

Highest density and species richness of snails were observed for the medium-diversity sites (DL 2). The three most abundant species Discus rotundatus, Aegopinella pura and Punctum pygmaeum regularly occurred on all study sites but had their maximum density in the DL 2 sites. In a differently diverse mixed oak forest, Johannessen (2000) found a number of widely distributed snail species, e.g. D. rotundatus and $P$. pygmaeum, which he considered as very tolerant and nearly omnipresent. $D$. rotundatus abundance has been found to be largely uncorrelated to soil $\mathrm{pH}$, whereas the highest numbers of $P$. pygmaeum were found at $\mathrm{pH}$ 44.5 (Martin and Sommer 2004). The authors observed a preference of Nesovitrea hammonis for low $\mathrm{pH}$ values, which is in accordance with the findings for the Hainich study sites.

Generally, snail density and species richness are often positively related to soil calcium content and pH (Kappes et al. 2006, Hylander et al. 2005). Additionally, Martin and Sommer (2004) found the influence of soil acidity on snail density to differ under different moisture conditions. A survey of Getz and Uetz (1994) showed interlinked effects of soil moisture and leaf litter diversity on snail species diversity. Generally, snail abundance and species richness increases with the amount and nutrient content $(\mathrm{Ca}, \mathrm{K}, \mathrm{N})$ of leaf litter (Getz and Uetz 1994, Millar and Waite 1999, Kappes et al. 2006). Although litter and soil moisture were highest in DL 2 and $\mathrm{DL} 3$ sites and $\mathrm{pH}$ and Ca content also increased from the beechdominated sites to the more diverse sites, it appears that the medium-diversity sites constitute a more habitable environment. Due to the presence of diverse and easily decomposable litter in the DL 3 sites, litter depth declines markedly from spring to autumn (Cesarz et al. 2007). Obviously, the more constant litter environment in the DL 2 sites containing a larger proportion of slowly decomposing beech litter promotes the development of a diverse snail community with higher population density.

\section{Lumbricids}

The medium-diversity and high-diversity forest sites harboured most earthworm individuals over the year. These sites were characterized by higher values of $\mathrm{pH}$ and base saturation and the tree litter mixture was of higher nutritional quality than pure beech litter $(\mathrm{C} / \mathrm{N}$ values: ash < 30, lime and mixture 30-40, beech 50-60; Jacob et al., 2009). Also, the herb layer was more diverse and productive in the mixed species sites as compared to the sites dominated 
by beech (Table 1, Mölder et al. 2008), providing additional high quality litter. Litter species identity can clearly affect litter microfauna, mesofauna and macrofauna during decomposition (Wardle et al. 2006). Important factors for saprophages are the polyphenolic and nitrogen content: lumbricids show marked preference for certain plant litter species, favouring those with high nitrogen and carbohydrate content and low phenolic content (Satchell 1967). In a choice experiment by Hendriksen (1990), Aporrectodea species (the most common genus in our sites) were preferably found under litter of Tilia, an observation which is consistent with our results. The preference for diverse sites by Aporrectodea species may also be due to higher $\mathrm{pH}$ values linked with high quality litter. The soil $\mathrm{pH}$ of the $\mathrm{DL} 1$ sites was relatively low ( 4.0). In a microcosm experiment Aporrectodea caliginosa could survive at a soil pH above 4.8 (Haimi and Einbork 1992). Reich et al. (2005) found that earthworm abundance and biomass depended on soil $\mathrm{pH}$ and calcium content. Some earthworm species are relatively tolerant against low pH values, e.g. epigeic Dendrobaena octaedra (Yli-Olli and Huhta 2000), hence a litter $\mathrm{pH}$ of 5.0 in the beech-dominated plots is unproblematic for this species.

Mean lumbricid species richness was not significantly influenced by altered tree species diversity. A similar effect was found by Aubert et al. (2003) in a comparison between a beech and a beech-hornbeam forest. Although the input of diverse litter can create microhabitats exploitable by different saprophages species (Hättenschwiler and Gasser 2005) our study indicates that the rapid decomposition on the highly diverse sites resulting in habitat loss is detrimental for a diverse litter-dwelling earthworm community (cf. Judas 1990). A keystone species enhancing litter decomposition is Lumbricus terrestris, which is well known for its midden construction and effective bioturbation up to ecosystem engineering. Abundance of L. terrestris were highest in DL 3 sites in which also highest numbers of middens were counted in spring (personal observation). Cesarz et al. (2007) found that lumbricid densities declined over the course of the year, but least so in the sites dominated by beech, where a thick litter layer is always present. Here, litter dwelling species were particularly dominant in the cold season.

\section{Isopods}

Isopod species richness was marginally enhanced by increasing tree species diversity. Most isopods occurred in the more diverse sites DL 2 and DL 3. Beyer (1964) compared the isopod communities in beech forests and in mixed beech forests in Central Germany and found differences in abundance, but not in species composition. Ecoclimatic factors, such as humidity, are important for isopod communities (e.g. Hornung and Warburg 1996). The diverse study sites DL 2 and 3 were more humid and likely to promote abundant isopod communities. For instance, the dominant species Trichoniscus pusillus needs high ambient humidity (Spungis 2008). The other common species, Trachelipus ratzeburgii, was found to 
be correlated to leaf litter cover and humidity (Hornung et al. 2007). It is a typical forest species in central Germany, preferring mesic deciduous and mixed coniferous forests (Beyer 1964). Haplophthalmus mengii occurred on one site of DL 3 which had the highest soil moisture contents. It is a small soil species which can be found in calcareous soils and moist habitats (Scheu 1990, Wijnhoven 2000). Like other saprophagous groups, isopods prefer certain plant litter species over others. The animals react to changes in litter quality (Cotrufo et al., 1998, Kautz et al., 2000) and show selective feeding activity (Catalán et al. 2008). Litter species with a higher $\mathrm{pH}$ and lower tannin and phenolic contents are beneficial (Kautz et al. 2000, Zimmer and Topp 2000). For instance, Oniscus asellus prefers litter with favourable nutrient and low phenolic content (Hättenschwiler and Bretscher 2001), a condition met in the highly diverse Hainich sites. Additionally, isopods depend on microorganisms as a high-quality food resource (Zimmer and Topp 1997).

\section{Carabids}

Carabid diversity was positively correlated to tree diversity. A reason for this response may be the increasing structural complexity of the sites with a more diverse and dense herb layer. Lassau et al. (2005) found more forest beetle species in highly complex habitats. Other factors influencing carabid diversity are soil moisture (Baguette 1993, Raino and Niemelä 2003, Sroka and Finch 2006, Mullen et al. 2008), soil pH and the amount of leaf litter (Magura et al. 2003, Fuller et al. 2008). However, the effect of increasing leaf litter cover on carabid beetle diversity can also be negative (Guillemain et al. 1997, Sroka and Finch 2006) as is the case in our study. Prey abundance is regarded as important for carabid beetle diversity (Baguette 1993, Raino and Niemelä 2003), but carabid species richness can also be independent of prey abundance (Guillemain et al. 1997).

In contrast to species diversity, most individuals were caught in the low-diversity sites of DL 1. Three of the most abundant species, namely Pterostichus burmeisteri, P. oblongopunctatus and Abax parallelepipedus, preferably occurred in these sites. Litter depth may be the key factor. Since interspecific competition can be important for carabid beetles (Loreau 1990, Raino and Niemelä 2003) more habitable space enhances the possibility of coexistence in the same microhabitat. Comparing coniferous, mixed and deciduous forest stands Fuller et al. (2008) found a positive correlation between number of tree species and carabid abundance, which he attributed to a larger number of favourable microhabitats in diverse stands. Prey availability also influences carabid densities. In our study, collembolan and epigeic lumbricid densities were high in the beech-dominated sites. Such a positive correlation between carabid abundance and collembolans as their potential prey was also found by Koivula et al. (1999), and Niemelä et al. (1997) concluded that a higher earthworm abundance leads to larger carabid populations. 


\section{Araneids}

No clear relationship between mean spider diversity and tree species richness could be found. Many juvenile Linyphiidae were collected with soil samples and could not be determined to species level. Thus highest spider abundance in the medium-diversity sites was not reflected in total species numbers, the latter being highest in low- and high-diversity sites. In contrast to the mean abundance of the spiders in soil samples, the spider activity density measured with pitfall traps was negatively correlated to tree species diversity.

Presumably, the spider fauna also was affected by litter depth and herb cover to a large extent, since the physical structure of the habitat is important for the habitat preference of spiders (Pearce et al. 1994). A thick litter layer has been found to be vital for spiders due to its influence on microclimate, prey abundance and web-building space (Bultman and Uetz 1982), i.e. web-building spiders, such as Linyphiidae, are more abundant in complex leaf litter (Bultman and Uetz 1984). Typical species associated with DL 1 were Diplocephalus picinus, Histopona torpida and Harpactea lepida which are known to prefer forest sites with a continuous and pronounced litter layer (Stippich 1986). Hahnia pusilla, in contrast, was absent in the beech-dominated sites. Ziesche and Roth (2008) found H. pusilla to be associated with moisture and moss cover, environmental conditions which were more pronounced in the diverse Hainich sites (Mölder et al. 2006). Ziesche and Roth (2008) studied coniferous and mixed deciduous forest stands and identified litter type as a major environmental factor influencing spider species distribution. Important other parameters were temperature, soil and litter water content, cover and composition of the herb layer. Herb cover was also recognised as an important factor by Oxbrough et al. (2005). A factor contributing to the high activity density in the less diverse sites is probably the abundance of potential prey, in this case collembolans. Schuldt et al. (2008) found a positive correlation between spider abundance and Collembola as potential prey organisms, with high abundances in the beech-dominated sites. Such a positive correlation between spiders and their prey from the decomposer community was also found in an experiment by Chen and Wise (1999), indicating close predator-prey associations. High spider densities in DL 2 may be ascribed to the beneficial combination of litter depth and prey abundance on the one hand and herb cover and humidity on the other hand. 


\section{Conclusions}

Tree species diversity in the Hainich study sites appears to be a key factor for the community structure of major soil animals groups. The tree diversity effects were mediated through alterations in habitat characteristics such as herb diversity and cover, litter depth and $\mathrm{pH}$.

Low-diversity beech and high-diversity mixed stands differed strongly in faunal composition as indicated by PCA ordination. These differences seemed to be more pronounced for the decomposer community than for the predator community. A gradient analysis (RDA) including the variables tree diversity, microbial biomass, amount of organic matter, herb cover, and litter and soil $\mathrm{pH}$ lead to the conclusion that $\mathrm{pH}$ and also the other variables are highly correlated with the tree diversity gradient. However, the relationship between increasing tree species diversity and diversity and abundance of major soil macrofauna groups was not uniform. Whereas decomposer density and diversity often responded positively to increased tree species diversity, predator abundance (not diversity) decreased in highly diverse sites. Tree species on the diverse Hainich sites produced high quality litter which led to higher abundance and feeding activity of decomposers. This feeding pressure reduced the litter layer markedly which in turn influenced other macrofauna. Additionally, the effect of tree species diversity was closely interlinked with the changing proportion of beech in the Hainich sites. The amount of high quality litter with its specific properties was crucial to many soil fauna groups. The quality of the litter material appears to be more important for the decomposers studied than the amount of carbon in organic layers (i.e. habitat space). Overall, the response of predatory and decomposer macrofaunal taxa to tree species and RDA ordination indicate that the groups studied are controlled by bottom-up forces. Dominance of bottom-up forces in decomposer systems has been postulated early (Hairston et al. 1960) and was demonstrated experimentally (Chen and Wise 1999). These bottom-up forces could be modulated by single species like anecic earthworms by altering the resource supply to other species. In conclusion, an outcome of the simultaneous study of different soil fauna groups is that tree species diversity has a marked effect on the structure of the soil animal food web. Additionally, however, the role of the ecosystem engineers Fagus sylvatica and Lumbricus terrestris is crucial for the whole ecosystem. Overall, tree species diversity and single keystone species are important driving forces for structuring soil macrofauna communities.

\section{Acknowledgements}

We thank Andreas Mölder and Mascha Jacob for supplying data on herb diversity and tree diversity, respectively. The study is funded by the German Research Council (DFG) within the Research Training Group 1086. 


\section{$\underline{\text { References }}$}

Anderson JM (1973) The breakdown and decomposition of sweet chestnut (Castanea sativa Mill.) and beech (Fagus sylvatica L.) leaf litter in two deciduous woodland soils. 1. Breakdown, Leaching and Decomposition. Oecologia 12: 251-274.

Anderson JPE, Domsch KM (1978) A physological method for the quantitative measurement of microbial biomass in soils. Soil Biology \& Biochemistry 10: 215-221.

Aubert M, Bureau F, Alard D, Bardat J (2004) Effect of tree mixture on the humic epipedon and vegetation diversity in managed beech forests (Normandy, France). Canadian Journal of Forest Research 34: 233-248.

Aubert M, Hedde M, Decaens T, Bureau F, Margerie P, Alard D (2003) Effects of tree canopy composition on earthworms and other macro-invertebrates in beech forests of Upper Normandy (France). Pedobiologia 47: 904-912.

Augusto L, Ranger J, Binkley D, Rothe A (2002) Impact of several common tree species of European temperate forests on soil fertility. Annals of Forest Science 59: 233- 253.

Baguette M, 1993. Habitat selection of carabid beetle in deciduous woodlands of southern Belgium. Pedobiologia 37: 365-378.

Beyer R (1964) Faunistisch-ökologische Untersuchungen an Landisopoden in Mitteldeutschland. Zoologische Jahrbücher, Systematik 91: 341-402.

Bultman TL, Uetz GW (1984) Effect of structure and nutritional quality of litter on abundances of litterdwelling arthropods. American Midland Naturalist 111: 165-172.

Bultman TL, Uetz GW (1982) Abundance and community structure of forest floor spiders following litter manipulation. Oecologia 55: 34-41.

Cardinale BJ, Srivastava DS, Duffy JE, Wright JP, Downing AL, Sankaran M, Jouseau C (2006) Effects of biodiversity on the functioning of trophic groups and ecosystems. Nature 443: 989-992.

Catalán TP, Lardies MA, Bozinovic F (2008) Food selection and nutritional ecology of woodlice in Central Chile. Physiological Entomology 33: 89-94.

Cesarz S, Fahrenholz N, Migge-Kleian S, Platner C, Schaefer M (2007) Earthworm communities in relation to tree diversity in a deciduous forest. European Journal of Soil Biology 43: S61-S67.

Chapman K, Whittaker JB, Heal OW (1988) Metabolic and faunal activity in litters of tree mixtures compared with pure stands. Agriculture Ecosystems \& Environment 24: 33-40.

Chen B, Wise DH (1999) Bottom-up limitation of predaceous arthropods in a detritus-based terrestrial food web. Ecology 80: 761-772.

Cotrufo MF, Briones MJ, Ineson P (1998) Elevated CO2 affects field decomposition rate and palatability of tree leaf litter: importance of changes in substrate quality. Soil Biology \& Biochemistry 30: 1565-1571.

De Ruiter PC, Griffiths B, Moore JC (2002) Biodiversity and stability in soil ecosystems: patterns, processes and the effects of disturbance. In: Loreau, M., Naeem, S., Inchausti, P. (eds.), Biodiversity and ecosystem functioning. Synthesis and perspectives. Oxford University Press, Oxford, pp 102-113. 
FAO, ISRIC, IUSS (2006) World Reference Base for Soil Resources 2006. World Soil Resources Reports 103. Rome, Italy.

Fitter AH, Gilligan CA, Hollingworth K, Kleczkowski A, Twyman RM, Pitchford JW, The members of the NERC Soil Biodiversity Programme (2005) Biodiversity and ecosystem function in soil. Functional Ecology 19: 369-377.

Fuller R, Oliver TH, Leather SR (2008) Forest management effects on carabid beetle communities in coniferous and broadleaved forests: implications for conservation. Insect Conservation and Diversity 1: 242-252.

Gartner TB, Cardon ZG (2004) Decomposition dynamics in mixed-species leaf litter. Oikos 104: 230246.

Getz LL, Uetz GW (1994) Species diversity of terrestrial snails in the southern Appalachian Mountains, U.S.A. Malacological Review 27: 61-74.

Guckland A, Brauns M, Flessa H, Thomas FM, Leuschner C (2009) Acidity, nutrient stocks and organic matter content in soils of a temperate deciduous forest with different abundance of European beech (Fagus sylvatica L.). Journal of Plant Nutrition and Soil Science, accepted.

Guillemain M, Loreau M, Daufresne T (1997) Relationships beetween the regional distribution of carabid beetles (Coleoptera, Carabidae) and the abundance of their potential prey. Acta OEcologica 18: $465-483$.

Haimi J, Einbork M (1992) Effects of endogeic earthworms on soil processes and plant growth in coniferous forest soil. Biology and Fertility of Soils 13: 6-10.

Hairston NG, Smith FE, Slobodkin LB (1960) Community structure, population control, and competition. American Naturalist 94: 421-425.

Hättenschwiler S, Bretscher D (2001) Isopod effects on decomposition of litter produced under elevated CO2, N deposition and different soil types. Global Change Biology 7: 565-579.

Hättenschwiler S, Gasser P (2005) Soil animals alter plant litter diversity effects on decomposition. Proceedings of the National Academy of Sciences of the USA 102: 1519-1524.

Hättenschwiler S, Tiunov AV, Scheu S (2005) Biodiversity and litter decomposition in terrestrial ecosystems. Annual Review of Ecology Evolution and Systematics 36: 191-218.

Hector A, Joshi J, Scherer-Lorenzen M, Schmid B, Spehn EM, Wacker L, Weilenmann M, BazeleyWhite E, Beierkuhnlein C, Caldeira MC, Dimitrakopoulos PG, Finn JA, Huss-Danell K, Jumpponen A, Leadley PW, Loreau M, Mulder CPH, Neßhöver C, Palmborg C, Read DJ, Siamantziouras ASD, Terry AC, Troumbis AY (2007) Biodiversity and ecosystem functioning: reconciling the results of experimental and observational studies. Functional Ecology 21: 998-1002.

Hector A, Schmid B, Beierkuhnlein C, Caldeira MC, Diemer M, Dimitrakopoulos PG, Finn J, Freitas H, Giller PS, Good J, Harris R, Högberg P, Huss-Danell K, Joshi J, Jumpponen A, Körner C, Leadley PW, Loreau M, Minns A, Mulder CPH, O'Donovan G, Otway SJ, Pereira JS, Prinz A, Read DJ, Scherer-Lorenzen M, Schulze E-D, Siamantziouras ASD, Spehn EM, Terry AC, Troumbis AY, Woodward FI, Yachi S, Lawton JH (1999) Plant diversity and productivity experiments in European grasslands. Science 286: 1123-1127.

Hendriksen JB (1990) Leaf litter selection by detritivore and geophagous earthworms. Biology and Fertility of Soils 10: 17-21. 
Hooper DU, Bignell DE, Brown VK, Brussaard L, Dangerfield JM, Wall DH, Wardle DA, Coleman DC, Giller KE, Lavelle P, van der Putten WH, de Ruiter PC, Rusek J, Silver WL, Tiedje JM, Wolters V (2000) Interactions between aboveground and belowground biodiversity in terrestrial ecosystems: patterns, mechanisms, and feedbacks. BioScience 50: 1049-1061.

Hooper DU, Chapin FS, Ewel JJ, Hector A, Inchaustl P, Lavorel S, Lawton JH, Lodge DM, Loreau M, Naeem S, Schmid B, Setälä H, Symstad AJ, Vandermeer J, Wardle DA (2005) Effects of biodiversity on ecosystem functioning: a consensus of current knowledge. Ecological Monographs 75: 3-35.

Hornung E, Tóthmérész B, Magura T, Vilisics F (2007) Changes of isopod assemblages along an urbane suburbane-rural gradient in Hungary. European Journal of Soil Biology 43: 158-165.

Hornung E, Warburg MR (1996) Intra-habitat distribution of terrestrial isopods. European Journal of Soil Biology 32: 179-185.

Hylander K, Nilsson C, Jonsson BG, Göthner T (2005) Differences in habitat quality explain nestedness in a land snail meta-community. Oikos 108: 351-361.

Jacob M, Fahrenholz N, Platner C, Schaefer M, Leuschner C, Thomas FM. Nutrient release from decomposing leaf litter of temperate deciduous forest trees along a gradient of increasing tree species diversity. Soil Biology \& Biochemistry, submitted.

Joergensen RG (1991) Organic matter and nutrient dynamics of the litter layer on a forest rendzina under beech. Biology and Fertility of Soils 11: 163-169.

Johannessen LE (2000) Distribution of terrestrial snails in relation to environmental variables in a nemoral mixed oak forest at Havsåsen, Kristiansand. Cand. scient. thesis, Department of Zoology, University of Bergen, Norway, $119 \mathrm{pp}$.

Judas M (1990) The development of earthworm populations following manipulation of the canopy leaf litter in a beechwood on limestone. Pedobiologia 34: 247-255.

Kappes H, Topp W, Zach P, Kulfan J (2006) Coarse woody debris, soil properties and snails (Mollusca: Gastropoda) in European primeval forests of different environmental conditions. European Journal of Soil Biology 42: 139-146.

Kautz G, Topp W (2000) Acquisition of microbial communities and enhanced availability of soil nutrients by the isopod Porcellio scaber (Latr.) (Isopoda: Oniscidea). Biology and Fertility of Soils 31: 102-107.

Kautz G, Zimmer M, Topp W (2000) Responses of the parthenogenetic isopod, Trichoniscus pusillus (Isopoda: Oniscidea), to changes in food quality. Pedobiologia 44: 75-85.

Kerr G, Nixon CJ, Matthews RW (1992) Silviculture and yield of mixed-species stands: the UK experience. In: Cannell, M.G.R., Malcolm, D.C., Robertson, P.A. (eds.), The Ecology of MixedSpecies Stands of Trees. Blackwell, London, pp. 35-51.

Koivula M, Punttila P, Haila Y, Niemelä J (1999) Leaf litter and the small-scale distribution of carabid beetles (Coleoptera, Carabidae) in the boreal forest. Ecography 22: 424-435.

Lavelle P, Spain AV (2001) Soil Ecology. Kluwer Scientific Publications, Amsterdam.

Leuschner C, Jungkunst H, Fleck S (2009) Functional role of forest diversity: Pros and cons of synthetic stands and across-site comparisons in established forests. Basic and Applied Ecology 10: 1-9. 
Loreau M (1990) Competition in a carabid beetle community: a field experiment. Oikos 58: 25-38.

Magura T, Tóthmérész B, Elek Z, 2003. Diversity and composition of carabids during a forestry cycle. Biodiversity and Conservation 12: 73-85.

Martin K, Sommer M (2004) Relationships between land snail assemblage patterns and soil properties in temperate-humid forest ecosystems. Journal of Biogeography 31: 531-545.

Mikola J, Bardgett RD, Hedlund K (2002) Biodiversity, ecosystem functioning and soil decomposer food webs. In: Loreau, M., Naeem, S., Inchausti, P. (eds.), Biodiversity and ecosystem functioning. Synthesis and perspectives. Oxford University Press, Oxford, pp 169-180.

Millar AJ, Waite S (1999) Molluscs in coppice woodland. Journal of Conchology 36: 25-48.

Mölder A, Bernhardt-Römermann M, Schmidt W, 2006. Forest ecosystem research in Hainich National Park (Thuringia): First results on flora and vegetation in stands with contrasting tree species diversity. Waldökologie-Online 3: 83-99.

Mölder A, Bernhardt-Römermann M, Schmidt W (2008) Herb-layer diversity in deciduous forests: Raised by tree richness or beaten by beech? Forest Ecology and Management 256: 272-281.

Mönninghoff W, 1998. Nationalpark Hainich. VEBU, Berlin.

Mullen K, O'Halloran J, Breen J, Giller P, Pithon J, Kelly T (2008) Distribution and composition of carabid beetle (Coleoptera, Carabidae) communities across the plantation forest cycle-Implications for management. Forest Ecology and Management 256: 624-632.

Niemelä J, Spencer JR, Carcamo H (1997) Establishment and interactions of carabid populations: an experiment with native and introduced species. Ecography 20: 643-652.

Oxbrough AG, Gittings T, O'Halloran J, Giller PS, Smith GF (2005) Structural indicators of spider communities across the forest plantation cycle. Forest Ecology and Management 212: 171-183.

Pearce JL, Vennier LA, Eccles G, Pedlar J, McKenney D (1994) Influence of habitat and microhabitat on epigeal spider (Araneae) assemblages in four stand types. Biodiversity and Conservation 13: 1305-1334.

Postma-Blaauw MB, Bloem J, Faber JH, van Groenigen JW, de Goede RGM, Brussaard L (2006) Earthworm species composition affects the soil bacterial community and net nitrogen mineralization. Pedobiologia 50: 243-256.

Raino J, Niemelä J (2003) Ground beetles (Coleoptera: Carabidae) as Bioindicators. Biodiversity and Conservation 12: 487-506.

Reich PB, Oleksyn J, Modrzynski J, Mrozinski P, Hobbie SE, Eissenstat DM, Chorover J, Chadwick OA, Hale CM, Tjoelker MG (2005) Linking litter calcium, earthworms and soil properties: a common garden test with 14 tree species. Ecology Letters 8: 811-818.

Satchell JE (1967) Lumbricidae, in: Burges A, Raw F (eds.), Soil Biology. Academic Press, London, pp. 259-322.

Schaefer M (1990) The soil fauna of a beech forest on limestone: trophic structure and energy budget. Oecologia 82: 128-136.

Schaefer M (2002) The relationship between forest structure and animal species diversity. In: Spellmann $\mathrm{H}$ (ed.), Presentations of the 5th International Workshop of the EU-LIFE-Project: Demonstrations of Methods to Monitor Sustainable Forestry, 5.-8.5.2001. pp. 59-67. 
Scherer-Lorenzen M, Köhler C, Schulze E-D (2005) Forest diversity and function: temperate and boreal systems. Ecological Studies Vol. 176, Springer, Heidelberg.

Scheu S (1992) Automated measurement of the respiratory response of soil microcompartments: Active microbial biomass in earthwork faeces. Soil Biology \& Biochemistry 24: 1113-1118.

Scheu S (1990) Die saprophage Makrofauna (Diplopoda, Isopoda und Lumbricidae) in Lebensräumen auf Kalkgestein: Sukzession und Stoffumsatz.- Dissertation, Göttingen. Berichte des Forschungszentrums Waldökosysteme Göttingen (A) 57: 1-302.

Scheu S (2005) Linkages between tree diversity, soil fauna and ecosystem processes, in: SchererLorenzen M, Köhler C, Schulze E-D (eds.), Forest diversity and function: temperate and boreal systems. Ecological Studies Vol. 176, Springer, Heidelberg, pp. 211-233.

Scheu S, Albers D, Alphei J, Buryn R, Klages U, Migge S, Platner C, Salamon J-A (2003) The soil fauna community in pure and mixed stands of beech and spruce of different age: trophic structure and structuring forces. Oikos 101: 125-238.

Schuldt A, Fahrenholz N, Brauns M, Migge-Kleian S, Platner C, Schaefer M (2008) Communities of ground-living spiders in deciduous forests: Does tree species diversity matter? Biodiversity and Conservation 17: 1267-1284.

Setälä H (2002) Sensitivity of ecosystem functioning to changes in trophic structure, functional group composition and species diversity in belowground food webs Ecological Research 17, 207-215.

Siemann EH, 1998. Experimental tests of the effects of plant productivity and plant diversity on grassland arthropod diversity. Ecology 79: 2057-2070.

Spiecker H (2006) Minority tree species - a challenge for multipurpose forestry. In: Diaci J (ed.), Nature-Based Forestry in Central Europe. Alternatives to Industrial Forestry and Strict Presevation. University of Ljubljana, Ljubljana, pp. 47-59.

Spungis V (2008) Fauna, Distribution, Habitat Preference and Abundance of Woodlice (Oniscidea) in Latvia. Latvijas Entomologs 45: 25-37.

Sroka K, Finch O-D (2006) Ground beetle diversity in ancient woodland remnants in north-western Germany (Coleoptera, Carabidae). Journal of Insect Conservation 10: 335-350.

Stippich G (1986) Die Spinnenfauna (Arachnida: Araneida) eines Kalkbuchenwaldes: Bedeutung von Habitatstruktur und Nahrung. Dissertation, University of Göttingen.

Sydes C, Grime JP (1981a) Effects of tree leaf litter on herbaceous vegetation in deciduous woodland. I. Field investigations. Journal of Ecology 69: 237-248.

Sydes C, Grime JP (1981b) Effects of tree leaf litter on herbaceous vegetation in deciduous woodland. II. An experimental investigation. Journal of Ecology 69: 249-262.

Symstad AJ, Siemann E, Haarstad J (2000) An experimental test of the effect of plant functional group diversity on arthropod diversity. Oikos 89: 243-253.

Ter Braak CJF, Šmilauer P (2002) CANOCO Reference Manual and CanoDraw for Windows User's Guide: software for canonical community ordination (version 4.5). Microcomputer Power, Ithaca.

Tilman D, Wedin D, Knops J (1996) Productivity and sustainability influenced by biodiversity in grassland ecosystems. Nature 379: 718-720.

Wardle DA (2002) Communities and Ecosystems - Linking the aboveground and belowground components, Princeton University Press, Princeton. 
Wardle DA (2006) The influence of biotic interactions on soil biodiversity. Ecology Letters 9, 870-886.

Wardle DA, Yeates GW, Barker GM, Bonner KI (2006) The influence of plant litter diversity on decomposer abundance and diversity. Soil Biology \& Biochemistry 38: 1052-1062.

Wijnhoven H (2000) Landpissebedden van de Ooijpolder: Deel 1. Verspreiding (Crustacea: Isopoda: Oniscidea). Nederlandse faunistische Mededelingen 11: 55-131.

Yli-Olli A, Huhta V (2000) Responses of co-occurring populations of Dendrobaena octaedra (Lumbricidae) and Cognettia sphagnetorum (Enchytraeidae) to soil $\mathrm{pH}$, moisture and resource addition. Pedobiologia 44: 86-95.

Ziesche TM, Roth M (2008) Influence of environmental parameters on small-scale distribution of soildwelling spiders in forests: What makes the difference, tree species or microhabitat? Forest Ecology and Management 255: 738-752.

Zimmer M, Topp W (1997) Does leaf litter quality influence population parameters of the common woodlouse, Porcellio scaber (Crustacea: Isopoda)? Biology and Fertility of Soils 24: 435-441.

Zimmer M, Topp W (2000) Species-specific utilization of food sources by sympatric woodlice (Isopoda: Oniscidea). Journal of Animal Ecology 69: 1071-1082. 


\section{Appendix}

Species with abbreviations are shown in Fig. 2

Isopoda

\begin{tabular}{lll}
\hline Haplophthalmus mengii & (Zaddach 1844) & Hap_meng \\
Ligidium hypnorum & (Cuvier 1792) & Lig_hyp \\
Porcellium conspersum & (Koch 1841) & Por_cons \\
Trachelipus ratzeburgii & (Brandt 1833) & Tra_ratz \\
Trichoniscus pusillus & Brandt 1833 & Tri_pus \\
Armadillidium vulgare & (Latreille 1804) & \\
Philoscia muscorum & (Scopoli 1763) & \\
Oniscus asellus & Linné 1758 & \\
\hline
\end{tabular}

Lumbricidae

\begin{tabular}{lll}
\hline Aporrectodea caliginosa & (Savigny 1826) & Apo cal \\
Aporrectodea rosea & (Savigny 1826) & Apo ros \\
Dendrobaena octaedra & Savigny 1826 & Den oct \\
Dendrobaena pygmaea & (Savigny 1826) & Den pyg \\
Dendrodrilus rubidus & (Savigny 1826) & Den rub \\
Lumbricus castaneus & Savigny 1826 & Lum cas \\
Lumbricus rubellus & Hoffmeister 1843 & Lum rub \\
Octolasion tyrtaeum & (Savigny 1826) & Oct tyr \\
Lumbricus terrestris & Linné 1758 & \\
Octolasion cyaneum & (Savigny 1826) & \\
\hline
\end{tabular}

Gastropoda

\begin{tabular}{ll}
\hline Acanthinula aculeata & (Müller 1774) \\
Aegopinella nitidula & (Draparnaud 1805) \\
Aegopinella pura & (Alder 1830) \\
Balea biplicata & (Montagu 1803) \\
Carychium tridentatum & (Risso 1826) \\
Clausilia bidentata & (Ström 1765) \\
Clausilia pumila & (Pfeiffer 1828) \\
Cochlicopa lubrica & (Müller 1774) \\
Cochlodina laminata & (Montagu 1803) \\
Columella edentula & (Draparnaud 1805) \\
Discus rotundatus & (Müller 1774) \\
Eucobresia diaphana & (Draparnaud 1805) \\
Euconulus fulvus & (Müller 1774) \\
Helicodonta obvoluta & (Müller 1774) \\
Isognomostoma isognomostomos & (Schröter 1784) \\
Macrogastra ventricosa & (Draparnaud 1801) \\
Monachoides incarnatus & (Müller 1774) \\
Oxychilus cellarius & (Müller 1774) \\
Perpolita hammonis & (Ström 1765) \\
Punctum pygmaeum & (Draparnaud 1801) \\
Trichia hispida & (Linné) \\
Vitrea contracta & (Westerlund 1871) \\
Vitrea crystallina & (Müller 1774) \\
Vitrea diaphana & (Studer 1820) \\
Vitrina pellucida & (Müller 1774) \\
\hline &
\end{tabular}


Species with abbreviations are shown in Fig. 3

Araneae

\begin{tabular}{|c|c|c|}
\hline Agroeca brunnea & (Blackwall 1833) & Agro brun \\
\hline Agyneta ramosa & Jackson 1912 & Agy ram \\
\hline Apostenus fuscus & Westring 1851 & Apo fus \\
\hline Centromerus leruthi & Fage 1833 & Cen ler \\
\hline Centromerus sylvaticus & (Blackw. 1841) & Cen syl \\
\hline Ceratinella brevis & (Wider 1834) & Cera brev \\
\hline Cicurina cicur & (Fabricius 1793) & Cic cic \\
\hline Clubiona terrestris & Westr. 1851 & Club ter \\
\hline Coelotes inermis & (L. Koch 1855) & Coel iner \\
\hline Coelotes terrestris & (Wider 1834) & Coel ter \\
\hline Cybaeus angustiarum & L. Koch 1868 & Cyb ang \\
\hline Dicymbium tibiale & (Blackw. 1836) & Dicy tib \\
\hline Diplocephalus latifrons & (O.P.-Cambr. 1863) & Dip lat \\
\hline Diplocephalus picinus & (Blackw. 1841) & Dip pic \\
\hline Diplostyla concolor & (Wider 1834) & Dip con \\
\hline Gonatium rubellum & (Blackw. 1851) & Gon rub \\
\hline Hahnia pusilla & C.L. Koch 1841 & Hah pus \\
\hline Harpactea lepida & (C.L. Koch 1838) & Harp lep \\
\hline Histopona torpida & (C.L. Koch 1834) & His torp \\
\hline Linyphia hortensis & Sundevall 1830 & Lin hor \\
\hline Macrargus rufus & (Wider 1834) & Mac ruf \\
\hline Micrargus herbigradus & (Blackw. 1854) & Mic her \\
\hline Microneta viaria & (Blackw. 1841) & Mic via \\
\hline Ozyptila trux & (Blackw. 1847) & Ozy trux \\
\hline Palliduphantes pallidus & (O.P.-Cambr. 1871) & Pal pal \\
\hline Panamomops mengei & Simon 1926 & Pan men \\
\hline Robertus lividus & (Blackw. 1836) & Rob liv \\
\hline Saloca diceros & (O.P.-Cambr. 1871) & Sal dic \\
\hline Tapinocyba insecta & (L. Koch 1869) & Tap ins \\
\hline Tegenaria silvestris & L. Koch 1872 & Teg sylv \\
\hline Tenuiphantes cristatus & (Menge 1866) & Ten cri \\
\hline Tenuiphantes mengei & Kulczynski 1887 & Ten men \\
\hline Tenuiphantes tenebricola & (Wider 1834) & Ten ten \\
\hline Tenuiphantes zimmermanni & Bertkau 1890 & Ten zim \\
\hline Walckenaeria atrotibialis & O.P.-Cambr. 1878 & Walc atr \\
\hline Walckenaeria corniculans & (O.P.-Cambr. 1851) & Walc cor \\
\hline Walckenaeria cucullata & (C.L. Koch 1837) & Walc cuc \\
\hline Walckenaeria cuspidata & (Blackw. 1833) & Walc cus \\
\hline Walckenaeria dysderoides & (Wider 1834) & Walc dys \\
\hline Walckenaeria mitrata & (Menge 1868) & Walc mit \\
\hline Walckenaeria obtusa & Blackw. 1836 & Walc obt \\
\hline Xysticus lanio & C.L. Koch 1824 & Xys Ian \\
\hline Zora spinimana & (Sundev. 1833) & Zora spin \\
\hline Amaurobius fenestralis & (Stroem 1768) & \\
\hline Ballus chalybeius & (Walckenaer 1802) & \\
\hline Enoplognatha ovata & (Clerck 1757) & \\
\hline Eperigone trilobata & (Emerton 1882) & \\
\hline Erigonella hiemalis & (Blackwall 1841) & \\
\hline Ero furcata & (Villers 1789) & \\
\hline Helophora insignis & (Blackwall 1841) & \\
\hline Lepthyphantes minutus & (Blackwall 1833) & \\
\hline Linyphia triangularis & (Clerck 1757) & \\
\hline
\end{tabular}


Maso sundevalli

Metellina mengei

Neon reticulatus

Neriene emphana

Paidiscura pallens

Pardosa lugubris

Pardosa pullata

Pirata uliginosus

Porrhomma lativelum

Robertus neglectus

Segestria senoculata

Tenuiphantes alacris

Tenuiphantes flavipes

Tenuiphantes tenuis

Trochosa terricola

Walckenaeria alticeps
(Westring 1851)

(Blackwall 1869)

(Blackwall 1853)

(Walckenaer 1841)

(Blackwall 1834)

(Walckenaer 1802)

(Clerck 1757)

(Thorell 1856)

Tretzel 1956

(O.P.-Cambr. 1871)

(Linné 1758)

(Blackwall 1853)

(Blackwall 1854)

(Blackwall 1852)

Thorell 1856

(Denis 1952)

\section{Carabidae}

\begin{tabular}{|c|c|c|}
\hline Abax carinatus & (Duftschmid 1812) & Ab-cari \\
\hline Abax parallelepipedus & (Piller \& Mitterpacher 1783) & Ab-pepi \\
\hline Abax parallelus & (Duftschmid 1812) & Ab-para \\
\hline Carabus coriaceus & (Linné 1758) & Ca-cori \\
\hline Carabus irregularis & Fabricius 1792 & Ca-irre \\
\hline Carabus nemoralis & Müller 1764 & Ca-nemo \\
\hline Cychrus caraboides & (Linné 1758) & Cy-cara \\
\hline Limodromus assimilis & (Paykull 1790) & Li-assi \\
\hline Loricera pilicornis & (Fabricius 1775) & Lo-pili \\
\hline Molops elatus & (Fabricius 1801) & Mo-elat \\
\hline Molops piceus & (Panzer 1793) & Mo-pice \\
\hline Nebria brevicollis & (Fabricius 1792) & Ne-brev \\
\hline Notiophilus biguttatus & (Fabricius 1779) & No-bigu \\
\hline Pterostichus aethiops & (Panzer 1797) & Pt-aeth \\
\hline Pterostichus burmeisteri & Heer 1841 & Pt-burm \\
\hline Pterostichus madidus & (Fabricius 1775) & Pt-madi \\
\hline Pterostichus melanarius & (Illiger 1798) & Pt-mela \\
\hline Pterostichus niger & (Schaller 1783) & Pt-nige \\
\hline Pterostichus oblongopunctatus & (Fabricius 1787) & Pt-oblo \\
\hline Trechus obtusus & Erichson 1837 & Te-obtu \\
\hline Trichotichnus laevicollis & (Duftschmid 1812) & Ti-laev \\
\hline Amara similata & (Gyllenhal 1810) & \\
\hline Asaphidion flavipes & (Linné 1761) & \\
\hline Badister unipustulatus & Bonelli 1813 & \\
\hline Badister lacertosus & Sturm 1815 & \\
\hline Bembidion guttula & (Fabricius 1792) & \\
\hline Carabus arvensis & Herbst 1784 & \\
\hline Carabus auratus & Linné 1761 & \\
\hline Leistus rufomarginatus & (Duftschmid 1812) & \\
\hline Notiophilus palustris & (Duftschmid 1812) & \\
\hline Pterostichus ovoideus & (Sturm 1824) & \\
\hline Synuchus vivalis & (Illiger 1798) & \\
\hline Trechus quadristriatus & (Schrank 1781) & \\
\hline
\end{tabular}




\title{
Chapter 5
}

\author{
Nutrient release from decomposing leaf litter \\ of temperate deciduous forest trees \\ along a gradient of increasing tree species diversity
}

\author{
Mascha Jacob, Nadine Weland, \\ Christan Platner, Matthias Schaefer \\ Christoph Leuschner \& Frank M. Thomas
}




\section{$\underline{\text { Abstract }}$}

In the litter of six deciduous tree species (Fagus sylvatica, Tilia spp., Fraxinus excelsior, Carpinus betulus, Acer pseudoplatanus and Acer platanoides) and in stand-specific litter mixtures, we compared mass loss and nutrient release across diversity levels along a gradient of decreasing proportion of Fagus in stands with similar environmental and physical soil conditions. The litterbag studies ran over 22 months. The decomposition rate constants (k) of the temperate forest species ranged from $k=0.5$ for Fagus to $k=1.5-2$ for all other tree species. In Fagus, $\mathrm{k}$ was closely negatively correlated with the thickness of the litter layer and positively correlated with soil $\mathrm{pH}$ and isopod abundance. $\mathrm{k}$ was significantly higher in the mixed species stands (except for Carpinus and Fraxinus) and was positively correlated with earthworm abundance. Over the whole incubation time, nutrient amount and release rates of $\mathrm{N}, \mathrm{P}, \mathrm{K}, \mathrm{Ca}$ and $\mathrm{Mg}$ as well as C-related ratios showed significant differences between tree species but no consistent differences among the diversity levels. Initial Crelated nutrient ratios of the leaf litter and abundance of mesofauna and macrofauna were correlated with the length of time lag before nutrient release. We conclude that the mere number of tree species is not the main driver of nutrient release and decomposition processes, but that key groups of the decomposer fauna as well as the characteristic traits of the individual tree species are decisive.

Keywords: Decomposition rate / Litter decay / Soil fauna / Nutrient release / Tree species diversity / Litterbag / C/N ratio 


\section{$\underline{\text { Introduction }}$}

There is a vital debate about the effects of plant species diversity on ecosystem functions such as productivity, nutrient cycling and carbon storage in managed and near-natural ecosystems (e.g. Hooper et al. 2005, Hector et al. 2007). Effects of biodiversity on ecosystem functioning were mainly studied with grassland experiments. Such experiments with artificially created gradients of even-aged plants are important to detect underlying mechanisms between diversity and ecosystem processes, although they have shortcomings to transfer these results to multi-aged mature forest stands with complex stand structure and a high longevity of dominant trees (Scherer-Lorenzen et al. 2007). Therefore, observational studies in mixed forests comparing adult trees of stands with near-natural structure, intact food web structures and nutrient cycling at a quasi steady state are indispensable (Leuschner et al. 2009). Our study aimed at investigating the effects of tree species diversity in terms of species richness on the decomposition of and the nutrient release from litter of tree leaves, which are two fundamental processes that underlie the supporting services of ecosystems. The study was performed in near-natural forest stands with beech as the main tree species as this is the predominant tree species in Central Europe.

Plant litter decomposition has long been recognized as an essential process for organic matter turnover and nutrient fluxes in most ecosystems. The subsequent release of carbon (C) and nutrients represents the primary source of nutrients for plants and microbes (e.g. Swift et al. 1979, Berg and McClaugherty 2008). These are key processes for the functioning of ecosystems and the delivery of ecosystem goods and services (Hättenschwiler and Gasser 2005). Rates of plant litter decomposition and nutrient mineralization are influenced mainly by three factors: (i) climate on a broad regional scale with warmer and more humid climate generally leading to faster decomposition, (ii) litter quality on a smaller scale with higher nitrogen $(\mathrm{N})$ contents mostly enhancing decomposition and (iii) nature and abundance of decomposing organisms (Côteaux et al. 1995, Jonsson and Wardle 2008). Plant-species composition affects ecosystem nutrient cycling through plant-nutrient uptake and use, amount and chemical composition of the leaf litter, rhizosphere interactions and microenvironmental changes (Hättenschwiler et al. 2005, Hättenschwiler and Gasser 2005). There is increasing interest in the interactions among litter types and their effects on decomposer-driven processes such as litter decomposition and nutrient mineralization (e.g. Blair et al. 1990, McTiernan et al. 1997, Wardle et al. 1997; reviewed by Gartner and Cardon 2004). In recent years, studies have revealed that the rates of mixed-litter mass loss may deviate greatly from those expected from the correspondent single-species litter decomposition rates. This was ascribed to non-additive effects of mixtures on mass loss, nutrient dynamics and decomposer associations compared to leaf litter of an individual species, resulting in enhanced decomposition in the mixture (e.g. Gartner and Cardon 2004, 
Brandtberg and Lundkvist 2004, Gnankambary et al. 2008, Harguindeguy et al. 2008). Studies using litterbag experiments on single- and mixed-species litter decomposition rates often neglected the influence of the decomposer fauna (mesofauna and especially macrofauna), although the interaction of the leaf litter composition with the soil fauna has been shown to alter the decomposition rates of the litter, as has been revealed by a number of studies (e.g. Seastedt 1984, Schädler and Brandl 2005, Hättenschwiler and Gasser 2005). The relationship between litter-species richness and decomposition rates or nutrient dynamics is thus difficult to predict with the identity and the functional traits of the species within a mixture possibly being more important than the mere number of species.

We studied the effects of tree species richness on species-specific and mixed-species litter decomposition and included the influence of mesofauna and macrofauna to investigate the mechanistic effects of the leaf-litter richness - decomposition effects. Our study has been conducted in the Hainich National Park, Central Germany, which is exceptionally rich in deciduous forest tree species regarding European standards (up to 14 tree species per hectare) within the framework of a long-term research project (Guckland et al. 2009, Leuschner et al. 2009). Along a gradient of a decreasing proportion of the European beech (Fagus sylvatica), the predominant tree species in temperate deciduous forests of Central Europe, plots with increasing numbers of five other broad-leaved tree species (Fraxinus excelsior, Tilia spp., Acer pseudoplatanus, Acer platanoides, and Carpinus betulus) where chosen.

The increasing abundance of leaf litter with higher degradability and better litter quality along the diversity levels can promote higher soil fauna diversity and create more favourable conditions for decomposition and nutrient release. Therefore, we hypothesized that (i) in mixed-species stands, the nutrient release rates will be higher than in pure beech stands, and (ii) nutrient release rates of the individual tree species will be higher in the multispecific stands compared to monospecific beech stands.

\section{Materials and Methods}

\section{Study area and sampling design}

We conducted the study in the Hainich National Park, Thuringia, Central Germany, in oldgrowth deciduous forest stands differing in tree species diversity. The forest stands are situated in the north-eastern part of the National Park at an elevation of about $350 \mathrm{~m}$ a.s.l. $\left(51^{\circ} 04^{\prime} \mathrm{N}, 10^{\circ} 30^{\prime} \mathrm{E}\right)$. The mean annual temperature is $7.5^{\circ} \mathrm{C}$. The mean annual precipitation ranges from $600 \mathrm{~mm}$ to $670 \mathrm{~mm}$, with approximately $65 \%$ falling during the 7 -months vegetation period. Soils are Luvisols with stagnic properties, developed from Pleistocene loess and underlain by limestone (Triassic Upper Muschelkalk formation) (FAO 2006). They 
are characterized by high silt contents (about 75\%) and have a loess cover of at least $60 \mathrm{~cm}$ (Guckland et al. 2009).

Three stand types differing in the diversity level (DL) of tree taxa were selected: one stand type with European beech ( $F$. sylvatica L., DL 1); one type of stand mainly consisting of beech, lime (Tilia cordata Mill. and Tilia platyphyllos Scop.) and ash (F. excelsior L.) (DL 2); and one stand type with beech, lime, ash, hornbeam (C. betulus L.) and maple (A. pseudoplatanus L. and A. platanoides L.) (DL 3) as the predominant tree taxa. Stand characteristics, including the proportion of the individual tree species in the canopy cover, are given in Table 1. At each diversity level (stand type), three plots with a central area of $50 \mathrm{~m} \times$ $50 \mathrm{~m}$ were fenced to exclude wild boar and game. All plots were comparable regarding slope, physical soil conditions and stand structure (Guckland et al. 2009). Within each plot, three $30-\mathrm{m}$ transects with two randomly selected subplots $(6 \mathrm{~m} \times 5 \mathrm{~m})$ were installed for vegetation studies and zoological investigations.

Table 1 Stand characteristics of the three diversity levels (DL) (means \pm 1 SE of three plots per DL). Different letters indicate significant differences between DL; $\mathrm{P}<0.05$.

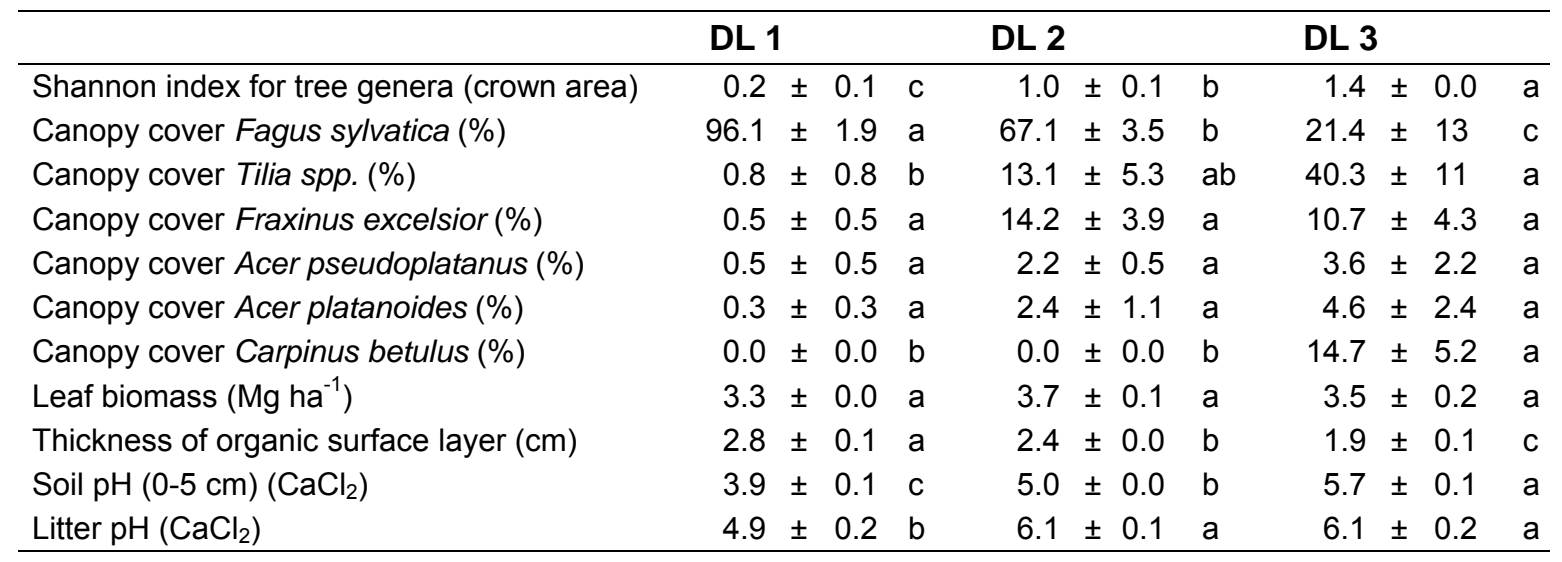

\section{Litter collection and litterbag construction}

At each site, freshly fallen leaves were collected with litter collectors (aperture: $0.29 \mathrm{~m}^{2}$ ) during peak litterfall in October 2005. The leaves were separated into species and oven-dried at $25{ }^{\circ} \mathrm{C}$ for two days, or until constant mass. Two types of litterbags were prepared: small litterbags with a size of $9 \mathrm{~cm} \times 11 \mathrm{~cm}$, and large litterbags with a size of $20 \mathrm{~cm} \times 20 \mathrm{~cm}$. Both litterbag types had a mesh size of $5 \mathrm{~mm}$. This mesh size allows macrofauna to enter the litterbags and we therefore measure leaf litter disappearance instead of the mere litter decomposition from the bags. Small litterbags were filled with $2 \mathrm{~g}( \pm 0.02 \mathrm{~g}$; exact mass determined with 2 decimals) of single-species leaves of F. sylvatica, F. excelsior, Tilia spp., C. betulus, $A$. pseudoplatanus and $A$. platanoides (mono litterbags) sampled from all plots of the trees' occurrence. Large litterbags were filled with $8 \mathrm{~g}( \pm 0.02 \mathrm{~g}$; exact mass determined 
with 2 decimals) of a litter mixture representative of the leaf litter composition of the respective plot at the end of October 2005 (mixed litterbags).

A total of 1944 mono and 324 mixed litterbags were deployed on $18^{\text {th }}$ of November 2005, whereas three litterbags per litterbag type were kept in the laboratory to determine the initial dry mass (oven-dried at $70^{\circ} \mathrm{C}$ ). Overall, 42 litterbags ( 6 tree species +1 mixed litterbag, for resampling on six dates) were randomly placed on each of the six subplots at the nine fenced plots. All litterbags were arranged in two rows on the litter layer surface and covered with freshly fallen leaves. Litterbags were collected in 2005 on $15^{\text {th }}$ December, in 2006 on $27^{\text {th }}$ March, $19^{\text {th }}$ June and $26^{\text {th }}$ September, and in 2007 on $24^{\text {th }}$ April and $18^{\text {th }}$ September. On every sampling date, six replicates of each type of litterbag were removed (one per subplot and site). Each resampled litterbag was brushed clear of external soil and litter and the litter of the mixed litterbags was separated into species. Litterbags were handled with great care during removal and each bag was carefully transported in a separate plastic bag to minimize the loss of small litter fragments from the litterbags. All leaves were oven-dried at $70^{\circ} \mathrm{C}$ and weighed. Mass loss was calculated as the difference between the initial dry mass and the actual dry mass of leaves at each sampling date. Due to the small sample amount, ash analysis could not be conducted. However, calculated k values for carbon disappearance did not change the results obtained for whole litter (mixed litterbags as well as single litter species).

\section{Physico-chemical analyses and microbial activity}

For each sampling date, total carbon and nitrogen contents were determined in pulverized litter material (Siebtechnik GmbH, TS 1000, Mühlheim an der Ruhr, Germany; 940 rpm) from all leaves of the litterbags (max $8 \mathrm{~g}$ ) by an automated $\mathrm{C}$ and $\mathrm{N}$ analyzer (Heraeus Elementar Vario EL, Hanau, Germany). Nutrient concentrations were analyzed by ICP-AES (Spectro, Kleve, Germany) after pressure digestion with nitric acid. We used $300 \mathrm{mg}$ sample material and $3 \mathrm{ml}$ of $65 \% \mathrm{HNO}_{3}$ in $50 \mathrm{ml}$ teflon containers. The material was digested for 10 hours at $180^{\circ} \mathrm{C}$. Samples were filtered and rinsed with double distilled $\mathrm{H}_{2} \mathrm{O}$ (final total extraction fluid: $100 \mathrm{ml})$.

On $11^{\text {th }}$ May 2005, $3^{\text {rd }}$ August 2005, $23^{\text {rd }}$ November 2005 and $23^{\text {rd }}$ February 2006, small litter and soil samples $\left(5 \mathrm{~cm}\right.$ depth) were taken to measure $\mathrm{pH}\left(\mathrm{CaCl}_{2}\right)$, moisture content and litter depth. The moisture content was determined gravimetrically for litter and soil separately. In addition, microbial biomass was determined by substrate-induced respiration (SIR; Anderson and Domsch 1978) using an $\mathrm{O}_{2}$ micro-compensation apparatus (Scheu 1992). Fresh material equivalent to $0.5 \mathrm{~g}$ (L/Of) and $5.0 \mathrm{~g}(\mathrm{Ah})$ dry weight was analyzed. $40 \mathrm{mg}$ of glucose were added to each sample and the microbial respiratory response was measured at hourly intervals for 20 hours at $22^{\circ} \mathrm{C}$. SIR results were converted to microbial biomass carbon $\left(C_{\text {mic }}\right)$ 
using the formula established for the respirometer system in use (Beck et al. 1997). Temperature $5 \mathrm{~cm}$ above ground was recorded continuously with one datalogger per plot (HOBO RH/Temp H08-32-08; Onset Computer Corporation, Bourne, USA). The annual mean was calculated for 2006.

\section{Soil fauna}

Soil cores (L/Of-layer plus the uppermost $5 \mathrm{~cm}$ of the mineral soil) with a diameter of $21 \mathrm{~cm}$ for the macrofauna and $5 \mathrm{~cm}$ for the mesofauna were taken from every subplot $(n=6$ per plot and soil fauna category). Each sample was separated into litter layer and mineral soil and animals were extracted by heat using a modified high-gradient canister method (Schauermann 1982). Slowly increasing heat from above $\left(20^{\circ} \mathrm{C}\right.$ up to $50^{\circ} \mathrm{C}$ (mesofauna) or $55^{\circ} \mathrm{C}$ (macrofauna) over 12 days) and steady cooling from the bottom create a temperature and desiccation gradient that drives the animals into a collecting vessel. The animals were captured in glycol and transferred to $70 \%$ alcohol after extraction. The individuals were counted and we calculated the annual mean (numbers were given in individuals per $\mathrm{m}^{2}$ ). Our focus was on Collembola and Acari, main groups of the soil mesofauna, and Isopoda and Lumbricidae, main groups of the soil macrofauna. All these groups influence decomposition processes via grazing on the microflora and macrofauna groups additionally contribute to the breakdown of leaf litter (Schaefer 1990).

\section{Calculation of decomposition rates and statistical analysis}

Mass loss is expressed as the percentage of total initial dry mass, and litter chemistry data are expressed as the percentage of total leaf dry mass. We used a graphical method and modelled the best fit for each decay curve. Overall, exponential models had the highest $\mathrm{R}^{2}$ values. However, as residuals showed no trend, the use of linear models would also be possible. We determined the decomposition rates $(k)$ for each litter species by fitting exponential curves to remaining litter mass over 1.83 years (22 months). For a better comparison with other studies, we calculated 'annual k-values' with $t=1$ for one year as:

$$
M_{t}=M_{0} * e^{-k t} \text {. }
$$

Nutrient release in $\%$ was calculated as:

$$
\left(C_{0} \times M_{0}\right) /\left(C_{t} \times M_{t}\right) \times 100
$$

where $M_{t}$ is the dry mass of the decomposed leaf litter at time $t, M_{0}$ is the initial dry mass of the litter, $C_{0}$ is the initial concentration of the nutrient, and $C_{t}$ is the concentration of the nutrient at sampling time $t$.

Statistical analyses were conducted using SAS 9.1 (SAS Institute Inc., Cary, NC, USA), and Statistica 8.0 (StatSoft Inc., Tulsa, OK, USA). If not stated otherwise, means and standard 
errors of 3 plots per diversity level were calculated. To examine differences among the diversity levels (DL 1 - 3), we used a Kruskal-Wallis single factor analysis of variance followed by non-parametric Mann-Whitney two sample U-tests ( $p<0.05$ in all analyses). Relationships between the decomposition rate as the dependent variable and the predictor variables tree diversity (Shannon index), litter layer thickness, $\mathrm{pH}$ and water content of litter and soil, microbial biomass in litter and soil, earthworm abundance and woodlice (isopod) abundance were analyzed using Spearman's rank correlation. The correlation analysis was performed with mean values of the individual tree species (mono bags) from all nine plots. Correlations of the length of time lag before $\mathrm{N}$ release (days of incubation time) with initial $\mathrm{C} / \mathrm{N}, \mathrm{C} / \mathrm{P}$ and N/P ratios and fauna abundances were conducted using data from all nine plots. We are aware that our statistical approach involves the risk of type I error inflation, and would have called for some kind of Bonferroni-correction. This is, however, under heavy discussion and may lead to overly conservative tests (Garcia 2004, Roback and Askins 2005). Due to the exploratory nature of our studies, we thus used raw p-values, but discuss these with some caution.

\section{$\underline{\text { Results }}$}

\section{Litter decomposition}

In the tree species studied, the litter decay exhibited a negative exponential course except for Fagus, whose litter was decomposed at an almost linear rate. After seven (mono litterbags) and ten (mixed litterbags) months of incubation, the decomposition of Fagus litter was significantly higher at DL 3 compared to DL 1 and DL 2 (Fig. 1).

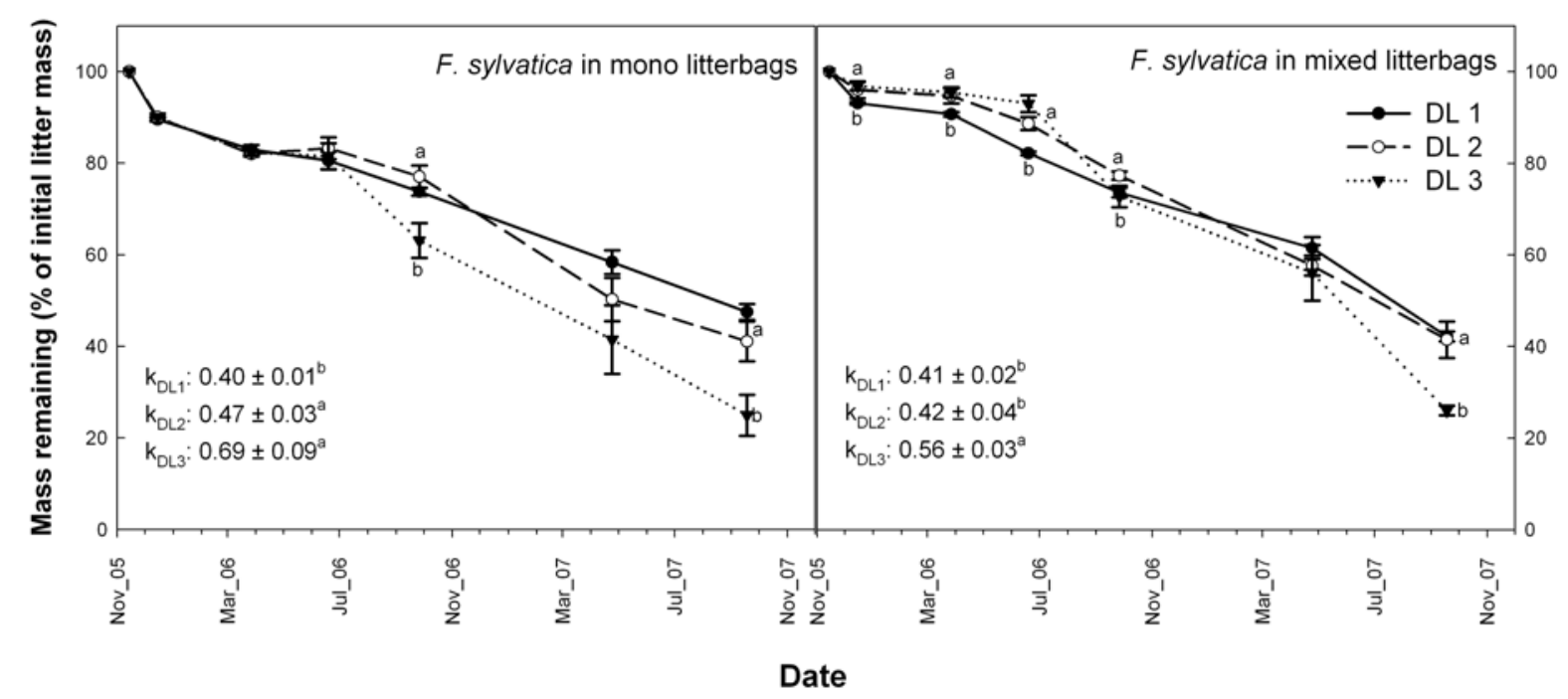

Fig. 1 Mass loss and decay constant $\mathrm{k}\left(\mathrm{y}^{-1}\right)$ of Fagus sylvatica in mono litterbags and mixed litterbags in different diversity levels $(D L)$ (means \pm 1 SE of three plots per $D L$ ). Different letters indicate significant differences between the $\mathrm{DL}(\mathrm{P}<0.05)$. 
For the entire investigation period, Fagus had the lowest $\mathrm{k}$ values (approximately 0.6), followed by Acer spp., Tilia spp., C. betulus and F. excelsior (Fig. 1, 2). Significant differences between the different diversity levels were found for all tree species, except for F. excelsior, with significantly higher decomposition rates at DL 3 compared to DL 1 . The mixed-species litterbags exhibited a significantly higher mass loss at the mixed species stands DL 2 and DL 3 (Fig. 2). After 7 months, all three diversity levels differed significantly. At the end of the experiment (after 22 months), $60 \%$ of the initial litter mass at the beechdominated DL 1 stands and $90 \%$ of the initial litter mass at the highly diverse mixed-species stands (DL 3) were decomposed or removed from the bags.

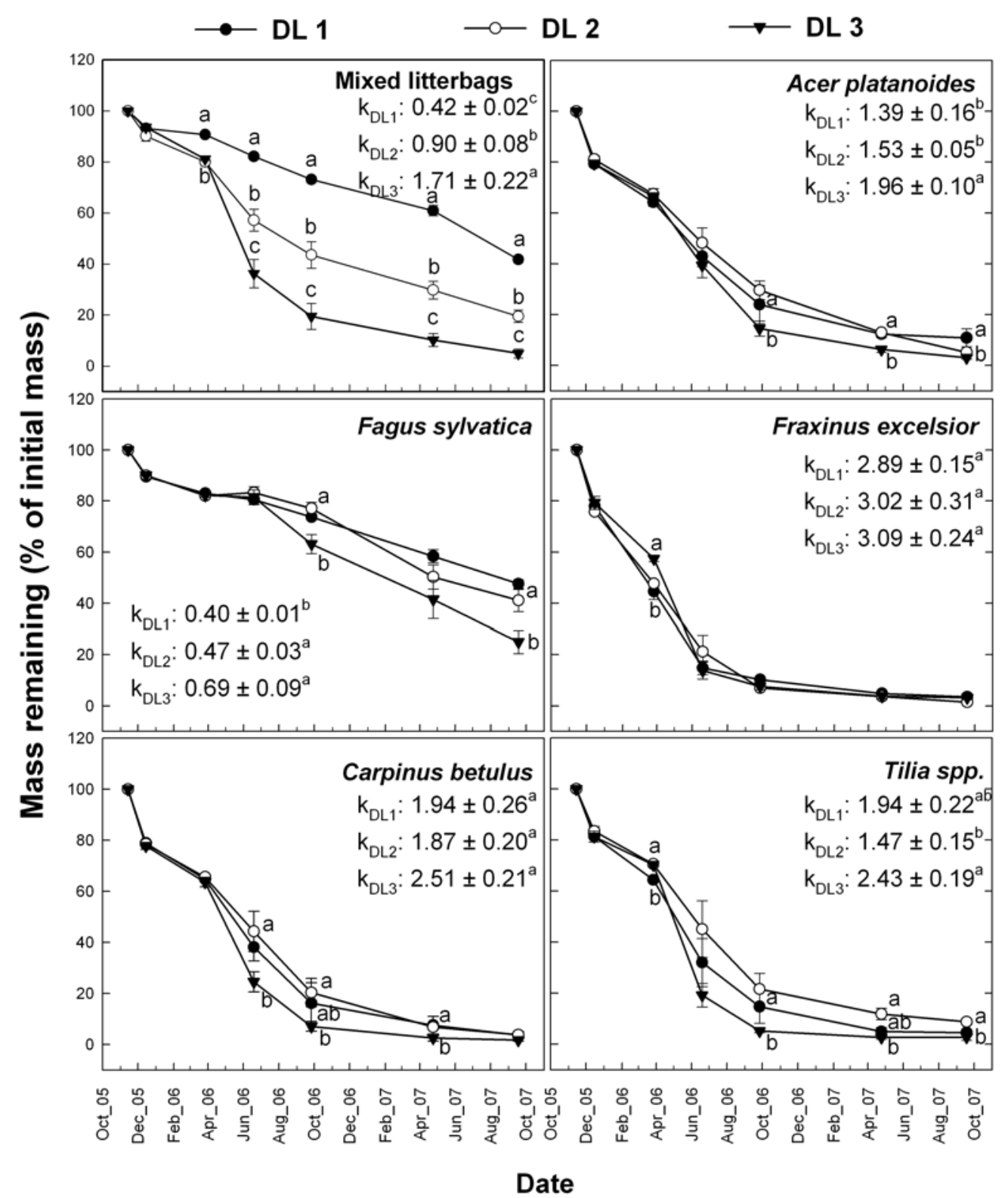

Fig. 2 Mass loss and decay constant $\mathrm{k}\left(\mathrm{y}^{-1}\right)$ of mixed litterbags and five studied tree species in different diversity levels (DL). Given are mean of three plots and standard error. Different letters indicate significant differences between the $D L(P<0.05)$. 


\section{Soil fauna and microbial biomass}

In the beech-dominated DL 1 stands, we found almost the threefold amount of mesofauna compared to DL 3 (Table 2). In contrast, macrofauna significantly increased with increasing tree species diversity due to the double number of Lumbricidae and the fourfold number of Isopoda at DL 3 compared to DL 1 . In the uppermost $5 \mathrm{~cm}$ of the soil, microbial biomass was significantly lower in the DL 1 stands compared to the other stand types. However, microbial biomass was not different in the leaf litter layer of all stands.

Table 2 Microbial biomass ( $\mathrm{mg} \mathrm{C}_{\text {mic }} \mathrm{g}^{-1} \mathrm{dm}^{-1}$ ) and decomposer fauna abundances (individuals $\mathrm{m}^{-2}$ ). Given are annual means of three plots and standard error. Different letters indicate significant differences between diversity levels $(P<0.05)$.

\begin{tabular}{|c|c|c|c|c|c|c|c|c|c|c|c|c|}
\hline & DL 1 & & & & DL 2 & & & & DL 3 & & & \\
\hline \multicolumn{13}{|l|}{ Microflora } \\
\hline Litter layer & 10020 & \pm & 638 & $\mathrm{a}$ & 10588 & \pm & 425 & a & 9886 & \pm & 307 & a \\
\hline Soil $(5 \mathrm{~cm})$ & 596 & \pm & 94 & $b$ & 886 & \pm & 55 & $a$ & 1068 & \pm & 68 & a \\
\hline \multicolumn{13}{|l|}{ Mesofauna } \\
\hline Collembola & 90708 & \pm & 7364 & $a$ & 52802 & \pm & 8125 & $\mathrm{~b}$ & 34167 & \pm & 8878 & $b$ \\
\hline Acari & 123454 & \pm & 11690 & a & 47500 & \pm & 3904 & $b$ & 36309 & \pm & 2161 & $b$ \\
\hline \multicolumn{13}{|l|}{ Macrofauna } \\
\hline Isopoda & 107 & \pm & 36 & $b$ & 314 & \pm & 73 & a & 410 & \pm & 17 & a \\
\hline Lumbricidae & 125 & \pm & 17 & $\mathrm{~b}$ & 105 & \pm & 15 & $\mathrm{~b}$ & 210 & \pm & 15 & a \\
\hline
\end{tabular}

\section{Element concentrations, element ratios and nutrient release rates}

Leaf litter of $F$. sylvatica displayed lower concentrations of most nutrients and higher Crelated ratios than the other tree species (Table 3). The highest $\mathrm{N}$ and $\mathrm{P}$ concentrations of the leaf litter were found in Fraxinus. A. pseudoplatanus leaf litter was rich in $\mathrm{Ca}$ and $\mathrm{Mg}$. Tilia, Carpinus and $A$. platanoides had intermediate nutrient concentrations, except for high $\mathrm{K}$ values in A. platanoides.

Table 3 Initial nutrient concentrations (mg gDM-1) of tree litter of all main tree species (mono litterbags, $N=1$ ) and mixed litterbags (means $\pm 1 \mathrm{SE}, \mathrm{N}=3$ ).

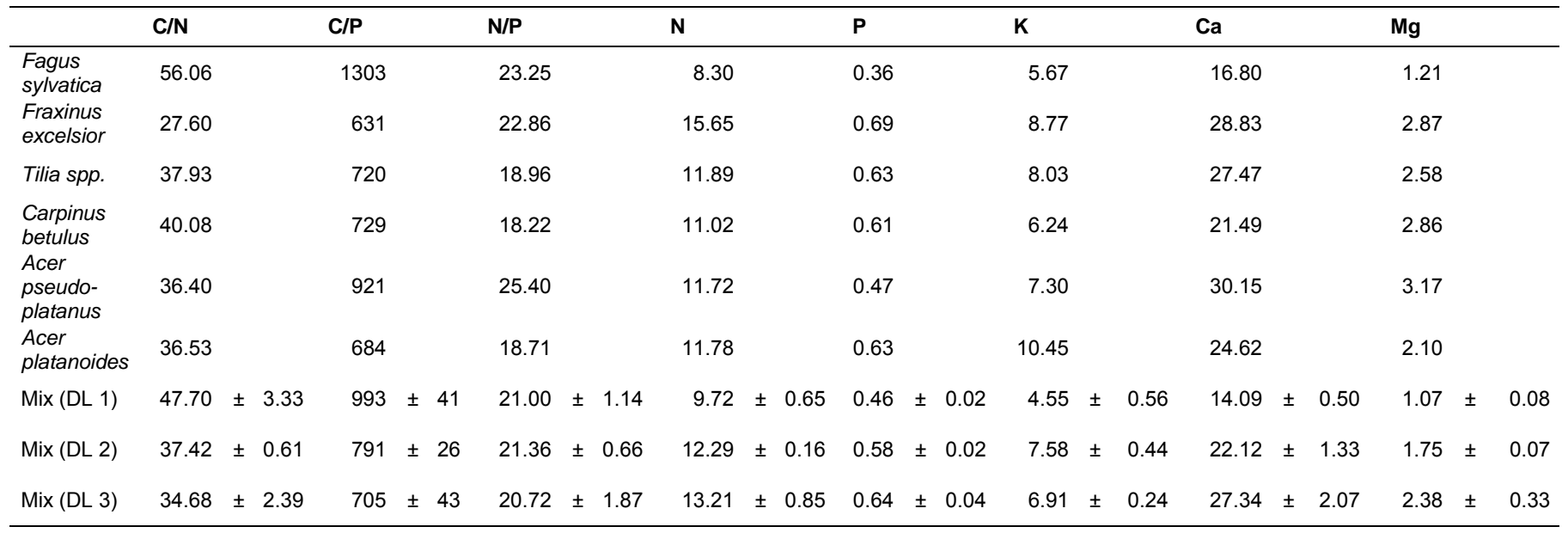


The changes in the amounts and ratios of nutrients during the 22 months of incubation time relative to the initial values are presented in Figs. 3 and 4 . We do not show values for all tree species studied, as curves for $A$. platanoides and $A$. pseudoplatanus were very similar, and C. betulus showed patterns very similar to the fast decomposing Tilia species. For most nutrients and tree species, we found an exponential nutrient release right from the beginning of leaf litter decomposition. For $\mathrm{N}$ and $\mathrm{P}$, nutrient accumulation (immobilization) was found in F. sylvatica and to a smaller extent also in Tilia (Fig. 3). In Fagus, N and P amounts decreased during the first few months at DL 1 and DL 2 and increased afterwards to maximum values of $140 \%$ to $200 \%$. Finally, a decrease started 7 to 10 months after incubation until the values levelled off. The $C / N$ and $C / P$ ratios showed a steep linear decrease during the first year of decomposition and were almost constant in the second year. Differences between DL did not occur in Fagus, but most of the other species had lower $\mathrm{C} / \mathrm{N}$ and C/P values in DL 1 and DL 2 stands compared to DL 3 stands.

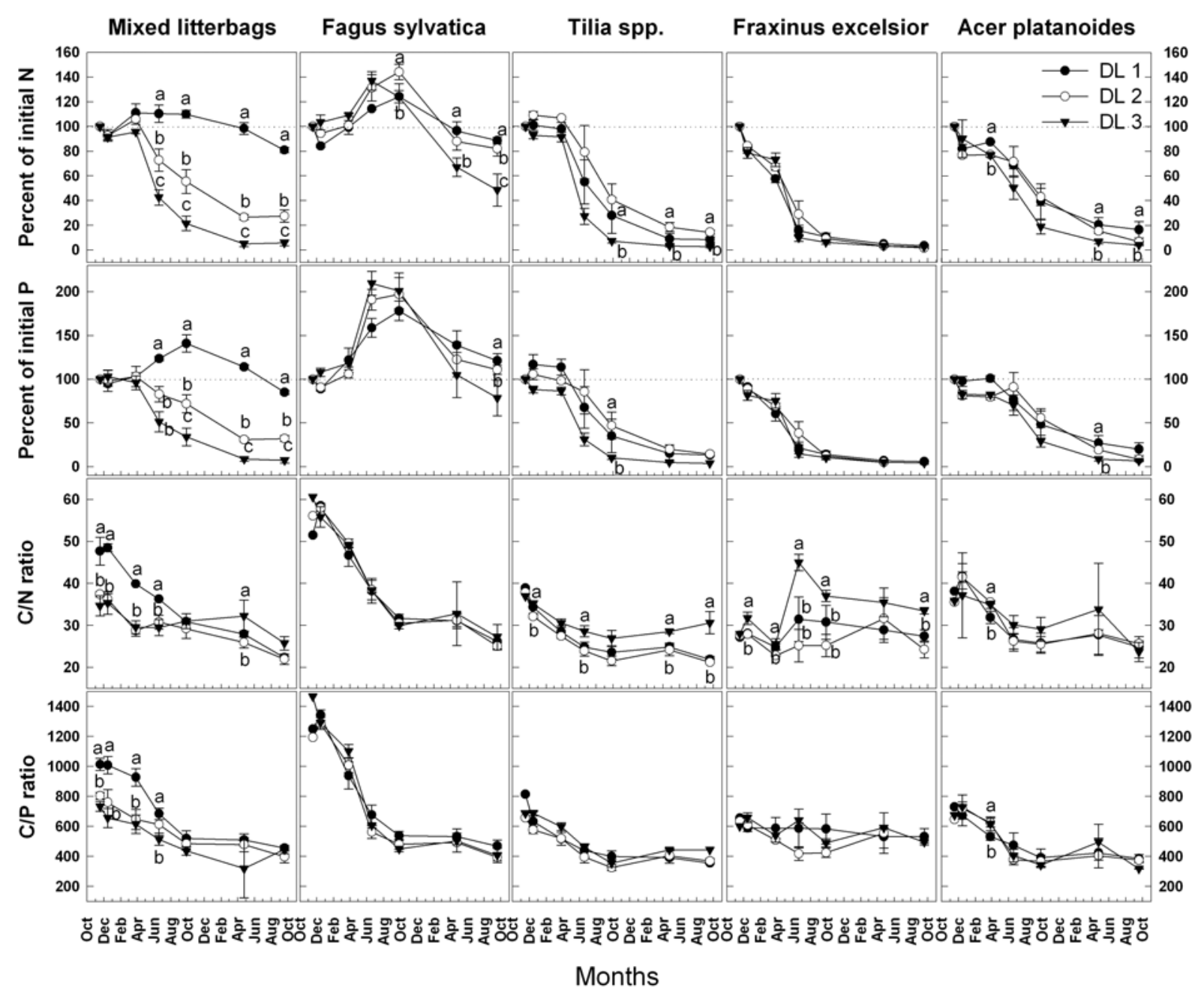

Fig. 3 Remaining amounts of $N$ and $P$ relative to the initial values, and changes in the $C: N$ and $C: P$ ratios $\left(g^{-1}\right)$, in mixed and mono litterbags (containing litter of individual tree species) during decomposition (means \pm 1 SE of three plots per $\mathrm{DL})$. 
The release rates of $\mathrm{K}, \mathrm{Mg}$ and $\mathrm{Ca}$ were high in all tree species and particularly high in Fraxinus (Fig. 4). In mixed litterbags, patterns of nutrient release were shaped by the predominant tree species. In DL 1, which consisted of almost pure beech leaf litter, patterns were similar to Fagus. DL 2 and DL 3 values decreased after four months according to their main components Tilia and Fraxinus.

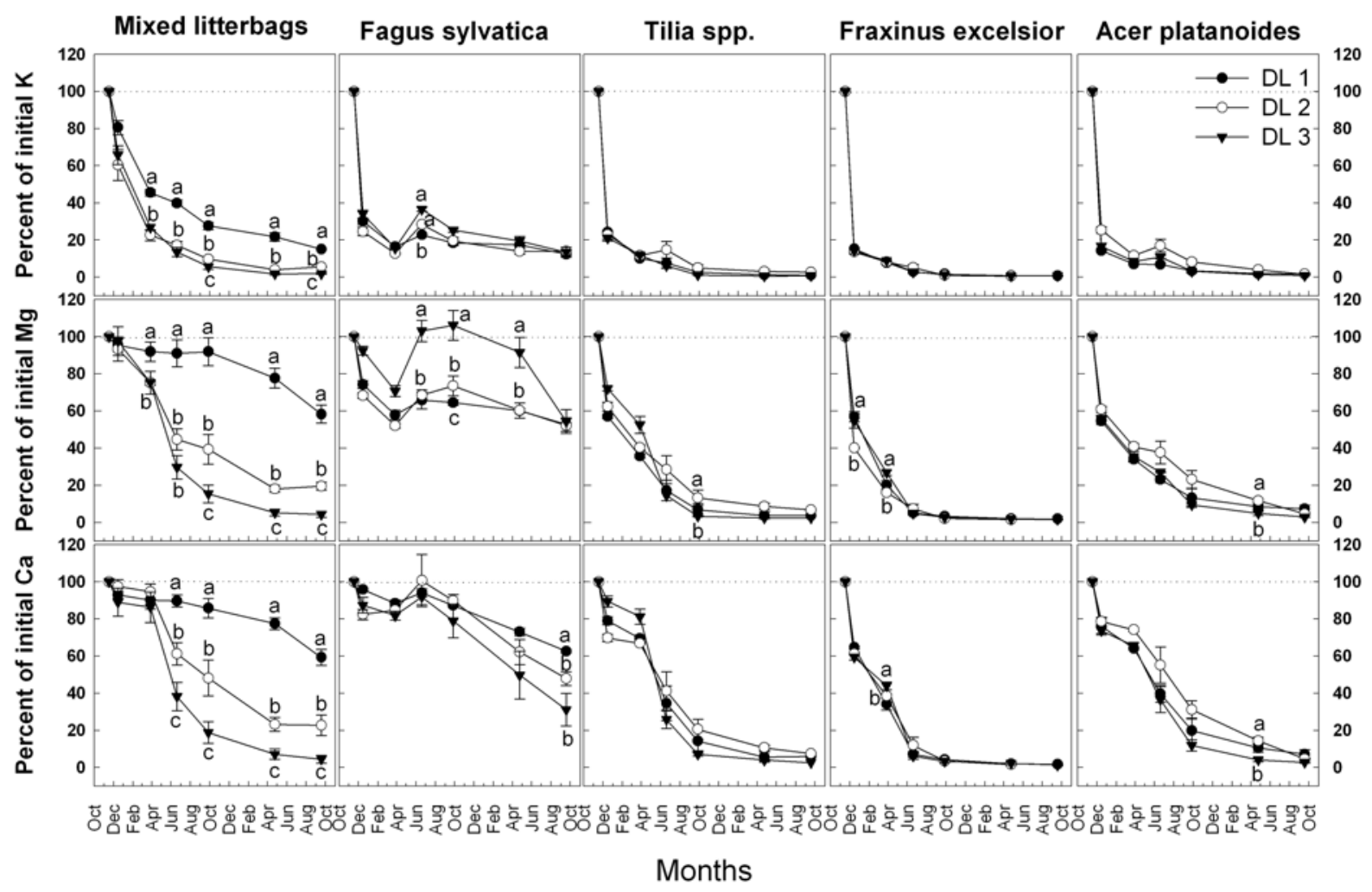

Fig. 4 Remaining amounts of $\mathrm{Na}, \mathrm{Mg}$, and $\mathrm{Ca}$ relative to the initial values in mixed and mono litterbags (containing litter of individual tree species) during decomposition (means \pm 1 SE of three plots per $\mathrm{DL}$ ).

\section{Effects of site factors, soil biota and nutrient concentrations of the litter on litter decomposition and nutrient release}

The decomposition rate constant $\mathrm{k}$ of Fagus, $A$. pseudoplatanus and $A$. platanoides correlated positively with the Shannon index of the crown area, the $\mathrm{pH}$ values of the topsoil and correlated negatively with the litter layer thickness (Table 4). There was no relationship between $\mathrm{k}$ and the $\mathrm{pH}$ value of the organic surface layer. In the litter of most tree species, $\mathrm{k}$ was positively correlated with the abundance of Lumbricidae, but only the decay of Fagus litter was correlated with the abundance of Isopoda. Fraxinus was the only tree species whose $\mathrm{k}$ values did not correlate with any predictor variable. In general, the high $\mathrm{k}$ values of Fraxinus, Tilia and Carpinus did not or only weakly correlate with the predictor variables, whereas the $\mathrm{k}$ values of the more slowly decomposing litter of $A$. pseudoplatanus and $A$. platanoides were more dependent on environmental variables. In particular, the $k$ value of 
the very slowly decomposing Fagus litter was also negatively correlated with the thickness and the water content of the litter layer and the microbial biomass in the soil.

Table 4 Influence of environmental variables on the decomposition rate k of the litter species studied. Spearman's rank correlation coefficients for decomposition constants $k\left(y^{-1}\right)$ of single tree species and mixtures $(N=9)$.

\begin{tabular}{|c|c|c|c|c|c|c|c|c|c|c|}
\hline & $\begin{array}{l}\text { Shannon } \\
\text { Index } \\
\text { (crown area) }\end{array}$ & $\begin{array}{c}\text { Thickness } \\
\text { litter layer } \\
(\mathrm{cm})\end{array}$ & Litter $\mathrm{pH}$ & $\begin{array}{l}\text { Soil pH } \\
(0-5 \mathrm{~cm})\end{array}$ & $\begin{array}{c}\text { Litter layer } \\
\text { water } \\
\text { content } \\
(\%\end{array}$ & $\begin{array}{l}\text { Soil water } \\
\text { content } \\
\text { dm) }\end{array}$ & $\begin{array}{c}\text { Microbial } \\
\text { biomass } \\
\text { (litter) } \\
\quad(\mu \mathrm{g} \mathrm{C} \text { m }\end{array}$ & $\begin{array}{l}\text { Microbial } \\
\text { biomass } \\
(\text { soil }) \\
\left.\mathrm{dm}^{-1}\right)\end{array}$ & $\begin{array}{l}\text { Lumbricidae } \\
\text { abundance } \\
\text { (ind }\end{array}$ & $\begin{array}{l}\text { Isopoda } \\
\text { abundance } \\
\mathrm{m}^{2} \text { ) }\end{array}$ \\
\hline Fagus sylvatica & $0.93^{\star *}$ & $-0.93^{\star *}$ & 0.62 & $0.83^{*}$ & $0.68^{*}$ & 0.43 & -0.18 & $0.82^{*}$ & 0.42 & $0.82^{*}$ \\
\hline Fraxinus excelsior & 0.38 & -0.38 & 0.32 & 0.15 & 0.25 & -0.28 & -0.13 & 0.05 & -0.20 & 0.13 \\
\hline Tilia spp. & 0.42 & -0.42 & -0.22 & 0.35 & -0.18 & -0.03 & -0.43 & 0.32 & $0.88^{\star *}$ & 0.15 \\
\hline Carpinus betulus & 0.53 & -0.53 & -0.05 & 0.40 & -0.10 & -0.07 & -0.18 & 0.35 & $0.75^{*}$ & 0.17 \\
\hline $\begin{array}{l}\text { Acer } \\
\text { pseudoplatanus }\end{array}$ & $0.73^{*}$ & $-0.73^{*}$ & 0.23 & $0.67^{*}$ & 0.25 & 0.27 & -0.22 & 0.57 & $0.88^{\star *}$ & 0.43 \\
\hline Acer platanoides & $0.73^{*}$ & $-0.73^{*}$ & 0.25 & $0.67^{*}$ & 0.18 & 0.05 & -0.32 & 0.58 & $0.87^{\star *}$ & 0.43 \\
\hline Mixed litterbags & $0.97^{* * *}$ & $-0.97^{* * *}$ & 0.61 & $0.93^{* * *}$ & 0.63 & 0.35 & -0.33 & $0.82^{\star *}$ & $0.68^{*}$ & $0.75^{*}$ \\
\hline
\end{tabular}

In the litter of the individual tree species as well as in the litter mixtures, the temporal patterns of nutrient release were correlated with the initial $\mathrm{C}$ - and $\mathrm{N}$-related ratios and the abundance of Collembola, Acari, Lumbricidae and Isopoda (Table 5).

Table 5 Influence of environmental variables on the temporal pattern of nitrogen and phosphorus release of the litter species studied. Spearman's rank correlation coefficients (rho), $\mathrm{N}=9$.

\begin{tabular}{|c|c|c|c|c|c|c|c|}
\hline & $\begin{array}{l}\text { Initial } \\
\text { C:N } \\
\left(\mathrm{g} \mathrm{g}^{-1}\right)\end{array}$ & $\begin{array}{c}\text { Initial } \\
\text { C:P } \\
\left(\mathrm{g} \mathrm{g}^{-1}\right)\end{array}$ & $\begin{array}{c}\text { Initial } \\
\mathrm{N}: \mathrm{P} \\
\left(\mathrm{g} \mathrm{g}^{-1}\right)\end{array}$ & $\begin{array}{c}\text { Collembola } \\
\text { abundance } \\
\text { (ind } \mathrm{m}^{-2} \text { ) }\end{array}$ & $\begin{array}{c}\text { Acari } \\
\text { abundance } \\
\text { (ind } \mathrm{m}^{-2} \text { ) }\end{array}$ & $\begin{array}{l}\text { Lumbricidae } \\
\text { abundance } \\
\text { (ind } \mathrm{m}^{-2} \text { ) }\end{array}$ & $\begin{array}{c}\text { Isopoda } \\
\text { abundance } \\
\text { (ind } \text { m }^{-2} \text { ) }\end{array}$ \\
\hline \multicolumn{8}{|c|}{ Fagus sylvatica } \\
\hline $\mathrm{N}$ & $-0.87^{\star *}$ & $-0.87^{\star *}$ & 0.00 & $0.73^{*}$ & $0.73^{*}$ & $-0.82^{\star *}$ & -0.64 \\
\hline$P$ & -0.33 & 0.00 & 0.33 & 0.62 & 0.52 & -0.21 & -0.10 \\
\hline \multicolumn{8}{|c|}{ Fraxinus excelsior } \\
\hline $\mathrm{N}$ & $0.82^{\star *}$ & $-0.82^{\star *}$ & $-0.82^{\star *}$ & -0.61 & $-0.69^{*}$ & $0.69^{*}$ & 0.61 \\
\hline$P$ & $0.86^{* *}$ & $-0.86^{* *}$ & $-0.86^{* *}$ & $-0.73^{*}$ & $-0.73^{*}$ & $0.82^{* *}$ & 0.64 \\
\hline \multicolumn{8}{|c|}{ Tilia spp. } \\
\hline $\mathrm{N}$ & 0.00 & -0.65 & -0.65 & 0.10 & 0.10 & -0.52 & 0.31 \\
\hline$P$ & -0.22 & $-0.72^{*}$ & $-0.72^{*}$ & -0.20 & -0.20 & -0.19 & 0.52 \\
\hline \multicolumn{8}{|c|}{ Carpinus betulus } \\
\hline $\mathrm{N}$ & -0.58 & 0.29 & 0.29 & 0.46 & 0.46 & $-0.73^{*}$ & -0.09 \\
\hline$P$ & -0.29 & 0.06 & 0.06 & 0.48 & 0.48 & -0.48 & -0.02 \\
\hline \multicolumn{8}{|c|}{ A. pseudoplatanus } \\
\hline $\mathrm{N}$ & -0.29 & 0.29 & 0.29 & 0.46 & 0.27 & -0.46 & -0.18 \\
\hline$P$ & -0.24 & 0.24 & 0.24 & 0.60 & 0.54 & $-0.82^{* *}$ & -0.19 \\
\hline \multicolumn{8}{|c|}{ Mixed litterbags } \\
\hline $\mathrm{N}$ & 0.59 & $0.71^{*}$ & 0.37 & 0.64 & 0.64 & -0.25 & $-0.73^{*}$ \\
\hline $\mathrm{P}$ & $0.69^{*}$ & 0.61 & -0.17 & $0.78^{*}$ & $0.87^{\star *}$ & -0.52 & -0.52 \\
\hline
\end{tabular}


In Fagus and Fraxinus, the length of the time lag before $N$ release was significantly correlated with the initial $\mathrm{C} / \mathrm{N}$ and $\mathrm{C} / \mathrm{P}$ ratios of the litter (and with the initial N/P ratio in the case of Fraxinus). The other tree species showed no significant correlation between the length of the time lag before $\mathrm{N}$ release and initial nutrient ratios of the litter. In the litter mixtures, the duration of the lag phase was only correlated with the litter's initial $\mathrm{C} / \mathrm{N}$ ratio. The temporal pattern of $P$ release was correlated with initial $C / N, C / P$ and N/P ratios in Fraxinus, initial $\mathrm{C} / \mathrm{P}$ and N/P ratios in Tilia and the initial $\mathrm{C} / \mathrm{N}$ ratio of the litter mixture. With regard to $P$ release, we found no such correlations in Fagus.

\section{$\underline{\text { Discussion }}$}

\section{Species richness effects on decomposition and nutrient release}

Litterbags with stand-specific (of up to six tree species) litter mixtures decomposed significantly faster with increasing tree species richness. This finding is in accordance with about half of all mixed litterbag studies, which found rates of mass loss being higher in litter mixtures than in single species litter despite unaltered climatic conditions and litter chemistry (Gartner and Cardon 2004, Hättenschwiler et al. 2005). It should be noted, however, that in the majority of the litter mixture experiments, the mixtures are composed of equal amounts of the individual litter species, whereas in our study, we used site-representative mixtures that contained unequal amounts of litter from the individual tree species. These differences in the approach put the comparability of the results into perspective.

In a comparable study, Hättenschwiler and Gasser (2005) observed a significantly increased mass loss from litter mixtures (on average, $10 \%$ compared with the predicted values from the corresponding monocultures) of up to six tree species that included most of the species investigated in the present study. Previous studies in the area have shown a significant impact of tree species richness on chemical soil properties such as soil $\mathrm{pH}$, base saturation and cation exchange capacity, with lowest values in the monospecific stands (Guckland et al. 2009). These effects were correlated to the gradient of beech abundance along the forest stands.

Generally, microorganisms are important controllers of decomposition and mineralization (Lavelle and Spain 2001), but the meso- and macrofauna affect these processes through their grazing pressure on the microflora (Schaefer 1990, Kautz and Topp 2000, Cragg and Bargett 2001). In our study, we found a lower $\mathrm{pH}$, a lower microflora biomass in the upper soil, a thicker litter layer and significantly higher mesofauna abundance in the beech stands compared to the mixed-species stands. A litter layer being thicker throughout the year is an important habitat for soil fauna and keeps moisture as well as temperature rather constant. The reduced thickness of the litter layer, in combination with a high earthworm feeding 
activity, is probably an important reason for the low number of the mesofauna on the diverse stands (cf. Maraun et al. 2003).

Macrofauna presence can change not only litter mass loss, but most importantly, the relationship between litter mass loss and litter diversity can be strongly influenced by animals (Hättenschwiler and Gasser 2005). Earthworms additionally influence decomposition and mineralization through structural impacts on the litter and soil matrix (Marhan and Scheu 2006, Postma-Blaauw et al. 2006). Comparing the decomposition of different litter mixtures, Schädler and Brandl (2005) found a large influence of the fauna on decomposition, although the effect changed with litter type. The positive effects of the soil fauna on decomposition were highest in $\mathrm{N}$ rich and $\mathrm{C}$ poor litter. The significantly higher decay rate in the more diverse forest stands of our study was probably due to the combined effect of higher earthworm abundance, better litter quality and elevated soil $\mathrm{pH}$ values. The influence of litterfeeding soil animals on litter diversity could be driven by changing feeding rates as a function of litter diversity, by indirect effects on microbial or mesofauna communities, or a combination of both (Hättenschwiler and Gasser 2005).

Increasing species richness may not affect decomposition if litter mixtures are composed of chemically similar species. In contrast, litter mixtures composed of chemically diverse species may exhibit significant effects on decomposition, due to the positive correlation between plant species richness and increased diversity of litter compounds. Meier and Bowman (2008) found that the chemical composition of the litter mixtures was the strongest predictor of soil respiration, net $\mathrm{N}$ mineralization, and microbial biomass $\mathrm{N}$. In our study, the release dynamics of all nutrients differed significantly between the diversity levels. We found lower potassium $(\mathrm{K})$ and magnesium $(\mathrm{Mg})$ release rates in the monospecific stands compared to the mixed species stands. Mg concentration of the leaf litter are strongly dependent on soil properties and bedrock type (Berg and Laskowski 2006) and lower stocks of exchangeable Mg were measured in the topsoil of the DL1 stands (Guckland et al. 2009).

\section{Species identity effects on decomposition and nutrient release}

We found significant differences between the three diversity levels regarding the decomposition rates of the litter from individual tree species, but - in contrast to our hypothesis - not for the nutrient release rates.

In our study, the annual $k$ values of beech litter ranged from 0.4 to 0.7 and were similar to data from the literature: decomposition studies on soils with $\mathrm{pH} 3-4$ yielded annual $\mathrm{k}$ values between 0.18 and 0.3 (e.g. Albers et al. 2004, Enriquez et al. 1993, Irmler 2000, Hobbie et al. 2006), and rich mull sites with higher $\mathrm{pH}$ values exhibited $\mathrm{k}$ values of 0.5-0.8 (e.g. Seastedt 1984, Schaefer 1990). Hättenschwiler and Gasser (2005) found that decomposition of relatively recalcitrant litter from species such as Fagus is accelerated when other species are 
present, but accompanying litter species are of limited importance for changing the mass loss of more rapidly decomposing species. In Fagus, the only tree species occurring in all forest stands of this study, we found no acceleration of decomposition in mixed litterbags compared to mono litterbags.

Litter quality of the individual tree species differed particularly between the recalcitrant Fagus leaves and the fast decomposing litter of Fraxinus, Tilia and Carpinus. The typical triphasic pattern of $\mathrm{N}$ leaching, microbial immobilization and mineralization (Berg and McClaugherty 2008) was only found in F. sylvatica and - to a small extent - in Acer species. In Tilia, Fraxinus and Carpinus, we observed an immediate $\mathrm{N}$ release after incubation and no mineralization. We possibly could not observe the initial leaching or a mineralization for fast decomposing litter, as incubation of one month for fast decomposing might be too long.

The point at which $\mathrm{N}$ release from litter begins has often been related to a particular or "critical" $\mathrm{C} / \mathrm{N}$ ratio or $\mathrm{N}$ concentration of the litter ( $\mathrm{C} / \mathrm{N}$ ratio of $25-30$, initial $\mathrm{N}$ concentration of $20 \mathrm{mg} \mathrm{g}^{-1}$ as a threshold for net accumulation or net release of $\mathrm{N}$ ) (Berg and Laskowski 2006, Moore et al., 2006). However, critical $\mathrm{C} / \mathrm{N}$ ratios appear to vary with the ecosystem and the studied tree species. Berg and McClaugherty (1987) found that $\mathrm{N}$ release can start at $\mathrm{C} / \mathrm{N}$ ratios between 29 and 80 , and concluded that the $\mathrm{C} / \mathrm{N}$ ratio is not a good predictor for the onset of net $\mathrm{N}$ release from decomposing litter. In our study, $\mathrm{N}$ release from Fagus litter started earlier in the highly diverse stands (DL 3) - with initial litter $\mathrm{C} / \mathrm{N}$ ratios of about 35 in the mixed litterbags - than in the pure and intermediately diverse stands of DL 1 and DL 2 with initial $\mathrm{C} / \mathrm{N}$ ratios of 40 to 50 in the mixed litterbags. The limited predictive power of the nutrient ratios may be due to the fact that they do not consider the quality of the $\mathrm{C}$ and $\mathrm{N}$ constituents of the litter.

In contrast to many other studies and tree species, we found no or only little accumulation of calcium $(\mathrm{Ca})$ in the leaf litter but a fast $\mathrm{Ca}$ release from the litter of Tilia, Fraxinus and $A$. platanoides. $\mathrm{Ca}$ is known to be part of the structural plant tissue, hence its release is related to the second decomposition phase (Blair 1988, Laskowski et al. 1995). In our study, Ca release differed between tree species but not between the diversity levels (except for Fagus after 22 months). In a previous analysis, we found decomposition rates to be positively correlated with the initial Ca concentration of the litter (Jacob et al. submitted for publication). In the present study, Ca release rates are also highest in the species with the highest initial Ca concentration (Fraxinus, Tilia, Acer) and slowest in Fagus, a tree species with a low initial Ca concentration of the litter.

In a recent common garden experiment with 14 different tree species (including most tree species of our study), Reich et al. (2005) found that Lumbricus terrestris was more abundant in plots of trees with a high $\mathrm{Ca}$ content, which, in turn, was most important for the decomposition rate. This was also found in our study, with the highest earthworm 
abundance, highest decomposition rates and the Ca-rich litter being present in the mixed species stands. An exclusion experiment by Staaf (1987) demonstrated the strong influence of earthworms on litter decomposition, which we could confirm in our study for all tree species studied except Fagus and Fraxinus: the decomposition rate constant k of Tilia, Acer and Carpinus leaf litter as well as of the litter mixtures were positively correlated to earthworm abundance. This is consistent with findings of Hättenschwiler and Gasser (2005) showing earthworms as an important factor in determining mass loss of more rapidly decomposing leaf litter species (Tilia, Carpinus, Prunus). On the other hand, we found an overall close correlation between the decomposition rate of $F$. sylvatica litter and isopod abundance. Isopods have also been found to be positively correlated with beech litter mass loss rates in a pure beech forest. In the same study, lumbricids even showed a negative correlation to the decay rate of beech leaf litter (Irmler 2000).

From our results, we can infer mechanistic interactions among litter quality, soil conditions, effects of soil biota and decomposition rates as follows: the European beech, which tolerates a broad range of exchangeable $\mathrm{Ca}, \mathrm{Mg}$ and $\mathrm{K}$ as well as of $\mathrm{pH}$ values in the soil (Leuschner et al. 2006), produces litter with low concentrations of $\mathrm{N}, \mathrm{Ca}$ and $\mathrm{Mg}$ and wide $\mathrm{C} / \mathrm{N}$ ratios. The resulting low litter quality prevents the establishment of large populations of lumbricids, which prefer litter with high $\mathrm{Ca}$ concentrations and small $\mathrm{C} / \mathrm{N}$ ratios. Low densities of these soil biota result in lower rates of litter decomposition and nutrient release. In combination with the low $\mathrm{Ca}$ and $\mathrm{Mg}$ concentrations of the litter, the slower release rates of these "base" cations lead to a more intense acidification of the beech stands' topsoils, which extends the decomposition process even more by affecting the species composition and the activity of the soil biota.

Thus, over decades and centuries, the European beech creates its own site conditions, which are characterized by a relatively low litter quality, a thicker litter layer, lower values of $\mathrm{pH}$ and base saturation in the topsoil (Guckland et al. 2009), and by a lower abundance of the saprophagous macrofauna that are functionally important for litter decomposition. These interactions explain the differences in the soil conditions - including the abundance and species composition of soil biota - between neighbouring mature deciduous forest stands differing in their fraction of the European beech, even if they grow on the same bedrock and under the same climatic conditions.

\section{Conclusion}

We could confirm the hypothesis that in the mixed species stands, the nutrient release rates are higher than in pure beech stands. Corresponding to the decomposition rates, the rates of nutrient release from the litter mixtures were significantly higher in the highly diverse DL 3 stands. On the other hand, we have to reject the hypothesis that in the mixed stands, the 
rates of nutrient release from the litter of the individual tree species are increased: at all levels of tree species diversity, the individual tree species exhibit similar nutrient release rates. It appears that the mere number of tree species is not the main driver for nutrient dynamics and decomposition processes. In contrast, the release of nutrients from decomposing litter seems to be largely determined by the proportion of the European beech in the tree species composition of the stands. Owing to the chemical composition of its litter, the beech influences the chemical conditions of the soil and the composition and abundance of the soil fauna, which, in turn, interacts with the structure of the organic surface layer and the decomposition of the litter. Thus, through their species-specific traits, the presence and abundance of individual tree species appears to be more important for the dynamics of litter decomposition than the tree species diversity per se.

\section{Acknowledgements}

Funding by the Deutsche Forschungsgemeinschaft (DFG; Graduiertenkolleg 1086) is greatly acknowledged. We want to thank two anonymous reviewers for the detailed comments on previous versions of the manuscript.

\section{$\underline{\text { References }}$}

Albers D, Migge S, Schaefer M, Scheu S (2004) Decomposition of beech leaves (Fagus sylvatica) and spruce needles (Picea abies) in pure and mixed stands of beech and spruce. Soil Biology \& Biochemistry 36: 155-164.

Anderson JPE, Domsch KM (1978) A physological method for the quantitative measurement of microbial biomass in soils. Soil Biology \& Biochemistry 10: 215-221.

Beck T, Joergensen RG, Kandeler E, Makeschin F, Oberholzer HR, Nuss HW, Scheu S (1997) An inter-laboratory comparison of ten different ways of measuring soil microbial biomass $\mathrm{C}$. Soil Biology \& Biochemistry 29: 1023-1032.

Berg B, Laskowski R (2006) Litter decomposition: A guide to carbon and nutrient turnover. Advances in Ecological Research, Elsevier, Amsterdam, 421 pp.

Berg B, McClaugherty C (1987) Nitrogen release from litter in relation to the disappearance of lignin. Biogeochemistry 4: $219-224$.

Berg B, McClaugherty C (2008) Plant Litter - Decomposition, Humus Formation, Carbon Sequestration. Springer, Berlin, $338 \mathrm{pp}$.

Blair JM (1988) Nutrient release from decomposing foliar litter of three species with special reference to calcium, magnesium and potassium dynamics. Plant and Soil 110: 49-55.

Blair JM, Parmelee RW, Beare MH (1990) Decay rates, nitrogen fluxes, and decomposer communities of single-species and mixed-species foliar litter. Ecology 71: 1976-1990. 
Brandtberg PO, Lundkvist H (2004) Does an admixture of Betula species in Picea abies stands increase organic matter quality and nitrogen release? Scandinavian Journal of Forest Research 19: $127-141$.

Côuteaux M-M, Bottner P. Berg B (1995) Litter decomposition, climate and litter quality. Tree 10: 6366.

Cragg RG, Bardgett RD (2001) How changes in soil faunal diversity and composition within a trophic group influence decomposition processes. Soil Biology \& Biochemistry 33: 2073-2081.

Enriquez S, Duarte CM, Sand-Jensen K (1993) Patterns in decomposition rates among photosynthetic organisms: the importance of detritus C:N:P content. Oecologia 94: 457-471.

FAO, ISRIC, IUSS (2006) World Reference Base for Soil Resources 2006. World Soil Resources Reports 103. Rome, Italy, 128 pp.

García LV (2004) Escaping the Bonferroni iron claw in ecological studies. Oikos 105: 657-663.

Gartner TB, Cardon ZG (2004) Decomposition dynamics in mixed-species leaf litter. Oikos 104: 230 246.

Gnankambary Z, Bayala J, Malmer A, Nyberg G, Hien V (2008) Decomposition and nutrient release from mixed plant litters of contrasting quality in an agroforestry parkland in the south-Sudanese zone of West Africa. Nutrient Cycling in Agroecosystems 82: 1-13.

Guckland A, Jacob M, Flessa H, Thomas FM, Leuschner C (2009) Acidity, nutrient stocks and organic matter content in soils of a temperate deciduous forest with different abundance of European beech (Fagus sylvatica L.). Journal of Plant Nutrition and Soil Science, in press (doi 10.1002/jpln.200800072).

Harguindeguy NP, Blundo CM, Gurvich DE, Díaz S, Cuevas E (2008) More than the sum of its parts? Assessing litter heterogeneity effects on the decomposition of litter mixtures through leaf chemistry. Plant Soil 303: 151-159.

Hättenschwiler S, Gasser P (2005) Soil animals alter plant litter diversity effects on decomposition. PNAS 102: 1519-1524.

Hättenschwiler S, Tiunov AV, Scheu S (2005) Biodiversity and litter decomposition in terrestrial ecosystems. Annual Review of Ecology, Evolution, and Systematics 36: 191-218.

Hector A, Joshi J, Scherer-Lorenzen M, Schmid B, Spehn EM, Wacker L, Weilenmann M, BazeleyWhite E, Beierkuhnlein C, Caldeira MC, Dimitrakopoulos PG, Finn JA, Huss-Danell K, Jumpponen A, Leadley PW, Loreau M, Mulder CPH, Neßhöver C, Palmborg C, Read DJ, Siamantziouras ASD, Terry AC, Troumbis AY (2007) Biodiversity and ecosystem functioning: reconciling the results of experimental and observational studies. Functional Ecology 21: 998-1002.

Hobbie SE, Reich PB, Oleksyn J, Ogdahl M, Zytkowiak R, Hale C, Karolewski P (2006) Tree species effects on decomposition and forest floor dynamics in a common garden. Ecology: 87, 2288-2297.

Hooper DU, Chapin FS, Ewel JJ, Hector A, Inchausti P, Lavorel S, Lawton JH, Lodge DM, Loreau M, Naeem S, Schmid B, Setälä H, Symstad AJ, Vandermeer J, Wardle DA (2005) Effects of biodiversity on ecosystem functioning: A consensus of current knowledge. Ecological Monographs 75: 3-35.

Irmler $U$ (2000) Changes in the fauna and its contribution to mass loss and $\mathrm{N}$ release during leaf litter decomposition in two deciduous forests. Pedobiologia 44: 105-118. 
Jacob M, Viedenz K, Polle A, Thomas F Leaf litter decomposition in temperate deciduous forest stands along a gradient of increasing tree species diversity. (in revision)

Joergensen RG (1991) Organic matter and nutrient dynamics of the litter layer on a forest rendzina under beech. Biology and Fertility of Soils 11: 163-169.

Jonsson M, Wardle D (2008) Context dependency of litter-mixing effects on decomposition and nutrient release across a long-term chronosequence. Oikos 117: 1674-1682.

Kautz G, Topp W (2000) Acquisition of microbial communities and enhanced availability of soil nutrients by the isopod Porcellio scaber (Latr.) (Isopoda: Oniscidea). Biology and Fertility of Soils 31: 102-107.

Laskowski R, Niklińska M, Maryański M (1995) The dynamics of chemical elements in forest litter. Ecology 76: 1393-1406.

Lavelle P, Spain AV (2001) Soil Ecology. Kluwer Scientific Publications, Amsterdam, 688 pp.

Leuschner C, Jungkunst H, Fleck S (2009) Functional role of forest diversity: pros and cons of synthetic stands and across-site comparisons in established forests. Basic and Applied Ecology 10: $1-9$.

Leuschner C, Meier IC, Hertel D (2006) On the niche breadth of Fagus sylvatica: soil nutrient status in 50 Central European beech stands on a broad range of bedrock types. Annals of Forest Science 63: 355-368.

Maraun M, Salamon J-A, Schneider K, Schaefer M, Scheu S (2003) Oribatid mite and collembolan diversity, density and community structure in a moder beech forest (Fagus sylvatica): effects of mechanical perturbations. Soil Biology \& Biochemistry 35: 1387-1394.

Marhan S, Scheu S (2006) Mixing of different mineral soil layers by endogeic earthworms affects carbon and nitrogen mineralization. Biology and Fertility of Soils 42: 308-314.

McTiernan KB, Ineson P, Coward PA (1997) Respiration and nutrient release from tree leaf litter mixtures. Oikos 78: 527-538.

Meier CL, Bowman WD (2008) Links between plant litter chemistry, species diversity, and belowground ecosystem function. PNAS 105: 19780-19785

Moore TR, Trofymow JA, Prescott CE, Fyles J, Titus BD, CIDET Working Group (2006) Patterns of carbon, nitrogen and phosphorus dynamics in decomposing foliar litter in Canadian forests. Ecosystems 9: 46-62.

Postma-Blaauw MB, Bloem J, Faber JH, van Groeningen JW, de Groede RGM, Brussaard L (2006) Earthworm species composition affects the soil bacterial community and net nitrogen mineralization. Pedobiologia 50: 243-256.

Reich PB, Oleksyn J, Modrzynski J, Mrozinski P, Hobbie SE, Eissenstat DM, Chorover J, Chadwick OA, Hale CM, Tjoelker MG (2005) Linking litter calcium, earthworms and soil properties: a common garden test with 14 tree species. Ecology Letters 8: 811-818.

Roback PJ, Askins RA (2005) Judicious use of multiple hypothesis tests. Conservation Biology 19: 261-267.

Schädler M, Brandl R (2005) Do invertebrate decomposers affect the disappearance rate of litter mixtures. Soil Biology \& Biochemistry 37: 329-337. 
Schauermann J (1982) Verbesserte Extraktion der terrestrischen Bodenfauna im Vielfachgerät modifiziert nach Kempson und Macfadyen. Arbeitsberichte Sonderforschungsbereich 135: 39-45.

Schaefer M (1990) The soil fauna of a beech forest on limestone: trophic structure and energy budget. Oecologia 82: 128-136.

Scherer-Lorenzen M, Schulze ED, Don A, Schumacher J, Weller E (2007) Exploring the functional significance of forest diversity: A new long-term experiment with temperate tree species (BIOTREE). Perspectives in Plant Ecology, Evolution and Systematics 9: 53-70.

Scheu S (1992) Automated measurement of the respiratory response of soil microcompartments: Active microbial biomass in earthwork faeces. Soil Biology \& Biochemistry 24: 1113-1118.

Seastedt TR (1984) The role of microarthropods in decomposition and mineralization processes. Annual Review of Entomology 29: 25-46.

Staaf $H$ (1987) Foliage litter turnover and earthworm populations in three beech forests of contrasting soil and vegetation types. Oecologia 72: 58-64.

Swift MJ, Heal OW, Anderson JM (1979) Decomposition in terrestrial ecosystems. Blackwell, Oxford, $372 \mathrm{pp}$.

Wardle DA, Bonner KI, Nicholson KS (1997) Biodiversity and plant litter: experimental evidence which does not support the view that enhanced species richness improves ecosystem function. Oikos 79: 247-258. 


\section{Chapter 6}

\section{General synthesis}




\section{How does tree species diversity influence the soil macrofauna}

\section{communities?}

Tree species diversity in the Hainich study sites appeared to be a key factor for the community structure of major soil macrofauna groups. The tree diversity effects were mediated through alterations in a number of abiotic and biotic habitat characteristics, with $\mathrm{pH}$, herb cover and diversity, and litter depth and diversity as environmental variables being important for the soil fauna. Litter depth in the Hainich sites was predominantly influenced by the proportion of beech (Fagus sylvatica), because the thick litter layers are mainly due to the slowly decomposing beech leaves (Sydes and Grime 1981a, Sydes and Grime 1981b). Additionally, beech litter leads to more acidic soil conditions and lower base saturation. In contrast, litter of the other tree species in the Hainich sites, such as ash (Fraxinus excelsior), hornbeam (Carpinus betulus) and lime (Tilia spp.), lead to higher base saturation and $\mathrm{pH}$ of the soil (e.g. Augusto et al. 2002, Aubert et al. 2004). After litter fall, the leaves were rapidly decomposed which resulted in a reduced amount of organic matter in the litter layer of the more diverse sites. On the one hand, this decrease in organic matter in the litter layer in combination with increasing tree species diversity negatively affects the continuous availability of food resources and the volume of habitable space. On the other hand, the development of a diverse herb layer is favoured (Mölder et al. 2008) which enhances the structural complexity of the ground zone. These contrasting trends were reflected in the different relationships between increasing tree species diversity and diversity and abundance of the major soil macrofauna groups.

\section{Do certain trophic groups react differently to increasing tree species}

\section{diversity?}

\section{Sapro-/Phytophages - Gastropoda}

Snail diversity and abundance were most pronounced in the medium-diversity sites (DL 2). Generally, snail abundance and species richness have been found to increase with the amount and nutrient content (Ca, K, N) of leaf litter (Getz and Uetz 1994, Millar and Waite 1999, Kappes et al. 2006). There is also a positive relation between soil calcium content/soil $\mathrm{pH}$ and snail density and species richness (Kappes et al. 2006, Hylander et al. 2005), although the influence of soil acidity on snail density can differ under different moisture conditions (Martin and Sommer 2004). Other interlinked effects on snail species diversity have been found for soil moisture and leaf litter diversity (Getz and Uetz 1994). In the Hainich study, litter and soil moisture were highest in DL 2 and DL 3 sites. Ca content and 
$\mathrm{pH}$ also increased from the low-diversity sites dominated by beech to the more diverse sites, but the medium-diversity sites obviously constituted a more habitable environment. Lower snail diversity and snail numbers were probably due to the presence of diverse and easily decomposable litter in the DL 3 sites. Here, litter depth declined markedly from spring to autumn. Obviously, the more constant environment in the DL 2 litter layer, containing a larger proportion of slowly decomposing beech litter, promoted the establishment of a diverse snail community with a high population density.

\section{Saprophages - Isopoda}

Mean isopod species richness was slightly higher in the more diverse Hainich sites DL 2 and DL 3. The same pattern, albeit more pronounced, was found for isopod densities. Beyer (1964) observed a similar distribution pattern; he found differences in abundance, but not in species composition when comparing the isopod communities in beech forests and in mixed beech forests in Central Europe. Isopods, like other saprophagous groups, show marked preferences for certain plant litter species. The animals react to changes in litter quality (Cotrufo et al. 1998, Kautz et al. 2000) and show selective feeding activity (Hättenschwiler and Bretscher 2001, Catalán et al. 2008). Litter species with a higher pH and lower tannin and phenolic contents are favourable for isopod populations (Kautz et al. 2000, Zimmer and Topp 2000). These litter types are more frequent in the medium- and high-diversity Hainich sites. Other ecoclimatic factors, such as humidity and leaf litter cover, are also important for isopod communities (e.g. Hornung and Warburg 1996, Hornung et al. 2007, Spungis 2008). The litter layer of the diverse study sites was more humid and therefore likely to promote an abundant isopod community. However, isopod activity was most pronounced in the mediumdiversity sites which again could be due to the mixture of high quality litter and relatively continuous litter cover. Especially Trachelipus ratzeburgii, the dominant species in the pitfall trap catches, has been found to be associated with a thick litter layer and high humidity (Hornung et al. 2007).

\section{Saprophages - Lumbricidae}

Mean annual lumbricid species richness was not different in the Hainich forest sites. A positive correlation between tree and earthworm diversity in spring 2006 was probably due to a high density spring effect and was not consistent throughout the year (Cesarz, pers. comm.). In a comparison between a beech and beech-hornbeam forest, no tree effect on the earthworm species richness was found (Aubert et al. 2003). Although the input of diverse litter can create microhabitats to be exploited by different saprophages species (Hättenschwiler and Gasser 2005), our study indicates that the rapid litter decomposition on the highly diverse sites resulting in habitat loss precludes the development of a diverse litter- 
dwelling earthworm community (cf. Judas 1990). Over the year, most earthworm individuals have been found in the medium-diversity and high-diversity forest sites. In general, important factors for lumbricids are litter polyphenolic, carbohydrate and nitrogen content. Lumbricids prefer certain plant litter species over others, favouring those with high nitrogen and carbohydrate content and low phenolic content (Satchell 1967, Tian et al. 1993). During decomposition, litter species identity clearly affects decomposer abundance (Wardle et al. 2006). While, for example, beech and hornbeam litter lose their tannins after half a year, the phenol content of ash is low (Brown et al. 1963, Zicsi and Pobozsny 1977) and hence this litter species is fed on shortly after litter fall. Additionally, earthworm abundance and biomass have been found to depend on soil pH and calcium content (Reich et al. 2005). Accordingly, the diverse Hainich sites were characterized by higher $\mathrm{pH}$ values and by litter of higher nutritional quality as compared to pure beech litter. The more diverse and productive herb layer (Mölder et al. 2008) could provide additional high quality litter. Another factor influencing earthworm activity and abundance is the moisture content of litter and soil (Edwards and Bohlen 1996); however, in our study the moisture content was not correlated to earthworm abundance, an observation emphasizing the importance litter quality and quantity.

During the course of the year, earthworm densities declined. This is common for earthworm populations in base-rich Central European forests (Satchell 1967, Phillipson et al. 1978, Scheu 1992). Apart from a possible sampling effect in winter (surface-near sampling can not record hibernating individuals living deeper in the soil), the general decline is probably due to the reduction of easily degradable leaf litter (as in Scheu 1992). In summer, the litter layer in the high-diversity sites was almost completely decomposed. A keystone species enhancing litter decomposition is Lumbricus terrestris, which is known for its midden construction and effective bioturbation up to ecosystem engineering. Most L. terrestris were found in DL 3 sites in which also highest numbers of middens were counted in spring. Accordingly, the decline in lumbricid density was not as pronounced in the low-diversity sites with a thick litter layer providing a stable habitat and allowing higher (winter) activity of litter dwelling species.

\section{Zoophages - Carabidae}

Carabid species richness was positively influenced by tree species diversity. Factors affecting carabid diversity are soil moisture (Baguette 1993, Raino and Niemelä 2003, Sroka and Finch 2006, Mullen et al. 2008), soil pH and the amount of leaf litter (Magura et al. 2003, Fuller et al. 2008). Soil moisture did not differ between the DLs, but soil pH increased from the beech-dominated sites to the high-diversity sites. In the Hainich sites, leaf litter cover was negatively correlated with carabid diversity, which is in contrast to observations by Magura et al. (2003) and Fuller et al. (2008) and in accordance with findings of Guillemain et al. 1997 
and Sroka and Finch (2006). Another reason for the positive effect of tree diversity may be the increasing structural complexity of the diverse sites with a more species-rich and dense herb layer; Lassau et al. (2005) found more forest beetle species in highly complex habitats. Additionally, availability of prey is regarded as important factor for carabid beetle diversity (Baguette 1993, Raino and Niemelä 2003, but see Guillemain et al. 1997). In contrast to species richness, most carabid individuals occurred in the low-diversity sites of DL 1 , predominantly belonging to three of the most abundant species. Probably, the key factor is leaf litter cover. More habitable space increases the opportunity for coexistence in the same microhabitat, which can be important for carabid beetles to reduce interspecific competition (Loreau 1990, Raino and Niemelä 2003). In a comparison of coniferous, mixed and deciduous forest stands, a positive correlation between tree species numbers and carabid abundance was found (Fuller et al. 2008). This was also attributed to a higher availability of favourable microhabitats in more diverse stands. Prey abundance also affects carabid densities; Koivula et al. (1999) found a positive correlation between carabid abundance and collembolans as their potential prey, which is in accordance to our study. Higher earthworm abundance may lead to larger carabid populations (Niemelä et al. 1997). In our study, earthworms were most abundant in the diverse forest sites, but throughout the year a steady number of epigeic lumbricids was active in the low-diversity sites, thus providing food for carabids.

\section{Zoophages - Araneidae}

The spider communities in the Hainich sites were most species-poor in the beech-dominated sites (DL 1) and most species-rich in the medium-diversity sites (DL 2). Apparently, the spider communities were strongly affected by the physical structure of the habitat, in this case the combination of litter depth and herb cover (cf. Pearce et al. 1994, Ziesche and Roth 2008). Both factors were found to promote spider species richness in deciduous forests (e.g. Uetz 1979, Docherty and Leather 1997, Willett 2001). Like spider species richness, mean spider abundance in the soil samples was highest in the DL 2 sites, but this pattern was more pronounced for adults than for total abundance with juveniles included. High spider densities in the medium-diversity sites may be again due to the favourable combination of litter depth and herb cover. A thick litter layer has been found to be vital for spiders due to its positive influence on microclimate, prey abundance and web-building space (Bultman and Uetz 1982). For instance, web-building spiders, such as Linyphiidae, are more abundant in complex leaf litter. Additionally, herb cover in the more diverse sites is important for webbuilding spiders, since they can use the lower parts of the plants for web construction (Standen 2000; Oxbrough et al. 2005). The low spider abundance in DL 1, despite high availability of habitat and prey, was rather unexpected. The absence of the abundant species 
Hahnia pusilla in the beech-dominated sites may be the reason. This is in accordance to Hänggi et al. (1995) who found this species to be rare in pure beech forests and more abundant in mixed deciduous forests. In contrast to the mean abundance of spiders from the soil samples, spider activity density in the Hainich was negatively correlated with tree species diversity but strongly positively correlated with increasing litter depth. Apart from its influence on species diversity, litter depth is also known to favour spider activity density as well as spider abundance by increasing interstitial space as a microhabitat available for locomotory activity (Bultman and Uetz 1982, Stippich 1989, Irmler 2005). Litter depth was found to be very important especially for wandering spiders (Uetz 1979). The abundance of potential prey is probably a factor contributing to the high activity density in the less diverse sites. In our study sites, we found a positive correlation between spider numbers and Collembola as potential prey being most abundant in the beech-dominated sites. This is in accordance to an experiment of Chen and Wise (1999), where a positive correlation between spiders and their prey from the decomposer community was found, indicating close predator-prey associations.

In summary, the faunal composition differed strongly in beech-dominated low-diversity and diverse Hainich sites. These differences seemed to be more pronounced for the decomposer community than for the predator community. The environmental variables soil microbial biomass, amount of organic matter in the litter layer, herb cover, and litter and soil pH were highly correlated with the tree diversity gradient. Density and diversity of important saprophagous groups often responded positively to increased tree species diversity, except for diplopoda densities which did not correlate with tree species diversity. In contrast, mesofauna groups like collembolans and mites were most abundant in pure beech sites. Likewise, predator abundance (but not diversity) decreased in highly diverse sites. Generally, the effect of tree species diversity was closely interlinked with the changing proportion of beech in the Hainich sites. Tree species in the diverse sites, like lime, ash or hornbeam, produced litter of high nutritional quality. The amount of high-quality litter with its specific properties was more important for the saprophages and led to higher abundance and feeding activity. The feeding pressure reduced the litter layer noticeably throughout the year which in turn influenced other fauna groups. Whereas the quality of the litter material appears to be more important for the decomposers studied than the amount of carbon in organic layers (i.e. habitat space), zoophages were strongly influenced by the amount of habitable leaf litter and the structural complexity of the herb layer.

Overall, the response of predatory and decomposer macrofaunal taxa to tree species diversity indicate that the groups studied are controlled by bottom-up forces. Certain taxa, 
e.g. earthworms (above all Lumbricus terrestris), can modulate these bottom-up forces by altering the resource supply to other species. In conclusion, tree species diversity had a marked effect on the structure of the soil animal food web, but single keystone species (e.g. Fagus sylvatica or Lumbricus terrestris) are also important driving forces for structuring soil macrofauna communities.

\section{How does tree species diversity influence decomposition processes?}

\section{Leaf litter quality and annual decomposition rates}

In general, three factors influence the decomposition process, (i) the abiotic environment, (ii) the resource quality of leaf litter and (iii) the nature and abundance of decomposer organisms (Swift et al. 1979, Côuteaux et al. 1995, Jonsson and Wardle 2008). The relatively slow decomposition rate of beech is attributed to the high $\mathrm{C} / \mathrm{N}$ ratio of $40-60$ in comparison to the lower C/N ratios of ash, lime and hornbeam (Wise and Schaefer 1994, Cotrufo et al. 2000; Hättenschwiler and Gasser 2005; Hobbie et al. 2006). Accordingly, the annual litter decomposition rates $(k)$ measured in our study varied strongly between the different tree species. Fagus litter had high $\mathrm{C}: \mathrm{N}$ ratios and low nutrient concentrations which led to lower degradability and relatively low annual decomposition rates $\mathrm{k}$ of $0.4-0.7$ compared to the litter of the other tree species in the Hainich. These values are in accordance to other studies for central-European forests (e.g. Seastedt 1984, Schaefer 1990, Irmler 2000, Hobbie et al. 2006). At the other end of the scale, litter of Fraxinus decayed the fastest $(k=2)$. After six months, mass loss of the quickly decomposing species Tilia, Carpinus or Fraxinus has been found to reach $55-70 \%$ or more than 80\%, respectively (Bocock and Gilbert 1957, Cornelissen 1996) Accordingly, in the Hainich DL 3 sites with large fractions of Tilia, Carpinus and Fraxinus litter, we found litter mass loss of about $80 \%$.

Litter decomposition of most tree species was accelerated in the diverse sites compared to the beech-dominated DL 1 sites. This was especially pronounced for the slowly decaying species Fagus sylvatica which was decomposed significantly faster in the presence of other tree species. This is in accordance to other studies where rates of mass loss were higher in litter mixtures than in single species litter despite unaltered climatic conditions and litter chemistry (Gartner and Cardon 2004, Hättenschwiler and Gasser 2005). On the other hand, the high quality litter of Fraxinus excelsior was decomposed equally quickly in all Hainich forest sites. Decomposition rates of the site specific litter mixtures were heavily influenced by the proportion of beech litter versus faster decomposing litter of the other tree species. DL 1 litter mixtures had decay rates comparable to the pure beech litter and the other mixtures decomposed gradually better, according to the proportion of Carpinus, Fraxinus and Tilia. 
Litter decomposition rates in the Hainich sites were positively correlated with initial $\mathrm{N}$ and $\mathrm{Ca}$ concentrations but negatively with $\mathrm{C}: \mathrm{N}$, lignin: $\mathrm{N}$ and $\mathrm{C}: \mathrm{P}$ ratios (Jacob et al. subm). This is in accordance to findings where within a climatic region, $\mathrm{N}$ concentrations or ratios of $\mathrm{N}$ to other foliar compounds belong to the main factors that influence the rates of litter decomposition (Aerts 1997; Cornelissen 1996; Parton et al. 2007). Besides the effect of these important chemical variables, there was also a positive influence of tree species diversity and soil $\mathrm{pH}$ on the $\mathrm{k}$ values of Fagus and Acer litter, as well as on the site specific litter mixtures. Additionally, decomposer abundance was positively correlated to the annual decomposition rate except for Fraxinus. In contrast, litter depth was negatively correlated to $\mathrm{k}$ values of litter of several tree species, which is due to the increasing litter depth on the beech-dominated sites.

\section{Influence of soil fauna on litter decomposition}

The importance of litter quality and identity for the abundance and activity of the saprophagous macrofauna has already been emphasized (Zimmer and Topp 2000, Reich et al. 2005). For instance, the amount of soluble carbohydrates and nitrogen in the litter increases earthworm biomass in sites with high tree diversity (Satchell 1967, Phillipson et al. 1978). In a New Zealand rainforest, litter species identity had marked effects on litter microfauna, mesofauna and macrofauna during decomposition (Wardle et al. 2006). It is further known that the composition of the soil fauna depends on the humus type and corresponding $\mathrm{pH}$ values. High macrofauna abundances are typical for rich mull forest stands (e.g. Petersen and Luxton 1982, Staff 1987, Schaefer and Schauermann 1990).

Hence, higher leaf litter decomposition rates in the more diverse Hainich sites could be attributed to a combination of higher litter quality, higher abundances and activity of saprophagous fauna and higher soil $\mathrm{pH}$. The annual decomposition rates of litter of Tilia, Acer, Carpinus and site specific litter mixtures were positively correlated with mean earthworm abundance. This is in accordance to results from Hättenschwiler and Gasser (2005) showing earthworms as an important factor in determining mass loss of more easily decomposing leaf litter species (Tilia, Carpinus, Prunus). Other studies also detected a positive effect of earthworms on rates of litter disappearance (Swift et al. 1979, Staff 1987, Ponge et al. 1999, Hale et al. 2005). In our study, the strong connection of earthworms with litter decomposition could be confirmed for all tree species studied, except Fagus and Fraxinus. However, decomposition of Fagus litter was more closely correlated with mean isopod abundance. Both saprophagous taxa were most common in the high-diversity DL 3 sites but isopods were also significantly more abundant in the medium-diversity sites than in the low-diversity DL 1 sites. A recent litter exchange experiment in the same study sites (General introduction: Fig. 1) confirms the different connections between earthworms and 
isopods with litter of the different tree species. Besides a clear effect of the general tree species diversity, earthworm abundances have been found to increase with the availability of Tilia litter, whereas isopod numbers increased in the presence of Fagus litter (Fahrenholz in prep). In a pure beech forest, isopods were positively correlated with beech litter mass loss rates (Irmler 2000). In the same study, lumbricids were even negatively correlated to the decay rate of beech leaf litter. In a comparison of the decomposition of different litter mixtures, Schädler and Brandl (2005) found the soil fauna to have a large influence on the disappearance rate of the litter. This influence was generally most pronounced in N-rich and C-poor litter but increased with time only for the slowly decomposing litter, suggesting that low-quality litter becomes a more suitable food source during decomposition. Hence, the positive effect of litter mixing on decomposition rates (reviewed by Gartner and Cardon 2004) may well be due to the activity of the soil fauna.

By accelerating decomposition rates, soil fauna can reduce nutrient immobilization (Anderson 1973, Staaf 1987, Joergensen 1991). In our study, especially the abundance of earthworms was correlated with the length of time lag before $N$ and $P$ release. Nutrient release of $\mathrm{N}$ in beech started earlier and was significantly higher in mixed species sites. Similar findings for $\mathrm{N}$ release in beech also showed a positive correlation to earthworm biomass (Irmler 2000). In another decomposition study with isopods as dominant saprophagous group, most changes in litter nutrient content were positively correlated to microbial activity and/or isopod abundance (Zimmer 2002). However, in our study, the only significant correlation between $\mathrm{N}$ release and isopod abundance was found for site specific litter mixtures.

In summary, besides the initial chemical composition of the litter, other (environmental) factors such as soil $\mathrm{pH}$, structure and quality of the organic surface layer and associated saprophagous fauna influence litter decomposition rates and nutrient release patterns. According to the site specific litter mixtures, decomposition rates and nutrient release rates increased with increasing tree species diversity. However, nutrient release patterns of the litter of most individual tree species were similar in all sites, except Fagus litter. Hence, in this case the simple number of tree species may not be the main driver for decomposition processes and nutrient dynamics. In some cases, plant species identity but not diversity has been found to drive soil properties and processes (Wardle et al. 2006, Nilsson et al. 2008). Other studies as well found the belowground system being driven by traits of the dominant plant species (Hooper and Vitousek 1998, Wardle et al. 2003, but see Tilman et al. 1996). Due to the quality of its litter, beech affects soil properties and abundance and activity of the soil fauna in a way contrasting to lime or ash. In a feedback, the soil fauna can affect the 
aboveground system by different pattern of mineralization through preference of certain habitat conditions and food resources (Hättenschwiler and Bretscher 2001; Hättenschwiler and Gasser 2005). Therefore, presence and abundance of certain tree species is a key factor for the dynamics of litter decomposition.

\section{$\underline{\text { Conclusion }}$}

In conclusion, tree species diversity (in the Hainich) affects multiple abiotic and biotic habitat characteristics, which on their part influence the soil fauna communities (Fig. 1). Firstly, quality of food resources for phyto- and saprophagous groups is improved due to an increasing amount of high quality tree and herb litter in the diverse sites. Microorganisms and saprophagous fauna positively respond to this change in food quality. Additionally, both groups are linked via trophic interactions. Microorganisms are an important dietary component of larger saprophages, but these are also known to positively influence the activity of microorganisms by selective grazing. Hence, decomposition processes are influenced, inter alia, by tree species diversity via litter quality and altered soil fauna community structures. High quality litter is rapidly decomposed by microorganisms as well as by larger saprophages. Through an acceleration of decomposition rates, soil fauna increases nutrient mobilization, which enhances microbial biomass in the soil, soil $\mathrm{pH}$ and plant quality. This in turn feeds back positively to the soil fauna. The $\mathrm{pH}$ value may close the interaction cycle by a minor influence on tree species diversity, because the lower the $\mathrm{pH}$ the fewer tree species are able to compete in the crucial sapling stage. Especially the litter of Fagus sylvatica is of lower quality than litter of the other tree species, which again leads to such a decrease in soil $\mathrm{pH}$ and base saturation on beech dominated sites. However, main factors influencing tree species composition are e.g. former management practices, disturbance events and soil parameters, such as clay content.

Secondly, tree species diversity positively influences the structural diversity of the habitat. A well structured herb layer promotes phytophages as well as certain groups of predators, i.e. web-building spiders. On the other hand, the indirect result of the increased decomposition in the diverse forest sites is a reduction of organic matter in the litter layer. This decrease in habitat structure of the litter layer negatively affects most soil fauna communities. However, in monospecific stands Fagus litter decomposes only slowly, which leads to the accumulation of organic matter under beech. On the one hand, this pronounced litter layer is detrimental to saplings of many other tree species except beech itself. On the other hand, the litter layer offers a continuous microclimate and microhabitat to all soil animals, especially to predators. They are connected to the saprophagous groups in a typical predator-prey relationship and react positively on increasing numbers of prey organisms. 
In summary, there are two coherent feedback loops mediated by saprophagous soil fauna: a quality related feedback loop, which reinforces itself, and a structure related feedback system with negative interrelations. In combination, there is a trade-off for saprophages between food quality and habitable space. To further unravel the strength of the influence of tree species diversity in contrast to the decreasing amount of beech in the Hainich sites, causal patterns of top-down and bottom-up effects have to be studied separately and experimentally.

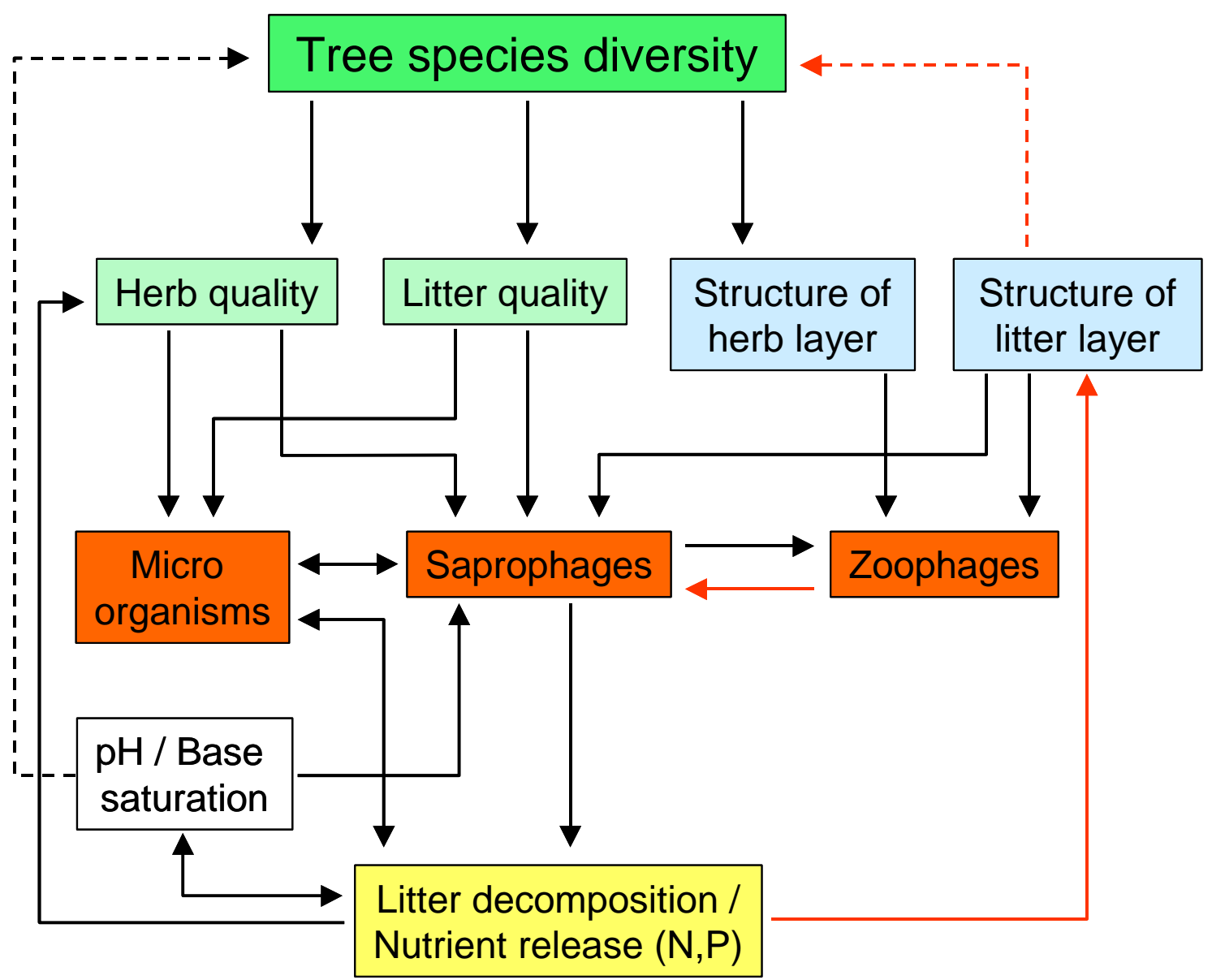

Fig 1 Model of possible interactions between tree species diversity, soil macrofauna and decomposition processes. Interactions are presented as arrows (positive = black, negative = red, weak feedbacks = dashed). Data from Guckland et al. (2009) and Mölder (2008) are integrated. Phytophages are not separately displayed due to low abundances of purely phytophagous groups. 


\section{$\underline{\text { References }}$}

Aerts R (1997) Climate, leaf litter chemistry and leaf litter decomposition in terrestrial ecosystems: A triangular relationship. Oikos 79: 439-449.

Anderson JM (1973) The breakdown and decomposition of sweet chestnut (Castanea sativa Mill.) and beech (Fagus sylvatica L.) leaf litter in two deciduous woodland soils. 1. Breakdown, Leaching and Decomposition. Oecologia 12: 251-274.

Aubert M, Bureau F, Alard D, Bardat J (2004) Effect of tree mixture on the humic epipedon and vegetation diversity in managed beech forests (Normandy, France). Canadian Journal of Forest Research 34: 233-248.

Aubert M, Hedde M, Decaens T, Bureau F, Margerie P, Alard D (2003) Effects of tree canopy composition on earthworms and other macro-invertebrates in beech forests of Upper Normandy (France). Pedobiologia 47: 904-912.

Augusto L, Ranger J, Binkley D, Rothe A (2002) Impact of several common tree species of European temperate forests on soil fertility. Annals of Forest Science 59: 233- 253.

Baguette M (1993) Habitat selection of carabid beetle in deciduous woodlands of southern Belgium. Pedobiologia 37: 365-378.

Beyer R (1964) Faunistisch-ökologische Untersuchungen an Landisopoden in Mitteldeutschland. Zoologische Jahrbücher, Systematik 91: 341-402.

Bocock KL, Gilbert OJW (1957) The disappearance of leaf litter under different woodland conditions. Plant and Soil 9: 179-185.

Brown BR, Love CW, Handley WRC (1963) Protein-fixing constituents of plants: Part III Rep. Forest. Res. Lond. 1961/1962. pp 90-93.

Bultman TL, Uetz GW (1982) Abundance and community structure of forest floor spiders following litter manipulation. Oecologia 55: 34-41.

Catalán TP, Lardies MA, Bozinovic F (2008) Food selection and nutritional ecology of woodlice in Central Chile. Physiological Entomology 33: 89-94.

Chen B, Wise DH (1999) Bottom-up limitation of predaceous arthropods in a detritus-based terrestrial food web. Ecology 80: 761-772.

Cornelissen JHC (1996) An experimental comparison of leaf decomposition rates in a wide range of temperate plant species and types. The Journal of Ecology 84: 573-582.

Cotrufo MF, Briones MJ, Ineson P (1998) Elevated CO2 affects field decomposition rate and palatability of tree leaf litter: importance of changes in substrate quality. Soil Biology \& Biochemistry 30: 1565-1571.

Cotrufo MF, Miller M, Zeller B (2000) Litter decomposition. In: Schulze E-D (ed.), Carbon and Nitrogen Cycling in European Forest Ecosystems, Springer, Berlin, Vol. 142, pp. 276-296.

Côuteaux M-M, Bottner P, Berg B (1995) Litter decomposition, climate and litter quality. Tree 10: 6366.

Docherty M, Leather SR (1997) Structure and abundance of arachnid communities in Scots and lodgepole pine plantations. Forest Ecology and Management 95: 197-207. 
Edwards CA, Bohlen PJ (1996) Biology and Ecology of Earthworms, third ed., Chapman and Hall, London.

Fuller R, Oliver TH, Leather SR (2008) Forest management effects on carabid beetle communities in coniferous and broadleaved forests: implications for conservation. Insect Conservation and Diversity 1: 242-252.

Gartner TB, Cardon ZG (2004) Decomposition dynamics in mixed-species leaf litter. Oikos 104: 230246.

Getz LL, Uetz GW (1994) Species diversity of terrestrial snails in the southern Appalachian Mountains, U.S.A. Malacological Review 27: 61-74.

Guillemain M, Loreau M, Daufresne T (1997) Relationships beetween the regional distribution of carabid beetles (Coleoptera, Carabidae) and the abundance of their potential prey. Acta Ecologica 18: 465-483.

Guckland A, Brauns M, Flessa H, Thomas FM, Leuschner C (2009) Acidity, nutrient stocks and organic matter content in soils of a temperate deciduous forest with different abundance of European beech (Fagus sylvatica L.). Journal of Plant Nutrition and Soil Science, in press.

Hale CM, Frelich LE, Reich PB, Pastor J (2005) Effects of European earthworm invasion on soil characteristics in northern hardwood forests of Minnesota, USA. Ecosystems 8: 911-927.

Hänggi A, Stöckli E, Nentwig W (1995) Habitats of Central European spiders. Miscellanae Faunistica Helvetica 4: 1-459.

Hättenschwiler S, Bretscher D (2001) Isopod effects on decomposition of litter produced under elevated CO2, N deposition and different soil types. Global Change Biology 7: 565-579.

Hättenschwiler S, Gasser P (2005) Soil animals alter plant litter diversity effects on decomposition. Proceedings of the National Academy of Sciences of the USA 102: 1519-1524.

Hobbie SE, Reich PB, Oleksyn J, Ogdahl M, Zytkowiak R, Hale C, Karolewski P (2006) Tree species effects on decomposition and forest floor dynamics in a common garden. Ecology 87: 2288-2297.

Hooper DU, Vitousek PM (1998) Effects of plant composition and diversity on nutrient cycling. Ecological Monographs 68: 121-149.

Hornung E, Tóthmérész B, Magura T, Vilisics F (2007) Changes of isopod assemblages along an urbane suburbane-rural gradient in Hungary. European Journal of Soil Biology 43: 158-165.

Hornung E, Warburg MR (1996) Intra-habitat distribution of terrestrial isopods. European Journal of Soil Biology 32: 179-185.

Hylander K, Nilsson C, Jonsson BG, Göthner T (2005) Differences in habitat quality explain nestedness in a land snail meta-community. Oikos 108: 351-361.

Irmler U (2000) Changes in the fauna and its contribution to mass loss and N release during leaf litter decomposition in two deciduous forests. Pedobiologia 44: 105-118.

Irmler U (2005) Long-term fluctuations on the spider populations (Araneida) in a northern German woodland. Faunistisch-ökologische Mitteilungen 8: 337-352.

Jacob M, Viedenz K, Polle A, Thomas FM. Leaf litter decomposition in the initial phase of decay in temperate deciduous forest stands along a gradient of increasing tree species diversity. submitted

Joergensen RG (1991) Organic matter and nutrient dynamics of the litter layer on a forest rendzina under beech. Biology and Fertility of Soils 11: 163-169. 
Jonsson M, Wardle D (2008) Context dependency of litter-mixing effects on decomposition and nutrient release across a long-term chronosequence. Oikos 117: 1674-1682.

Judas M (1990) The development of earthworm populations following manipulation of the canopy leaf litter in a beechwood on limestone. Pedobiologia 34: 247-255.

Kappes H, Topp W, Zach P, Kulfan J (2006) Coarse woody debris, soil properties and snails (Mollusca: Gastropoda) in European primeval forests of different environmental conditions. European Journal of Soil Biology 42: 139-146.

Kautz G, Zimmer M, Topp W (2000) Responses of the parthenogenetic isopod, Trichoniscus pusillus (Isopoda: Oniscidea), to changes in food quality. Pedobiologia 44: 75-85.

Koivula M, Punttila P, Haila Y, Niemelä J (1999) Leaf litter and the small-scale distribution of carabid beetles (Coleoptera, Carabidae) in the boreal forest. Ecography 22: 424-435.

Lassau SA, Hochuli DF, Cassis G, Reid CAM (2005) Effects of habitat complexity on forest beetle diversity: do functional groups respond consistently? Diversity and Distributions 11: 73-82.

Loreau M (1990) Competition in a carabid beetle community: a field experiment. Oikos 58: 25-38.

Magura T, Tóthmérész B, Elek Z, 2003. Diversity and composition of carabids during a forestry cycle. Biodiversity and Conservation 12: 73-85.

Martin K, Sommer M (2004) Relationships between land snail assemblage patterns and soil properties in temperate-humid forest ecosystems. Journal of Biogeography 31: 531-545.

Millar AJ, Waite S (1999) Molluscs in coppice woodland. Journal of Conchology 36: 25-48.

Mölder A (2008) Zur Struktur und Diversität der Bodenvegetation in Laubwäldern mit unterschiedlicher Baumartenvielfalt. Dissertation zur Erlangung des Doktorgrades der Fakultät für Forstwissenschaften und Waldökologie der Georg-August-Universität Göttingen.

Mölder A, Bernhardt-Römermann M, Schmidt W (2008) Herb-layer diversity in deciduous forests: Raised by tree richness or beaten by beech? Forest Ecology and Management 256: 272-281.

Mullen K, O'Halloran J, Breen J, Giller P, Pithon J, Kelly T (2008) Distribution and composition of carabid beetle (Coleoptera, Carabidae) communities across the plantation forest cycle-Implications for management. Forest Ecology and Management 256: 624-632.

Niemelä J, Spencer JR, Carcamo H (1997) Establishment and interactions of carabid populations: an experiment with native and introduced species. Ecography 20: 643-652.

Nilsson M-C, Wardle DA, DeLuca TH (2008) Belowground and aboveground consequences of interactions between live plant species mixtures and dead organic substrate mixtures. Oikos 117: 439-449.

Oxbrough AG, Gittings T, O'Halloran J, Giller PS, Smith GF (2005) Structural indicators of spider communities across the forest plantation cycle. Forest Ecology and Management 212: 171-183.

Parton W, Silver WL, Burke IC, Grassens L, Harmon ME, Currie WS, King JY, Adair EC, Brandt LA, Hart SC, Fasth B (2007) Global-scale similarities in nitrogen release patterns during long-term decomposition. Science 315: 361-364.

Pearce JL, Vennier LA, Eccles G, Pedlar J, McKenney D (1994) Influence of habitat and microhabitat on epigeal spider (Araneae) assemblages in four stand types. Biodiversity and Conservation 13: 1305-1334. 
Petersen H, Luxton M (1982) A comparative-analysis of soil fauna populations and their role in decomposition processes. Oikos 39: 287-388.

Phillipson J, Abel R, Steel J, Woodell SRJ (1978) Earthworm numbers, biomass and respiratory metabolism in a beech woodland - Wytham Woods, Oxford, Oecologia 33: 291-309.

Ponge JF, Patzel N, Delhaye L, Devigne E, Levieux C, Béros P, Wittebroodt R (1999) Interactions between earthworms, litter and trees in an old-growth beech forest. Biology and Fertility of Soils 29: 360-370.

Raino J, Niemelä J (2003) Ground beetles (Coleoptera: Carabidae) as Bioindicators. Biodiversity and Conservation 12: 487-506.

Reich PB, Oleksyn J, Modrzynski J, Mrozinski P, Hobbie SE, Eissenstat DM, Chorover J, Chadwick OA, Hale CM, Tjoelker MG (2005) Linking litter calcium, earthworms and soil properties: a common garden test with 14 tree species. Ecology Letters 8: 811-818.

Satchell JE (1967) Lumbricidae, in: Burges, A., Raw, F. (eds.), Soil Biology. Academic Press, London, pp. 259-322.

Schädler M, Brandl R (2005) Do invertebrate decomposers affect the disappearance rate of litter mixtures. Soil Biology \& Biochemistry 37: 329-337.

Schaefer M (1990) The soil fauna of a beech forest on limestone: trophic structure and energy budget. Oecologia 82: 128-136.

Schaefer M, Schauermann J (1990) The soil fauna of beech forests: comparison between a mull and a moder soil. Pedobiologia 34: 299-314.

Scheu S (1992) Changes in the lumbricid coenosis during secondary succession from a wheat field to a beechwood on limestone, Soil Biology \& Biochemistry 24: 1641-1646.

Seastedt TR (1984) The role of microarthropods in decomposition and mineralization processes. Annual Review of Entomology 29: 25-46.

Spungis V (2008) Fauna, Distribution, Habitat Preference and Abundance of Woodlice (Oniscidea) in Latvia. Latvijas Entomologs: 45, 25-37.

Sroka K, Finch O-D (2006) Ground beetle diversity in ancient woodland remnants in north-western Germany (Coleoptera, Carabidae). Journal of Insect Conservation 10: 335-350.

Staaf $H$ (1987) Foliage litter turnover and earthworm populations in three beech forests of soil and vegetation types. Oecologia 72: 58-64.

Standen $\vee(2000)$ The adequacy of collecting techniques for estimating species richness of grassland invertebrates. Journal of Applied Ecology 37: 884-893.

Stippich G (1989) Die Bedeutung von natürlichen und künstlichen Strukturelementen für die Besiedlung des Waldbodens durch Spinnen (Zur Funktion der Fauna in einem Mullbuchenwald 14). Verhandlungen der Gesellschaft für Ökologie 17: 293-298.

Swift MJ, Heal OW, Anderson JM (1979) Decomposition in terrestrial ecosystems. Blackwell, Oxford, $372 \mathrm{pp}$.

Sydes C, Grime JP (1981a) Effects of tree leaf litter on herbaceous vegetation in deciduous woodland. I. Field investigations. Journal of Ecology 69: 237-248.

Sydes C, Grime JP (1981b) Effects of tree leaf litter on herbaceous vegetation in deciduous woodland. II. An experimental investigation. Journal of Ecology 69: 249-262. 
Tian G, Kang BT, Brussaard L (1993) Biological effects of plant residues with contrasting chemical compositions under humid tropical conditions: decomposition and nutrient release. Soil Biology \& Biochemistry 24: 1051-1061.

Tilman D, Wedin D, Knops J (1996) Productivity and sustainability influenced by diversity in grassland ecosystems. Nature 379: 718-720.

Uetz GW (1979) The influence of variation in litter habitats on spider communities. Oecologia 40: 2942.

Wardle DA, Yeates GW, Williamson W, Bonner KI (2003) The response of a three trophic level soil food web to the identity and diversity of plant species and functional groups. Oikos 102: 45-56.

Wardle DA, Yeates GW, Barker GM, Bonner KI (2006) The influence of plant litter diversity on decomposer abundance and diversity. Soil Biology \& Biochemistry 38: 1052-1062.

Willett TR (2001) Spiders and other arthropods as indicators in old-growth versus logged redwood stands. Restoration Ecology 9: 410-420.

Wise DH, Schaefer M (1994) Decomposition of leaf litter in a mull beech forest: comparison between canopy and herbaceous species. Pedobiologia 38: 269-288.

Zicsi A, Pobozsny M (1977) Einfluss des Zersetzungsverlaufes der Laubstreu auf die Konsumintensität einiger Lumbriciden-Arten, in: Lohm U, Persson T (eds.), Soil Organisms as Components of Ecosystems, Ecological Bulletins (Stockholm) 25: 229-239.

Ziesche TM, Roth M (2008) Influence of environmental parameters on small-scale distribution of soildwelling spiders in forests: What makes the difference, tree species or microhabitat? Forest Ecology and Management 255: 738-752.

Zimmer M (2002) Is decomposition of woodland leaf litter influenced by its species richness? Soil Biology \& Biochemistry 34: 277-284.

Zimmer M, Topp W (2000) Species-specific utilization of food sources by sympatric woodlice (Isopoda: Oniscidea). Journal of Animal Ecology 69: 1071-1082. 


\section{Summary}

The relationship between species diversity and ecosystem function is an important topic of modern ecological research. Plant diversity has often been found to affect structural and biotic properties of ecosystems. Although the basic dependence of the soil food web on the resources provided by primary production is well studied, the knowledge of tree species diversity interactions with belowground processes and soil animal communities is still imperfect. This is especially true for forest ecosystems with mixtures of more than two tree species. In this study, the effect of increasing diversity of deciduous tree species on the composition of soil macrofauna communities and on leaf litter decomposition was studied. Nine research sites with comparable edaphic and climatic conditions were established in the Hainich National Park (Thuringia, Germany). They formed a diversity gradient ranging from pure beech (Fagus sylvatica), to medium-diversity stands built by beech, ash (Fraxinus excelsior), and lime (Tilia spp.), and to high-diversity stands dominated by beech, ash, lime, maple (Acer pseudoplatanus and A. platanoides), and hornbeam (Carpinus betulus) (Diversity Levels 1, 2 and 3).

Canopy litter diversity had a marked effect on the composition of soil macrofauna communities. Though, the relationship between increasing tree species diversity and diversity or abundance of the animal taxa studied (gastropods, lumbricids, isopods, carabids and araneids) was not generally linear. Trophic groups responded differently to tree species diversity: the abundance of key groups of primary decomposers such as isopods and earthworms was promoted by a high diversity of litter resources with an increasing amount of high quality litter, whereas sapro- and phytophagous snails were most diverse and abundant in the medium-diversity forest sites. The activity density of predators in the litter layer such as spiders and carabid beetles decreased in the highly diverse plots due to the fast decomposition of the litter and the concomitant reduction of the litter habitat. On the other hand, predator diversity was positively correlated with the more diverse herb and litter layer in mixed sites. Overall, tree species diversity was an important driving force for soil macrofauna, but it was complemented by structuring forces exerted by single keystone species (e.g. beech).

Litter decomposition was studied for the six common tree species on the Hainich sites: beech. lime, ash, maple ( $A$. pseudoplatanus and $A$. platanoides) and hornbeam, as well as for site specific litter mixtures. The annual decomposition rates $(k)$ were typical for these temperate tree species, with $k=0.5$ for beech and $k=1.5-2$ for the other tree species. The decomposition rate of Fagus increased with increasing tree species diversity and was further correlated to soil $\mathrm{pH}$, moisture of the litter layer and isopod abundance. Litter decomposition of the other tree species was also faster in the mixed species sites (except for ash and 
hornbeam) and was positively correlated with earthworm abundance. Amounts and release rates of nutrients differed between tree species but were not consistently different between the diversity levels. Patterns of nutrient release were correlated to initial litter nutrient ratios and even more so with earthworm abundance. Mere tree species diversity may not be the driver of decomposition processes and nutrient dynamics. Characteristic traits of individual tree species, e.g. of beech in contrast to lime and ash, influence soil and habitat properties as well as soil fauna communities. Thus, presence and abundance of certain tree species and their associated soil fauna (e.g. earthworms) play a key role through their direct and indirect effects on the whole forest ecosystem. 


\section{Acknowledgements}

First and foremost, I want to thank Professor Dr. Matthias Schaefer for providing this interesting research topic and for his generous help and support. Furthermore, I would like to thank the members of my PhD examination board for their time and effort, especially Prof. Dr. Klaus Hövemeyer for reviewing my PhD thesis.

I am especially thankful for the opportunity to work in the 'Graduiertenkolleg 1086', which was kindly funded by the DFG. I would like to thank Prof. Dr. Christoph Leuschner, Dr. Frank Thomas, Dr. Hermann Jungkunst and Dr. Stefan Fleck for their organisation and coordination of the Research Training Group. All the PhD students have been great company and excellent co-workers. In particular, I want to thank Mascha Jacob, Inga Schmidt and Andreas Mölder for their friendship and superb teamwork. The management of the Hainich National Park has been very cooperative and without their kind permission nobody of us would have had the chance to work in this fascinating and beautiful forest.

To all my colleagues of the Ecology group I am deeply grateful, in particular Dr. Christian Platner and Dr. Sonja Migge-Kleian for their fruitful discussions and general support. Christel Fischer, Dieter Nünchert, Ingrid Kleinhans and Susanne Böning-Klein have been immensely helpful with all the lab and technical work. Many thanks to my former Diploma students Andreas Schuldt, Insa Mende and Nina Spottek; I wish you all the best for your future. Evelyn Schuhmacher, Simone Cesarz, Stephanie Beyer and Verena Eißfeller have become good friends during the last years. Thank you for your encouragement, your cooperation and the great time we could spend together.

Many thanks to my old friends from Bremen, who bore my sporadic calls and trips to the old home without complaints. My deepest thanks to my family, whose constant love and support were my foundation in all these years. Finally, I want to thank Hans-Georg Weland for his never-ending love and understanding. 


\section{Curriculum vitae}

\section{Nadine Weland, geb. Fahrenholz}

Personal details:

$\begin{array}{ll}\text { Date of birth: } & \text { 15.07.1980 } \\ \text { Place of birth: } & \text { Bremen, Germany } \\ \text { Nationality: } & \text { German }\end{array}$

\section{Education}

2005-2009 University of Göttingen, Germany

Ph.D. (Dr. rer nat.) study in Biology,

Thesis: „Diversity and trophic structure of the soil fauna and its influence on litter decomposition in deciduous forests with increasing tree species diversity“

1999-2005 University of Bremen, Germany

Study of Biology

Degree: Diplom

1999

SZ im Holter Feld Bremen (high school), Germany

High school diploma: Abitur

Date/Signature 